\title{
28 Research Soure \\ Joint Analysis as an Important Tool for an Optimizing Block Extraction of Natural Stones
}

\section{Christiane Schneider-Löbens}

University of Göttingen: Georg-August-Universitat Gottingen

Siegfried Siegesmund ( $\sim$ ssieges@gwdg.de)

University of Göttingen

Karl-Jochen Stein

Natursteinarchitektur Waldsee

\section{Stefan Lebens}

University of Göttingen: Georg-August-Universitat Gottingen

\section{Research Article}

Keywords: Quantification of unfractured rock masses, Raw block modelling, Fracture system, Data acquisition and exploration, 3D-Block Expert

Posted Date: June 8th, 2021

DOI: https://doi.org/10.21203/rs.3.rs-583642/v1

License: (1) (1) This work is licensed under a Creative Commons Attribution 4.0 International License. Read Full License

Version of Record: A version of this preprint was published at Environmental Earth Sciences on January 31st, 2022. See the published version at https://doi.org/10.1007/s12665-022-10177-3. 


\section{Abstract}

The steadily increasing demand on the natural stone market is accompanied by a predominantly poor economic balance in the extraction of the raw material "ornamental stone". Thus, the net production of raw blocks is far too low in relation to the resulting overburden, which is often the result of insufficient geoscientific input and evaluation of the deposit itself and the deposit-controlling factors.

Under these conditions, the investigation pursued the goal of capturing an essential part of the geological conditions with the analytical observation of the fractures systems, in order to contribute to an optimized stone extraction. Only by critically derived constraints on the quarrying process based on the geological situation can the economic viability of natural stone deposits be maintained or increased in the long term, and this from an environmentally friendly point of view.

Profitable dimensional stone production mainly depends on the number of extracted blocks. Compared to statistical approaches the application of the 3D-BlockExpert computer code is based on modelling the block sizes on the discontinuity system such as fracture spacing and fracture orientation. The assessment of all joint and fracture systems provides a forwards-looking approach for sustainable quarry management. It is essential to make the best possible use of high-quality material and to minimize the impact of quarrying activities to nature. Investigations were carried out in quarry areas of different lithologies in Germany and Spain like sandstones, limestones, slate and granites. The block sizes, the irregularity of acute-angled blocks and the waste to block ratio controls the economic success by avoiding time- and cost-consuming procedures based on geoscientific considerations.

\section{Introduction}

For thousands of years, natural building stones have been used for monumental buildings and works of art. Throughout the ages, builders and artists have created testimonies of extraordinary technical and artistic achievements in their works and monuments.

In the past decades, the latest technologies have led to considerable progress in mining and processing of natural stone for the aesthetic design of interiors, exterior facades and urban spaces. Recently, these state-of-the-art opportunities have caused a significantly increased demand for the application of natural building stones. Forecasts of net production indicate a continuous increase, whereby production volumes could double approximately every ten years (Montani 2003, 2008). It is already obvious that this amount of raw material cannot be extracted from currently available deposits, especially with regard to sought after and fashioned decors. Therefore, existing deposits have to be extended regarding available reserves and new deposits must be developed.

The economic viability of a deposit is largely determined by the ratio of usable raw material, i.e., building stone characterised by blocks, which can manually or industrially be used, to non-usable rock, e.g., overburden. Additionally, basic requirements like suitability of the rock for construction and a certain extraction volume must be fulfilled (Mosch et al. 2007, Hoffmann et al. 2007, Mosch 2008, Sousa, 2007, 
Sousa et al. 2017, Yarahmadi et al. 2018, Demarco et al. 2013a, Demarco et al. 2013b, Bogdanowitsch et al. 2021). According to Montani (2003), for the global average only one third of the raw material extracted for natural building production is sold as a finished product on the global market (Fig. 1). In this context approximately $51 \%$ are loss due to deposit characteristics (e.g., overburden) and another $21 \%$ are lost during industrial processing (e.g., cutting). Furthermore, for shale-like deposits this ratio can even be significantly lower.

For the optimal use of a deposit and a sustainable protection of resources, a detailed evaluation of the deposit including assessment of geological characteristics is necessary. Regarding deposits of natural building stones, in many cases, however, there is a lack of sufficient geological assessment that meets necessary requirements for such an evaluation. Information about formation, aerial extension, depth of the deposit as well as characteristics of overburden are indispensable for exploitation. In addition to these large-scale explorations, detailed knowledge of the resulting reservoir-controlling factors is required. Corresponding variables are important for the building stone itself and for its extraction. Furthermore, these factors determine the amount and quality of well-dimensioned and defect-free blocks (Mosch, 2008). In this context the fracture system is one of the most important factors. It describes all planar elements, which cause a dissection of the rock resulting in individual blocks, the so-called in-situ blocks (Lu \& Latham, 1999). If this is not considered while mining, significant and avoidable loss of valuable rock would be the consequence.

Therefore, a sustainable mining of such a resource is based on a substantiated mine plan, which, in turn, is the result of considering all geological aspects. Furthermore, the economic balance of a deposit can only be positively influenced by a sufficiently, geologically supported planning of the extraction of building stones (Mosch, 2008).

An essential part of the description of the geological conditions at different deposits or deposit types can be conducted by using the investigation of the fracture system. The detailed description, evaluation and modelling of the specific fracture system of a deposit must be critically considered, especially with regard to an optimized and an environmental friendly quarrying. For this purpose, various quarries in Germany and abroad were visited and examined regarding their structural inventory. In this publication they represent case studies of different lithologies (e.g., granite, sandstone, limestone and schist) with the aim to demonstrate how a greater efficiency or better block yield can be achieved by possible changes in the planning of the mine. In this context, the main goal is to maintain or increase the economic efficiency of natural building stone quarries in the long term.

\section{Building stones as mineral raw materials}

Building stones are a raw material. They are defined in the DIN EN 12670 as a naturally occurring rock used in construction, for monuments and are characterised by a variety of applications on the international market. For example, building stones can be used for load-bearing, constructive building 
elements or as purely decorative or ornamental elements, such as façade slabs or sculptures (Mosch, 2008, Mosch et al. 2007).

The building stone industry is an important sector of raw material extraction in more than 50 countries around the world. The world leaders in the production of building stones are a few Asian countries, Brazil and the European Union (Siegesmund \& Török, 2014).

The economically significant regions of building stone production in Europe are predominantly located in the Mediterranean region in countries like Italy, Spain, Greece or Portugal. Due to their advantageous conditions, being the result of the regional geology and the long tradition in the field of building stone processing, the main part of the European production is located in these countries. However, due to increasing extraction volumes and production in countries like China, India or Brazil, production rates have decreased in Europe over the past several years (Hoffmann, 2007, Hoffmann et al. 2007).

According to Mosch (2008), three basic quality levels can generally be distinguished for building stones:

- $1^{\text {st }}$ quality level: solitary blocks

- $2^{\text {nd }}$ quality level: gravestone sector and

- $3^{\text {rd }}$ quality level: construction sector.

The highest quality requirements are related to solitary blocks, which are used in sculpture, for example. Complete homogeneity in colour and decoration or special, individual requirements of the customer must be secured in this case resulting in a very high price segment. In the gravestone sector (2nd quality level), an immaculate petrographic and structural formation of the stone is generally expected. The third unit comprises all qualities, which are applied in the construction industry. In general, a further subdivision is possible related to the physical and structural properties, which then determines the potential area of application (Mosch, 2008). However, the spectrum of natural building stones ranges from unprocessed raw blocks and semi-finished products to refined customised products in various applications.

\section{Requirements to extraction and processing of natural building stones}

In contrast to other raw material industries, in the production of building stones there is no material transformation during the entire process from extraction and processing to usage as a building material (Peschel, 1983). Therefore, the quality is exclusively determined by the geologic conditions.

In this context, appearance (decor), physical and technical properties of the rock and the resulting behaviour are most important in construction application (Mosch, 2008). If the rock can generally be used as natural building stone, deposit-controlling factors and technical feasibility secondly determine the possibilities for a dimensionally appropriate production of blocks (Mosch, 2008). Thereby, the fracture system is one of the most essential elements. Depending on its orientation and distance distribution, it 
divides the deposit into individual blocks, and thus determines whether the resulting block sizes are sufficient and how many blocks with the required dimension can be extracted.

Applying state-of-the-art techniques for processing, which also generates a certain amount of losses, during production of building stones, certain minimum block sizes and dimensions are necessary to be produced to ensure an economical and efficient production of building stones (Selonen and Suominen, 2003), because the volume of the usable material decisively influence the economic viability of the deposit. Based on experience, Singewald (1992) defined a minimum block size with a volume of $>0.4 \mathrm{~m}^{3}$ and edge lengths of at least $0.4 \times 1.0 \times 1.0 \mathrm{~m}$, which results from the uniform requirements of many natural building stone deposits. A minimum edge length of $0.4 \mathrm{~m}$ is necessary in order to set up the blocks in a tilt-resistant position for further production steps. Furthermore, Primavori (1999) defines optimal raw block dimensions suitable for transport and processing, which are represented by an approximately cuboid block with a volume of $6-8 \mathrm{~m}^{3}$. Moreover, the United Nations Framework values (1976) determine detailed boundary conditions for building stone blocks, which are intended for export. These should meet a minimum volume of $1-6 \mathrm{~m}^{3}$ and be characterised by dimensions between $2 \times 1 \mathrm{x}$ $0.5 \mathrm{~m}$ and $3 \times 2 \times 1 \mathrm{~m}$.

Finally, when preparing plates from a block of building stone with pronounced structures, the most interesting decoration should be on the long side of the net block, so that it is entirely emphasised in its application. In contrast, regarding homogeneous building stones, the material can be used independent of its size ratio, as the same décor results from all cut layers.

\section{Methodology}

\section{Formation of the fracture system and its relevance for extraction of natural building stones}

The fracture system of a geological body includes all planar elements, which result in a dissection of the rock body (Palmström 1995, Mosch et al. 2007, Mosch et al. 2011, Sousa et al. 2017). The essential basic types are faults, joints, cracks, fractures, microcracks, bedding and shear planes. Quartz and calcite veins are also assigned to this system if reactivation of these discontinuities during block extraction is reasonable.

Joints generally occur as the dominant element of the surface structure. These are extensional fractures, which are generated as a result of the tensile strength of the rock being exceeded by brittle deformation, thus removing the cohesion of the bedrock (Davis and Reynolds, 1996). Joints are usually relatively planar as well as spatially enduring and form perpendicular to the least principal normal stress. Therefore, they reflect regional or tectonic stress fields. Depending on whether extension fractures are purely local or regional in nature, i.e., related to non-tectonic or tectonic stress fields, Eisbacher (1996) distinguishes between non-tectonic and tectonic extension fractures. 
Since the fracture geometry of a rock body determines the extent of its dissection, which in turn describes the potential usability of the deposit, it is necessary to obtain precise knowledge about the fracture orientation and density. In general, division surfaces are desirable for extraction of building stones, as they can facilitate the extraction of blocks by reducing the usage of machinery. Ideally, an orthogonal and wide fracture system is formed, resulting in cuboidal, well-dimensioned in-situ blocks (Fig. 2). However, such favourable conditions are rarely given. Figure 2 illustrates the increase in volume of waste with the occurrence of irregularities in the orientation of the fracture system. This can cause geometries of the insitu blocks, which deviate strongly from the orthogonality, which ultimately results in considerable material losses during the formatting of raw blocks. Therefore, the extent to which the material can be used as natural building stone depends on the density of the joints and the deviations of the dissection structure from orthogonality. In many cases, the stone is only suitable for gardening and landscaping or may only be used for the production of crushed stone.

Extremely large distances between the fracture surfaces can result in a detrimental effect on the extraction of building stones. However, there are hardly any natural dissection surfaces, which facilitate the extraction of blocks. Furthermore, an increased usage of machinery in the extraction of building stones results in increased production costs. Additionally, there is the problem of so-called in-situ stress ("mountain pressure"), described by stresses within a compact rock formation, which are released by extraction of material generating new cracks or fractures.

Furthermore, within the dissection surfaces, the homogeneous formation of the material is of primary importance. Therefore, it is also necessary to obtain veins, mineral veins and other elements such as enclaves, which represent an undesirable change in material or decoration. In addition, planar structural elements, such as foliation, and discontinuities, like faults or shear planes, must also be recorded and evaluated as part of the geological exploration of a deposit. Fault zones, for example, are characterised by a significantly higher density of fractures considerably restricting the extraction of building stone. In addition to a high fracture density and the resulting significantly smaller in-situ blocks, there can also be a severe reduction in rock quality.

\section{Record of the fracture system and its presentation options}

Fracture analyses are necessary in order to optimize and economically utilise and extract a natural building stone deposit. There are various approaches to evaluate the fracture system. These range from purely statistical calculation approaches to computer-aided two- and three-dimensional modelling. However, most computational approaches are based on a nearly orthogonal reference system, thus in many cases no reliable statement can be made regarding block volumes and block shape (e.g., Singewald, 1992; Palmström, 1982, 1986). Therefore, computer-aided modelling (e.g., Nikolayev et al., 2007, Mosch et al. 2011, Sousa et al. 2017) of a specific rock complex can often support the economic viability of a deposit. In this context analyses of joints, bedding planes and fault planes are of particular importance. 
Furthermore, various geophysical methods like Georadar (e.g., Singewald, 1992) have been developed to spatially investigate dissection surfaces. Imaging techniques such as optical or acoustic methods in boreholes are also used (Fricke and Schön, 1999). In most cases, however, these methods are associated with a high technical and financial effort.

Therefore, conventional methods, such as direct length measurement in the quarry, can be used to record the structure of the fracture system and represent a good alternative. The orientation of the fractures is determined with a geological compass. The basic principle of this method is based on the so-called, "window sampling" or "scanline sampling technique" (ISRM, 1978; Priest 1993). Applying this method, one vertical and one horizontal measuring line are defined on each extraction wall, thus two fracture layers are recorded (Fig. 3, wall 1, fracture layers A and C). In order to obtain a complete picture of the fracture system of the rock body, it is necessary to create a second measuring window on another extraction wall (Fig. 3, wall 2, fissure compartment B), which is as perpendicular as possible to wall 1 . This method can easily be applied in reservoir bodies of the most diverse lithologies. However, it is subject to certain limitations, as the orientation of the fracture clasts to each other should only deviate insignificantly from orthogonality. In this way, the recorded data allow a prediction of the fracture system within a given mining block. However, a limiting factor is mainly the termination behaviour of the joints.

\section{Analyses and display options of fracture distributions}

The spatial positions of the obtained fracture surface data and the analyses of their geometric interaction are precisely illustrated using stereographic projections. Two presentation options of the stereographic projection have been proven to be useful: distribution density diagrams (Fig. 4a left) and joint frequency diagrams (Fig. 4b right).

The average values of the distances between fracture surfaces per spatial orientation $(x, y, z)$ allows one to calculate the volume of a so-called "average block" (Singewald, 1992). Using these data, the amount of the so-called "net raw block" being extracted from the deposit can be estimated. It describes the portion of recoverable raw blocks, which meet the requirements of the minimum block $(1 \mathrm{~m} \times 1 \mathrm{~m} \times 0.4 \mathrm{~m})$. It is calculated from the distances of the respective fracture layers along a profile line ( $x, y$ or $z ;$ Fig. 3). For each of the three main directions $(x, y, z)$, the sum of all fracture surface distances, which are above the minimum value of $1 \mathrm{~m}$ or $0.4 \mathrm{~m}$, respectively, is calculated. Subsequently, each sum is converted into the percentage of the total distance. The average of that portion equals the "net raw block" $\eta$. However, since this method is based on an almost orthogonal reference system, this calculation of the net raw block can be used as a general estimate of the yield of a deposit, but does not consider expected shapes of the raw blocks (Mosch, 2008).

\section{Numerical modelling using the software 3D-BlockExpert}

The 3D-BlockExpert software developed by Nikolayev et al. (2007) follows a new approach. Based on conventional measurement methods to determine the distance distribution and orientation of the fracture system, the spatial trend of the fracture surfaces within a mining block is modelled. This allows conclusions to be made about the shape and volume of the expected in-situ blocks. The big advantage of 
this software is that fractures with various spatial orientations can be used as database and additionally, no orthogonal reference system is required.

For the application of the computer software 3D-BlockExpert, the detailed recorded data are defined as mathematical surfaces. There are exactly two possibilities for this in a three-axis coordinate system. The first is based on three points (Fig. 5), each defined by the parameters $x, y$ and $z$, which span the area to be determined. In the second possibility, the area is described via a point $A$ and two adjacent angles (see Mosch et al. 2008, Nikolayev et. al 2007).

The problem is that the outcrop layer does not have perpendicular and orthogonal deposit walls, or the mining wall itself is not rectilinear. The models do not capture potential fracture surfaces in the third dimension. Theoretical fracture distributions that reflect the characteristic interface system of the deposit complex can supplement the model in this case. In general, however, the resulting models are fundamentally highly error-prone.

A further limitation in the possible representation and the significance of the acquired results can be caused by the software limitations, because fracture surfaces are always described as a continuous interface. Thus, for example, in layered sedimentary rocks, in which the vertical interfaces often end at the layer-parallel fractures or are displaced, inaccurate models are often produced.

The software determines the area of a deposit to be observed as a geometric body composed of equally dimensioned voxels (voxel: volumetric pixel). All voxels belonging to an in-situ block are assigned a colour so that the dissection of the deposit body is clearly highlighted and displayed in colour.

Informative and mathematical background information on the detailed operation of the software is given in Nikolayev et al. (2007).

Another function of the software is the differentiated consideration of two cutting layers lying parallel to each other. This enables the construction of a potential mining slice, whereby the respective cut surfaces represent the front and back and thus determine the dimension of the final raw blocks. Finally, the "Optimisation" function is used to optimally utilise the quantified area by fitting adapted raw blocks. The direct information about the respective volume of the defect-free raw blocks, their percentage share of the total rock complex as well as the distances between two freely selectable points on a cut surface can be determined.

In the second step, the programme creates a data set which can be used to visualise a three-dimensional model using the Intel ${ }^{\circledR}$ Array Viewer software (Fig. 6). By arbitrarily moving the cut surfaces parallel to the outer walls and rotating the body, it is possible to gain an insight into the course of various parting surfaces using the model. In this way, conclusions can then be drawn regarding the volume and shape of the defect-free raw blocks as well as the possibility of detecting areas not worth mining.

\section{Case Studies}




\section{Theuma slate ("Fruchtschiefer")}

Theumaer Fruchtschiefer is a highly valued building stone in the construction industry. This metamorphic slate is known for its good workability and excellent technical properties resulting in a wide range of applications, for example as façade panels, floor coverings, masonry, monuments or gravestones. In addition, a wide variety of processing techniques for the visible surface, such as bush-hammered, flamed, ground or brushed, can give the stone a wide range of different looks.

The church of Theuma, consecrated as early as 1456, was built with natural stones from the immediate vicinity and provides evidence of the centuries-old tradition of quarrying as well as the excellent weathering resistance of this rock. The mining of Theumaer Fruchtschiefer is documented to have begun in 1858 .

The opencast mine currently covers an area of about 13 ha (Fig. 7a). On the terraced mining floors, natural fissures are drilled into with modern drilling equipment and blasted with black powder. The excavated blocks are finally cut to block sizes suitable for saw.

The size of the blocks varies between $1.8 \mathrm{~m} \times 0.8 \mathrm{~m} \times 0.4 \mathrm{~m}$, i.e., a volume of just under $0.6 \mathrm{~m}^{3}$, and $2.8 \mathrm{~m}$ $\times 1.45 \mathrm{~m} \times 1 \mathrm{~m}$, i.e., about $4 \mathrm{~m}^{3}$. On average, a high price level of $800 € / \mathrm{m}^{3}$ of rock is achieved for crevice blocks. The final production of the various natural stone products and their sale take place directly at the natural stone plant in Theuma (Fig. 7b).

The total monthly production is about 14,600 t of rock, of which, however, only about 1,200 t of ashlar are extracted. Of these, about $60 \%$ are lost in industrial processing as cuttings, so that the net production at the end is only about $3 \%$. As a by-product of the quarrying of the natural stone blocks, about $2-3 \%$ of the production can be used for gardening and landscaping purposes, e.g., paving stones. The remaining parts of the raw material that are not suitable for use as ashlar are processed into crushed grain mixtures, so that these components are also completely incorporated into saleable final products and $100 \%$ recycling of the material takes place.

\section{Geological situation}

The area of the Theumaer slate quarries lies in the contact zone of the Upper Carboniferous intruded granite massif of Bergen. The contact rocks (Fig. 7b), which originated from old Palaeozoic shales, are present as nodular or slate of variable petrographic composition. Essentially, two varieties of the Theumaer slate are distinguished:

- a blue-grey, finely streaked slate (so called "Fruchtschiefer", (Qgr) and

- a mostly greenish, banded and striped to banded slate (Qp), often intercalated with lenses and bands of quartz (Peschel and Franz, 1968).

The finely striped, blue-grey coloured slate (Qgr) is restricted to some narrow zones in the contact zone of the Bergen granite massif. The formation strikes N-S or NNW-SSE and reaches a thickness of about 60- 
$70 \mathrm{~m}$. With increasing depth, increased quartz content can be observed both in the groundmass and in the form of increased bands, lenses and striations. From a depth of approximately $80-0 \mathrm{~m}$ only the banded slate Qp) occurs, which has a greater hardness than Qgr due to its high quartz content. In addition to both varieties of slate, amphibolite deposits ("black gravels") also occur. These strata-parallel diabase rocks were found in five areas and reach thicknesses varying from 0.2-0.7 $\mathrm{m}$ (Peschel and Franz, 1968). Typical for some areas at the Theuma quarries are mylonitic fault zones that strike approximately E-W. In the vicinity of this zones the slate is sometimes bleached and in deeper areas mostly hematite alteration occurs.

\section{Lithological characterisation of the Theuma slate and its physical and technical properties}

The schistose rock has a blue-grey, macroscopically homogeneous and dense ground mass, in which dark grey to black prismatic porphyroblasts are intercalated. The typical minerals of this stone are cordierite, which are also responsible for the naming of the slate, as their shape is reminiscent of cereal

grains ("field fruits"). The spindle- to cigar-shaped cordierites are well oriented within the schistosity, while the long axes are randomly distributed. The foliation is defined due to an alternation of lighter and darker layers. The darker components are mainly ores (magnetite, ilmenite; Peschel and Franz 1968). According to Peschel and Franz (1968), the macroscopically homogeneous groundmass consists of a slaty to fine scale sericite-chlorite-biotite fabric with grain sizes of about $15 \mu \mathrm{m}$. Included are quartz grains of the same size. The cordierite is highly altered and shows in case also signs of pinitisation. Biotite and occasionally larger amounts of muscovite occur in the groundmass without a regular spatial arrangement. In addition, tiny streaky lenses of granoblastic quartz may occur in the schistosity plane (Peschel and Franz 1968).

\section{Geological characterisation of the deposit and its ashlar potential}

The area of the Theuma quarry ('Plattenbruch') syncline is bounded on both sides by faults and divided into sub-areas by further parallel faults. Despite its large-scale tectonic development, however, a characteristic and relatively homogeneous cleavage surface structure is formed, which is defined by three cleavage groups (KS A, KS B and KS C, Fig. 8). The cleavage surfaces of cleavage layer A run parallel to the schistosity, generally dipping at approx. $30-40^{\circ}$ to the WNW and consequently correlating with the strike direction of the fault zones laterally bounding the 'Plattenbruch'-syncline. Fissure B shows the same strike direction, but the fissures are much steeper with an average dip of $70-80^{\circ}$ to the ESE. The spatial position of the third fissure layer is approximately perpendicular to the strike of the excavation walls and is also relatively steep at $70-80^{\circ}$. The interfaces of the two steeply standing fissure layers are usually not continuous. Frequently, a jumping can be observed, or they end at the fracture structures parallel to the schistosity.

From the schematic representation of the interface structure (Fig. 9) it is clear that, based on the natural interface system, a uniform spreading of well-dimensioned raw blocks is often not possible. Since the 
fracture structures of fracture set $B$ are oriented at an acute angle (approx. $35^{\circ}$ ) to the strike of fracture set $\mathrm{C}$, the spread of raw blocks deviate strongly from orthogonality and have to be formatted with high material losses (Fig. 9).

The distances of the interfaces are predominantly formed between $1 \mathrm{~m}$ and $2 \mathrm{~m}$ within the fracture set $\mathrm{B}$ and $\mathrm{C}$, while the fissures developed parallel to the schistosity have smaller distances and are predominantly between $0 \mathrm{~m}$ and a maximum of $1 \mathrm{~m}$ in size (Fig. 9a). Based on the measured data, an average block size of $1.8 \mathrm{~m} \times 1.4 \mathrm{~m} \times 0.7 \mathrm{~m}$ is calculated, i.e., a raw block volume of approximately 1.6 $\mathrm{m}^{3}$ (Figs. 9).

Due to the strong deviation of the interface geometry from orthogonality, the determination of the dimensions of an average block must be considered critically. Therefore, in Fig. 9c, the maximum and minimum block dimensions documented by the Theuma company on the basis of many years of experience are shown as a supplement and comparison. It becomes clear that the average values determined on the basis of the fracture distance distribution correlate well with the average volume of the documented block dimensions, and can therefore be used as an initial estimate of emerging block volumes. Nevertheless, due to the unfavourable fracture geometry, it is very likely that blocks with lower volumes will be produced. This assumption is additionally supported by the comparative consideration of the arithmetic mean and the median (Fig. 9b). Thus, in the case of fracture groups $A$ and $C$, the median is below the mean value, so that the frequency of small fracture distances predominates and consequently the emergence of smaller block sizes dominates.

The deposit is developed via five terraced levels (Fig. 7), which do not show any vertical deposit walls due to selective mining. The excavation walls are inclined according to the schisosity and are unevenly formed due to many offsets. Under these conditions, it was not possible to determine the raw block values, as this is based on the measured fracture distances along several profile lines. In addition, due to the general outcrop conditions of the deposit, modelling using the 3D-BlockExpert software proved to be difficult.

\section{Concluding observations on the mining of the Theuma slate}

Overall, the deposit is determined by unfavourable geological conditions, which are caused by the large tectonic structure as well as by the occurring interface structure. In view of the perspectives of a finite deposit as well as additional considerable restrictions in mining, a targeted and optimal utilisation of the resource is economically imperative in order to be able to extract the Theuma slate in its typical decor and its good mechanical and physical properties in the long term. However, an optimisation and thus an increase in production is difficult in the investigated deposit complex. Various potential changes in the mining process were simulated in order to achieve a possible increase in the block yield. However, a change in the mining method does not achieve any advantages. The main problem is that existing in-situ blocks can be cut and thus reduced in volume. 
Building on the natural interface system, it therefore makes sense to consistently pursue selective mining that specifically targets singular large blocks. For each further mining step, a detailed recording and assessment of the interface structure would have to be carried out for individual rock sections in order to detect individual large blocks in the rock body.

\section{Case study Seeberg - Rhaetian sandstone}

For centuries, the sandstone of the Seeberg was an important raw material for building activity, especially for representative buildings in the city of Gotha, and was mined in numerous quarries, most of which are now abandoned. There is evidence of quarrying back to the 11th century when the stone was used in the construction of Wartburg Castle in Eisenach. It was also used, for example, in the construction of Sanssouci Palace in Potsdam and the Reichstag building in Berlin.

Today two quarries have been developed, one through the "Kammerbruch" and the other through the "Günthersleber Bruch". The "Kammerbruch" is a relatively small area of 50,000 $\mathrm{m}^{2}$, where mining is done by small explosive charges detonated in boreholes. The resulting gangue blocks reach sizes of 1-1.2 $\mathrm{mx}$ $1.5 \mathrm{~m} \times 2-2.5 \mathrm{~m}$, i.e. block volumes of $3.8 \mathrm{~m}^{3}$ to $6 \mathrm{~m}^{3}$. The material that cannot be used as a building stone is processed to golden-yellow sand. Part of the "Kammerbruch" is designated as a geotope and should therefore be preserved for a long time.

\section{Geological situation}

The Triassic sediments of the Thuringian Basin form a widely stretched basin, which essentially formed during the younger Mesozoic. NW-SE striking fault zones dissect the basin into strip-shaped floes (Henningsen and Katzung, 2006). The Seeberg is part of the Hercynian-striking Eichenberg-GothaSaalfeld fault zone that runs through Thuringia and was formed during the Saxonian fracture tectonics. Part of this fault zone is also exposed in the quarry .

At present, the "Kammer"-quarry in production offers a good insight into the sandstone sequence of the Rhaetian (Upper Keuper) and the overlying strata of the Lias (Lower Jurassic). The deposition of the Rhaetian sandstone took place about 215 million years ago mainly under continental, fluviatile-estuarine, and to a lesser extent under brackish-lagoonal conditions (Henningsen and Katzung, 2006). The Upper Keuper formation reaches a thickness of about $40 \mathrm{~m}$ in the deposit area (Fig. 10), whereas the exploitable building stone beds of the Middle and Upper Keuper only reach a maximum thickness of $15 \mathrm{~m}$ in the entire area.

\section{Lithological characterisation of the Seeberg sandstone and its physical and technical properties}

The rocks of the Rhaetian Formation exposed in the Kammerbruch (Fig. 10) represent a yellow to yellowgrey coloured, very fine-grained to fine-grained as well as siliceously cemented quartz sandstone. Brownish limonite precipitates in the form of Liesegang'rings and are frequently observed (Fig. 11). In addition, washed-in plant remains, representing a structural inhomogeneity that is susceptible to 
weathering. Oblique stratification and flow ripples were observed in sediment structures. The Seeberg sandstone in its grain size-dependent varieties (fine-grained, very fine-grained) is a pure quartz sandstone (approximately 95-98\%). The very fine-grained sandstones also contain insignificant amounts of mica and glauconite (Schwate, 1994).

The physical and technical characteristics shows that the bulk density and porosity are in the middle range for sandstones (Mosch \& Siegesmund 2007, Siegesmund \& Duerrast, 2014), while the compressive and flexural strength of the rock are relatively high. This is due, among other things, to a very high quartz content especially in the form of the siliceous cement.

\section{Geological characterisation of the deposit and its potential}

Currently, four sandstone layers are being mined in the Kammerbruch (Fig. 10), with thicknesses varying between $2 \mathrm{~m}$ and $3 \mathrm{~m}$ ( $1 \mathrm{st}$ to 4 th levels). Within these benches, clays and silts were observed, which can be several $\mathrm{dm}$ thick, but are often horizontally unstable and form larger, non-contiguous lenses or gullies.

On the slope of the sandstone layers viable for quarrying, there is an approximately $8 \mathrm{~m}$ thick cover of clay and silt layers, in which low-thickness layers of sandstones (dm-range) are intercalated. As a result, a thick layer of overburden must be removed before mining can begin, from which at most small masonry stones can be extracted for gardening and landscaping.

The interface system of the deposit is defined by two dominant fracture systems (KS A and KS B, Fig. 12), which are relatively steep with an average of $80^{\circ}$. Fracture A strikes approximately NNE-SSW, while fracture $B$ is characterised by WNW-ESE striking structures, and thus has the same orientation as the fault zone. Orthogonal fracture geometry is common for sandstones. It causes a uniform dissection of the rock complex, so that well-dimensioned, approximately cuboidal rough blocks can be extracted here.

The steeply oriented planes are mostly rectilinear, but rarely run through the entire rock complex, instead they offset or end at the strata-parallel bearing fissures (Fig. 13). These, on the other hand, are horizontally stable, although their surfaces are increasingly wavy and irregularly developed. At first glance, it is obvious that the uppermost three beds are more fissured than the lowest sandstone layer. Furthermore, on the western side of the quarry near the fault zone, tectonic events in the form of staggered thrusting have been observed, but these are restricted to the uppermost floor and further dissect it.

In this context it is differentiated between interface distances within the upper three levels and those in the 4th level. In the $x$ - and $y$-direction distances between $0 \mathrm{~m}$ and $1.5 \mathrm{~m}$ dominate, whereby the distances of the interfaces measured in the $x$-direction are generally smaller than in the $y$-direction.

Furthermore, the lowermost layer, compared to the upper layer, shows significantly less cleavage spacing between $0 \mathrm{~m}$ and $1 \mathrm{~m}$ and, especially in the $y$-direction relative to the $x$-direction, shows more cleavage spacing, ranging between $1.5 \mathrm{~m}$ and $2.5 \mathrm{~m}$. While average blocks of $1.2 \mathrm{~m} \times 1.4 \mathrm{~m} \times 2.5 \mathrm{~m}$ in size and a resulting volume of about $4.2 \mathrm{~m}^{3}$ can be recovered from the main extraction layer, the raw blocks of the 
uppermost layers only reach an average size of $2 \mathrm{~m}^{3}$. In the entire rock complex, however, the determined medians of all profile directions are generally below the arithmetic mean, so that the frequency of smaller block sizes generally predominates.

Based on the dimensions of the minimum block, this results in an average raw-block potentiality of approximately $79 \%$ for the uppermost levels, while the main extraction bench achieves an overall block potential of approximately $93 \%$. However, since it is very likely that extraction is usually based on larger volumes, the second calculation was carried out under the conditions of the average block sizes calculated on the basis of the distance distribution for the uppermost levels $\left(0.8 \mathrm{~m} \times 1 \mathrm{~m} \times 2.5 \mathrm{~m} ; 2 \mathrm{~m}^{3}\right)$ as well as the main extraction bench $\left(1.2 \mathrm{~m} \times 1.4 \mathrm{~m} \times 2.5 \mathrm{~m} ; 4.2 \mathrm{~m}^{3}\right)$.

As part of the geological characterisation of the deposit, a model was created for the excavation area illustrated in Fig. 14 using the 3D-BlockExpert software. Based on this illustration, it is clear that a large part of the fractures do not run through the entire rock complex, but are only developed in individual sandstone layers (Fig. 14). However, since the software describes all interfaces as continuous, this creates errors in the modelling that negatively affect the actual existing block volumes. Therefore, only interfaces that pass through at least two sandstone banks are included in the modelling (Fig. 14).

The frequency distribution of all block sizes occurring in the modelled rock complex shows that approximately $50 \%$ of the in-situ blocks have volumes between $0 \mathrm{~m}^{3}$ and $2.5 \mathrm{~m}^{3}$ and a good $13 \%$ are only formed up to a size of $0.5 \mathrm{~m}^{3}$. About $12 \%$ of the in-situ blocks are extremely large, exceeding $10 \mathrm{~m}^{3}$. Based on the data obtained, an average block volume of about $3.8 \mathrm{~m}^{3}$ was calculated. The calculated median of $2.4 \mathrm{~m}^{3}$ is clearly below the mean value, so that the frequency of smaller blocks generally predominates. Overall, strong fluctuations occur within the block size distribution, which are caused by a high number of very small or very large blocks. These can be caused by the aforementioned limitations in the modelling. For example, fissures that are only formed in two sandstone layers are determined as a continuous interface, and thus possibly cut an already relatively small in-situ block a second time. On the other hand, the model does not consider fractures that only pass through one bed, so that large raw blocks may be additionally dissected by existing interfaces in reality. Considering these sources of error as well as the comparative consideration of mean, median and standard deviation, the corresponding values were additionally and restrictively determined for all occurring block sizes with a volume between $0.5 \mathrm{~m}^{3}$ and $10 \mathrm{~m}^{3}$. The average block calculated in this way is $3.2 \mathrm{~m}^{3}$, which is slightly below the calculated mean value of the total data set $\left(3.8 \mathrm{~m}^{3}\right)$. This value correlates with the average block volume determined on the basis of the fracture distance distribution $\left(3.1 \mathrm{~m}^{3}\right.$. In both cases, however, the median is below the mean value, so that the frequency of smaller block sizes generally predominates.

In principle, however, it is important to note that the model is still subject to errors due to the softwarerelated limitations. In order to minimise the sources of error and to model the deposit in the best possible way, and not only to obtain knowledge about the average block sizes, but also to make possible statements regarding the amount of stock and the mineability of individual rock areas, separate modelling of all four sandstone benches would be necessary. As an example, such a model was created 
using the 4th level, i.e. the main extraction layer, which carries the largest potential of workable material, as well as the 2nd excavation level, which is probably the most dissected.

The modelled area of the 4th level represents a potential mining block with the dimensions $8 \mathrm{~m} \mathrm{x} 15 \mathrm{mx}$ $2.5 \mathrm{~m}$. It is already clear here that the front part, due to stronger fracturing in the $x$-direction, leads to smaller in-situ blocks than in the rear areas. With the help of the function difference analysis the actually usable material can now be distinguished from the resulting overburden. While the sandstone bank in the front area carries a lot of overburden and only allows the extraction of small bricks or paving stones, the in-situ blocks located in the rear area show great potential for the production of building stones.

Exemplarily, the quantified areas were exploited by fitting adapted rough blocks. These represent the average block with the dimensions $1.2 \mathrm{~m} \times 1.4 \mathrm{~m} \times 2.5 \mathrm{~m}$ determined on the basis of the gap distance distribution for the 4th extraction layer. Accordingly, 17 raw blocks with a volume of approximately $4.2 \mathrm{~m}^{3}$ could be extracted in the lowest level in the way shown.

Comparatively, the second invert was modelled, representing a potential mining block of $8 \mathrm{~m} \times 15 \mathrm{~m} \times 2.2$ $\mathrm{m}$. The more dissected sandstone bench consequently carries fewer large in-situ blocks than the fourth floor. Thus, six larger blocks with the dimensions of the average block from level 4 and 13 average blocks from the upper levels could be recovered from the schematically depicted mining series. For the average block dimensions, a size of only $2.2 \mathrm{~m}$ instead of $2.5 \mathrm{~m}$ was assumed here in accordance with the height of the excavation floor, so that the average volumes of the blocks must be corrected downwards accordingly compared to the modelling of the 4 th excavation floor $\left(1.8 \mathrm{~m}^{3}\right.$ instead of $2 \mathrm{~m}^{3}$ and $3.7 \mathrm{~m}^{3}$ instead of $4.2 \mathrm{~m}^{3}$ ). Based on these representations, approximately $75 \mathrm{~m}^{3}$ of ashlar can be extracted from this layer (approximately $25 \%$ of the total volume). The production in the second layer is significantly lower at approximately $38 \mathrm{~m}^{3}$ of ashlar (approximately $14.4 \%$ of the total volume).

\subsection{Case study Burgpreppach - Rhaetian sandstone}

In the past, the ashlars from the Burgpreppach quarry area were mainly used as building sandstone. In addition to well-known buildings, such as Bamberg Cathedral, or modern facade cladding (Bamberg Concert and Congress Hall), this sandstone characterises the entire region around Burgpreppach. Currently, Burgpreppach sandstone is quarried and sold by the Schubert stone factory on an area of approximately $100,000 \mathrm{~m}^{2}$ (oral communication from V. Deuster). The quarrying is done similarly to the Seeberg deposit complex with explosive charges that are detonated in boreholes. According to estimates, about half of the deposit in the mountain has been mined (oral communication from V. Deuster). In the trade, the sandstone is known as "Gelber Mainsandstein" (or Burgpreppacher Sandstone) and is used today partly for façade design and as flooring, but mainly as a wall stone for gardening and landscaping (Geyer and Schmidt-Kaler, 2006). In the case of larger raw blocks, the sandstone can also be used to make sculptures. According to current studies, the Rhaetian sandstone will also function as a hydraulic engineering stone in the future (Stein, 2009).

\section{Geological situation}


The Hassberge Mountains (Fig. 15) are built up by rocks of the Middle and Upper Keuper, a direct continuation of the Steigerwald, which lies S' of the Main (Geyer and Schmidt-Kaler, 2006). The Rhizosphere layers of the Upper Keuper are preserved in the Hassberge mainly as erosional relicts. According to the established lithostratigraphic division of the Keuper in Lower Franconia, the outcropping building stone beds are counted among the so-called Anoplophora sandstones, whose thickness is generally estimated at $10-12 \mathrm{~m}$. The Anoplophora sandstone is a marine-influenced, with sedimentation occurring under estuarine conditions. These deposits are located in a marine-terrestrial transition zone and reflect the interaction between fluviatile processes and marine influences (Geyer and Schmidt-Kaler, 2006).

The Triassic plates of the South German stratigraphic plateau are hardly dissected by major faults (Henningsen \& Katzung 2006). The significant faults as well as large saddle and trough structures all preferentially follow the Hercynian strike direction, i.e. are oriented roughly NW-SE (Geyer and SchmidtKaler, 2006).

A characteristic feature of the sandstone in the deposit is the strong siliceous cement, whereas the sandstones from the immediate vicinity contain significantly more clay, are not quartz-cemented and are therefore less suitable as an ornamental stone. The silicification could be due to post-diagenetic, hydrothermal influences, such as the supply of silicate solutions along tectonic fault paths. Such a phenomenon is described by v. Gehlen (1956) and Koch et al. (2003) for sandstones of the Keuper in the Nuremberg area. Here, the rocks are influenced by a fault system and were strongly hydrothermally silicified.

\section{Lithological characterisation of the Burgpreppacher Rhätsandstein and its rock physical and technical properties}

The Burgpreppach Rhaetian sandstone is characterised by a light grey to yellowish brown, sometimes also reddish colour. Overall it is fine-grained, with grain size changes occurring in part, which are formed as layer boundaries. In these areas there are coarse-grained sandstone layers, in which individual grains of predominantly grey quartz can be up to $5 \mathrm{~mm}$ in size. In individual sections of the deposit, crossstratification is also formed over shorter distances of a few metres. The typical appearance of the sandstone is accentuated by a limonitic brown colouration (Fig. 16a).

The rock generally does not show any noticeable signs of intensive alteration. Only rarely are slightly higher contents of kaolinite occur. The rock consists of 98-99\% of quartz. The proportion of polycrystalline quartz, which may show lower strength under mechanical or chemical stress, is less than $5 \%$. The mineral grains usually show a secondary quartz accretion fringe (Fig. 16b). The frequently occurring grain to grain contacts causes a high mechanical strength of the rock. In some cases, clusters of quartz grains up to $5 \mathrm{~mm}$ in size have formed, which controls an additional mechanical stability. 
The feldspar content is less than $1 \%$. The aggregates are fresh and show no clear signs of alteration. Sporadically, kaolinites as well as light mica and biotite are present, but they are so sparsely distributed that no slip planes can form under mechanical stress. The proportion of limonite and haematite has a colouring effect and is essentially encased as original grain adhesion to the primary quartz grains by the secondary quartz (Stein, 2009).

\section{Geological characterisation of the deposit and its ashlar potential}

Production takes place on the 2 nd mining level, which forms the actual core rock of the

deposit. The natural stones are overlain by approximately $3 \mathrm{~m}$ thick, thin-banked and obliquely bedded sandstones, which are partly formed as platy sandstone clasts and contain grey clay lenses. The sandstones here are strongly limonitically interbedded and deconsolidated and contain individual benches that are more strongly silicified. Occasional lenses with a high kaolinite content also occur. The uppermost bed is considered overburden and must be removed before actual quarrying, similar to the case of the Seeberg sandstone, but here it reaches a significantly lower thickness of approximately $3 \mathrm{~m}$. Under certain circumstances, these sandstones can still be used for the production of smaller wall stones or polygonal slabs for gardening and landscaping. If their clay content were lower, it would also be possible to grind up the rock.

The rock is strongly fractured. The horizontally layered fractures are usually boundaries of sedimentary sequences and usually have distinct layers with a higher proportion of clay minerals from $\mathrm{cm}$ to $\mathrm{dm}$ in thickness. The degradable bench heights here range from one to three metres. The spatial position of the developed interface structure was measured on the active excavation floor at three perpendicular deposit walls (Fig. 17, 18). The fracture surfaces determined in the y-direction (Fig. 17, 18) show a clear preferred direction with an almost N-S orientation (fracture layer A), perpendicular to the strike of the mining front. In addition, two further fracture sets are indicated (KS B and KS C), but these are rarely cut on this profile. These two sets, which were increasingly measured on the walls oriented in the $x$-direction, form an angle of approximately $50^{\circ}$, with an angle bisector perpendicular to the excavation front (Fig. 17b, 18). In addition, a fourth fracture set occurs here, which runs approximately perpendicular to the profile line (KS C).

Altogether, four preferred directions of the fracture surfaces can be determined, which run approximately N-S, E-W, WNW-ESE and WSW-ENE. The respective mining walls are oriented approximately N-S and E-W and thus well adapted to the strike of two fracture structures, which are consequently used as natural dividing surfaces in mining. However, despite the ideal orientation, more acute-angled in-situ blocks are formed during mining, which cause a high material loss when formatting to a net block (Fig. 17, 18).

The bedding surface system as a whole is heterogeneous and very changeable. While individual fracture sets are stable and run in a straight line, on the other hand it was often observed that fissures bend, jump, run out or end at horizontal interfaces. Bending and jumping of the fissures occurs especially at the 
horizontal interfaces as well as at the vertical fracture structures in the x-direction. Due to the heterogeneity of the interface, no reliable predictions can be made.

The average block size resulting from the joint sets and its distribution reaches a volume of about $1.5 \mathrm{~m}^{3}$, but must be considered critically because the calculation is not based on an orthogonal reference system. The determination of the raw blocks on the basis of the minimum block volume defined by Singewald (1992) results in a value of $\sim 88 \%$. In contrast, the second calculation was made on the basis of the average values resulting from the fracture distance distribution, which yields an average value of about $74 \%$.

The termination behaviour of the fracture is also problematic, as the 3D-BlockExpert software in its current state of only determines discontinuties as straight and continuous surfaces. Figure 17 shows the course of the interfaces on the respective excavation walls as well as the extrapolated or simplified course of the fractures that were used in the modelling. This necessary but serious simplification means that the model can only represent reality to a limited extent.

The frequency distribution of all in-situ block sizes occurring in the modelled rock complex is dominated by volumes between $0 \mathrm{~m}^{3}$ and $2.5 \mathrm{~m}^{3}(\sim 40 \%)$. With a volume $<0.5 \mathrm{~m}^{3}$, a good $16 \%$ of the blocks are not suitable as ashlars. A high number of extremely voluminous blocks $\left(\sim 50 \mathrm{~m}^{3}\right)$ results in larger arithmetic mean of approx. $7 \mathrm{~m}^{3}$, which cannot reflect reality at all and probably results from the strong simplification of the model. Therefore, the mean value of all occurring in-situ blocks with a volume between $0.5 \mathrm{~m}^{3}$ and $10 \mathrm{~m}^{3}$, i.e. without considering the extreme block sizes, was calculated additionally and comparatively. This is by far lower with a value of $3.8 \mathrm{~m}^{3}$, but is still clearly above the average block volume $\left(1.5 \mathrm{~m}^{3}\right)$ determined on the basis of the joint distance distribution. In principle, it is to be expected that the average block sizes are below the calculated value from the modelling, as it is very likely, due to the heterogeneity in the interface system, that in addition to the fracture structures recorded at the outer walls, further fractures occur in the entire rock complex that are not visible at the excavation fronts.

\subsection{Case study Treuchtlingen - "JURAMARMOR-limestone"}

JURAMARMOR limestone is quarried (Fig. 19) in the Treuchtlingen-Solnhofen-Eichstätt triangle of towns and has been used on a large scale as a building stone since the beginning of the last century. The easy extraction of the stone was an important settlement criterion in earlier times for the construction of castles and houses in the upper classes. Thus, since the late Middle Ages, the ashlar was highly valued, especially in the episcopal town of Eichstätt, as a result of which the townscape is still characterised by buildings made of JURAMARMOR today. The first major building tasks were the façade of the cathedral, the staircase in the residence and the Willibaldsakristei at the cathedral, which were built from JURAMARMOR.

A few decades ago, a second main mining area was established in the Petersbuch-Erkertshofen-Kaldorf area (Hafner, 1989). Currently, the rock is extracted in about 30 quarries with mechanical use and blasting after removal of non-usable surface layers in open-cast mining. After the blocks have been split off, they 
are divided according to size and geological conditions and sawn into 1-4 $\mathrm{cm}$ thick slabs in the factory and then mostly ground or polished. The colours of JURAMARMOR range from white to golden yellow to grey-blue.

\section{Geological situation}

The Franconian Alb, one of the dominant mountain ranges of the South German stratified plain, is predominantly built up by rocks of the Jurassic formation. The Jurassic units in Franconia are altogether less than $400 \mathrm{~m}$ thick and are traditionally subdivided into the Black, Brown and White Jurassic (Lias, Dogger, Malm). For the present work, the strata of the White Jurassic, which are the most prominent in the Southern Germany and contain the deposits of the JURAMARMOR as well as the Solnhofer Plattenkalke, are particularly relevant. These are limestones which, due to their resistance to weathering, form a morphological escarpment, the so-called Albtrauf. The bedded, partly dolomitised limestones, especially of the younger Malm, are intercalated with larger unstratified blocks. Here are former reefs formed from algae and siliceous sponges in the then prevailing shelf sea environment (Henningsen and Katzung, 2006).

A special geological feature of the JURAMARMOR is its large-scale occurrence. Thus, the benches extend over an area of $22 \mathrm{~km}^{2}$ across the southern Franconian Jura mountain range with more or less the same stratification and stratification sequence (Fig. 20). Therefore, a consistent quality can be guaranteed even with larger demands for building stones.

\section{Lithological characterisation of the Jurassic limestone and its physical and technical properties}

The trade name JURAMARMOR is misleading in the geological sense, since from a petrographic point of view it is a sedimentary rock, a fine-grained limestone. The rock found in the quarry under investigation is of the grey JURAMARMOR variety, although areas with a distinct yellow colouration have also been observed in places. The rock is overall predominantly light grey, micritic and shows dark grey to partly slightly reddish weathering features (Fig. 20). Furthermore, fossils like sponges, algae and ammonites can occur (Ritter-Höll, 2005). Washout and sinter formation occur especially on dominant fissure or stratified surfaces (Fig. 20b). In addition, coarse crystalline calcite veins penetrate the rock.

JURAMARMOR is comparatively soft, but in comparison to other softer rocks, it is characterised by the excellent polishing of its surface, which it owes to the extreme density of the material. This is why this natural stone is also called "marble". The material density, the polishability, the numerous colour and structure variations and the good abrasion resistance result in the decisive properties for the versatile uses of the stone. The natural stone also has a particularly good heat storage effect, making it additionally suitable as an ideal floor covering for hot water or electric underfloor heating systems.

The JURAMARMOR has a high compressive and flexural strength, which is in the upper range of carbonate rocks. 


\section{Geological characterisation of the deposit and its ashlar potential}

The JURAMAMOR deposit is developed as a kettle quarry. The thickness of the exploitable rocks is about $12 \mathrm{~m}$ with a current mining area of about $1500 \mathrm{~m}^{2}$. The rock sequence is divided into individual benches up to $1.6 \mathrm{~m}$ thick, which are separated from each other by several cm-thick marl layers. On the slopes of the limestone beds there is a dolomite layer about 1-2 $\mathrm{m}$ thick, which has to be removed before the valuable rock can be quarried.

The stereographic projection of the fracture surfaces shows three preferred directions oriented approximately NNW-SSE, WNW-ESE and SW-NE. In addition, the strike directions of the deposit walls shown in Fig. 19 are illustrated, whereby the two mining fronts in the x-direction represent fracture surfaces or fracture zones. They run at an acute angle to each other and can give a first estimate of the geometry of the resulting in-situ blocks. The vertical interfaces mostly run in a straight line, but jump or end predominantly at the layer-parallel discontinuities. The spacing distribution of the interfaces is characterised by a large variability of the fractures occurring in the $\mathrm{x}$-and $\mathrm{y}$-direction, while in the $z$ direction fracture spacing between $0.5 \mathrm{~m}$ and $1 \mathrm{~m}$ clearly predominates. On average, blocks with a volume of about $1.6 \mathrm{~m}^{3}$ are to be expected according to the computationally determined characteristic values. Here, too, the determination of the average block must be viewed critically, as the calculation is not based on an orthogonal reference system. The determination of the raw block on the basis of the minimum block defined by Singewald (1992) results in a value of $\sim 76 \%$. In contrast, based on the average blocks resulting from the fracture distance distribution, a value of $\sim 66 \%$ is calculated. Although this value is already lower, it must be assumed that the actual raw block average is still significantly lower due to the heterogeneities in the fracture system (Fig. 21). The first model describes the front part of the deposit, which is bounded by the two fracture surfaces oriented at an acute angle to each other. Figure 22 describes the course of the interfaces on the excavation walls (Fig. 22a), the simplification or extrapolation of these (Fig. 22b) and the model generated with 3D-BlockExpert. Well-dimensioned raw blocks can be extracted from the rock complex, as more or less orthogonal fracture geometry is given. Nevertheless, it must be noted that the probability of further interfaces in the y-direction, which have not been recorded here, is very high. However, these cannot under any circumstances be oriented at an acute angle to the other interfaces here, as they would otherwise have had to become apparent on the excavation walls examined.

The frequency distribution of the block sizes resulting from model 1 is dominated by volumes between 0 $\mathrm{m}^{3}$ and $2.5 \mathrm{~m}^{3}$. Extremely large blocks cause an arithmetic mean of $6.8 \mathrm{~m}^{3}$ that is clearly too high. Two things are responsible for this: part of the model represents an area of rock that has long been mined, so that some blocks must be reduced by at least half their volume. In addition, it is very likely that there are other discontinuities in the $y$-direction that are not covered by this model. Deducting the extreme block volumes $\left(<0.5 \mathrm{~m}^{3} ;>10 \mathrm{~m}^{3}\right)$ results in an average value of $3.4 \mathrm{~m}^{3}$. Even if this value is already lower and 
thus more realistic, the result must be viewed critically due to the lack of information about further potential fissure areas.

The second model describes a part of the current mining area. Since there is only information on fracture surfaces in the y-direction, a theoretical fracture distribution corresponding to the natural interface system is added at depth (Fig. 23). It describes fracture surfaces that run roughly parallel to the mining front and are characterised by distances of the mean fracture distance distribution in the x-direction. However, it must be noted that this model can only reflect reality to a limited extent and the deposit is most likely characterised by a much more complex fracture geometry.

The frequency distribution of all block sizes occurring in the modelled rock complex is determined to about $80 \%$ by volumes between $0 \mathrm{~m}^{3}$ and $2.5 \mathrm{~m}^{3}$. In contrast to model 1 , large blocks with $>10 \mathrm{~m}^{3}$ occur only occasionally, so that the arithmetic mean with $1.9 \mathrm{~m}^{3}$ and minus the extreme values with $2.3 \mathrm{~m}^{3}$ provides a realistic estimate.

\section{Case study ROSA PORRIŇO}

The ROSA PORRIŇO represents the best known granite in the Spanish mining region of Galicia (Fig. 24). On a total area of $1 \mathrm{~km}^{2}$ here, monthly $1.300 \mathrm{~m}^{3}$ of rock was extracted by the company Canteiras de Granito (Blockgándara S.L.), which corresponds to a block yield of about $20 \%$. A further $30 \%$ is used for the production of building or masonry stones, and the remaining $50 \%$ is processed into crushed rock material.

The dimensions of the formatted raw blocks vary between $0.8-2.1 \mathrm{~m} \times 1.4-1.85 \mathrm{~m} \times 2.8-3.3 \mathrm{~m}$, thus corresponding to volumes ranging from $3.1 \mathrm{~m}^{3}$ to maximum values of $12.8 \mathrm{~m}^{3}$. In general, however, the block sizes always depend on the machine equipment as well as on the requirements of the end product. Mining is done by blasting and diamond wire saws. The rock complex can be described by three spatial directions): "el norte", "el levante", "el andar". Due to a weak arrangement of biotites or veins, there is a slight preferred orientation in the granite complex, which is described by the surface "andar". Perpendicular to this is the surface "norte". Both are usually drilled and blasted. The third face ("levante") is usually sawn.

\section{Lithological and rock characterisation of ROSA PORRIŇO}

The stone ROSA PORRIŇO represents a slightly reddish, medium to coarsely crystalline, massive granite, which has a directionless granular structure in hand specimen (Fig. 25). In general, the average grain sizes in ROSA PORRIŇO 1 (Fig. 25a) are slightly larger than in ROSA PORRIŇO 2 (Fig. 25b). The reddish colour, which is already referred to in the trade name of the rock, is due to the high percentage of potassium feldspar. In addition, the rock is rich in quartz and plagioclase and contains biotite as dark components, which, however, have smaller grain sizes than the other minerals (Fig. 25). In places, finegrained aplite veins while in a second deposit of the ROSA PORRIŇO granite, fine-grained mafic enclaves occur. 


\section{Geological characterisation of the deposit and its ashlar potential}

\section{ROSA PORRIŇO deposit complex 1}

The ROSA PORRIŇO granite deposit 1 preserves the largest occurrence of this granite and is developed via numerous mining levels. The area can be divided into two sub-areas: the core areas, which mainly contain intact rock with the highest ashlar potential, and the peripheral areas, which are mostly highly fractured and mainly used for crushed stone mining.

The core area represents the current mining floor at the time of the site studies (Fig. 24) with vertical, on average up to $10 \mathrm{~m}$ high deposit walls, which are mostly arranged at right angles to each other. On a profile section of about $80 \mathrm{~m}, 14$ parting planes, a fissure zone and an aplite vein of about $5 \mathrm{~cm}$ thickness were recorded on the excavation walls, so that this area is only slightly dissected overall. The fissures mostly run in a straight line, but only partially through the entire rock complex, while a curvature or branching of interfaces was observed very seldom.

The orientation of the interfaces shows three preferred directions, which strike about $080^{\circ}, 100^{\circ}$ and $170^{\circ}$ and are predominantly steep with an average dip of about $80^{\circ}$. In addition, diagonal fracturing was recorded subordinately. The excavation walls were laid out according to the strike of the fracture layers oriented perpendicular to each other, which is to be evaluated positively with regard to the extraction of material suitable for quarrying. As a result of the natural interface system, irregularly formed to acuteangled in-situ blocks can be expected. A similar fracture geometry, characterised by three fracture layers oriented at an acute angle to each other, but partly with high variability in orientation, was determined over the entire deposit area.

Two models were created using the 3D-BlockExpert software (Model A and Model B). The position of the modelling was chosen in such a way that the majority of the fracture surfaces occurring on the excavation walls are captured. Due to the software related limitations, all fractures are represented as continuous interfaces, even if their course is not apparent on the excavation walls. However, since the fractures in a granite only rarely terminate at (sub-) horizontal interfaces and it is therefore very likely that they open further in the course of block excavation, the limitations mentioned only play a minor role in this case. In addition to recording the fracture structures, the course of an approximately $5 \mathrm{~cm}$ thick aplite vein was also modelled as a parting surface. Apart from an undesirable change in decor, which lowers the quality of the raw blocks, it is also possible that the rock breaks at this zone of weakness. The rock complex is clearly disturbed by four closely spaced partitioning planes in the central area, while to the left and right of these are well-dimensioned in-situ blocks. In accordance with the prevailing fissure geometry, these are not cuboidal, but in part strongly heterogeneous in shape.

The result of the second modelling shows an approximately $1 \mathrm{~m}$ wide fissure zone in the middle to rear area, which causes a strong dissection of the rock complex. In the front area, on the other hand, there are 
large in-situ blocks, which again show irregular shapes as a result of the natural interface geometry. About $40 \%$ of the in-situ blocks resulting from model $A$ are only between $0 \mathrm{~m}^{3}$ and $2.5 \mathrm{~m}^{3}$ in size, while in model $B$ a similar percentage is given for block volumes larger than $35 \mathrm{~m}^{3}$. The proportion of these block sizes in model $A$ is about $25 \%\left(>35 \mathrm{~m}^{3}\right)$. The calculated mean values result in $36 \mathrm{~m}^{3}$ for model $A$ and 50 $\mathrm{m}^{3}$ for model $\mathrm{B}$, while the medians of $8 \mathrm{~m}^{3}$ and $24 \mathrm{~m}^{3}$ are both significantly below the arithmetic average.

Looking at the frequency distribution of the raw block sizes determined in the block storage (Fig. 26a), it becomes clear that a minimum volume of about $7 \mathrm{~m}^{3}$ is obvious (Fig. 26b). Consequently, this value can be regarded as an applicable requirement for the dimensions of the raw blocks to be extracted. This shows that about $48 \%$ of the in-situ blocks located in deposit area 1 and about $23 \%$ of the in-situ blocks located in deposit area 2 are highly unlikely to be processed into ashlars.

Since the developed models represent the rock complex realistically, it is possible to align the extraction with the course of the fracture surfaces in order to avoid any further processing. Finally, the usable material can be converted into raw blocks in the best possible way through targeted mining planning.

The singular large blocks deviate predominantly from the cuboid shape, so that their material can only be used in a limited way. For clarification, a comparison of two in-situ blocks: The first describes an irregular block located in the right front part of model A (brown, Fig. 27a), while the second represents a nearly rectangular block located in the left rear area (yellow, Fig. 27b). In each case, excavation slices with a thickness of $1.5 \mathrm{~m}$, corresponding to the average block height (Fig. 26b), were created. In this way, both in-situ blocks show a comparable volume. However, while only three average blocks $(3.2 \times 1.9 \times 1.5 \mathrm{~m}$, Fig. 26b) can be extracted from the first one, it is possible to extract four blocks in the second case, so that the production is higher and the amount of overburden is lower.

Different mining approaches for the current extraction can be simulated through targeted planning steps (Fig. 28, 29). However, it must be noted here, especially from an economic point of view, that shifts in the arrangement of the raw blocks not only influence their possible number, but also the necessary processing work. Thus, although a higher number of blocks is realised in option $B$, their formatting is associated with an increased amount of work (relative cutting length) (Fig. 28, 29).

By assessing successive excavation volumes, prognostic statements can now be made about the number of recoverable raw blocks from the two rock complexes investigated. In relation to the total rock volume considered, a possible block yield of about $30 \%$ can thus be predicted.

In order to explain the relevance of the interface structure with regard to the possibilities of quarry stone extraction in the investigated deposit in more detail, two characteristic marginal areas of the deposit are examined comparatively in the following. Area 1 shows a highly dissected rock complex characterised by two dominant fracture sets striking about $035^{\circ}$ and $105^{\circ}$ and dipping at an average of $70^{\circ}$. The formation of the interface system is homogeneous with respect to its orientation and thus provides good conditions for the extraction of ashlars. However, the low fracture spacing $(<0.5 \mathrm{~m})$, which dominates the distribution within the approximately $035^{\circ}$ striking fracture structures (>75\%), has a limiting effect. Under 
these conditions, the investigated area can only be used for the extraction of fracture material. For this type of use, however, the given dissection is positive, as many natural separation areas already exist and thus less effort has to be made when extracting the materialArea 2 is also highly dissected Even though two preferred directions, sweeping about $045^{\circ}$ and $150^{\circ}$, are recognisable, there is a high variability in terms of incidence angles and orientations in the whole. The separation distances, on the other hand, are predominantly between $0.5 \mathrm{~m}$ and $1.5 \mathrm{~m}$ and thus more widely spaced than in area 1 . However, the aforementioned scattering with regard to the orientation of the interface is problematic, if selective extraction were possible, ongoing analyses of the interface system were necessary and material losses as well as time and machine input for the complex formatting of the extracted blocks had to be included. Under these cost-intensive conditions and the low price level of granite, a quarry stone extraction is consequently not economical even in the area 2 . Profitable quarrying could only be realised if correspondingly high market prices could be achieved.

\section{Concluding remarks on the ROSA PORRIŇO case study}

On a total area of $1 \mathrm{~km}^{2}, 1,300 \mathrm{~m}^{3}$ of ROSA PORRIÑO granite are extracted every month, which corresponds to a block yield of about $20 \%$. The raw blocks stored on the mining floors have an average volume of about $9.5 \mathrm{~m}^{3}$ upwards. In order to achieve an appealing cost-performance ratio in the extraction of the ROSA PORRIŇO, extraction of ashlars can only take place in the weakly dissected core areas. Since the rock areas to be investigated have all the prerequisites for realistic modelling using 3DBlockExpert, it makes sense to obtain such information in advance using models.

In this way, prognostic statements can be made about the resulting block sizes and numbers in progressive mining. By implementing potential mining plans, it is finally possible to achieve an increase in production in mining. In addition to supporting current mining planning, it is also possible to react directly to the needs of the market through targeted mining.

\section{Case study GRIS ALBA}

The GRIS ALBA granite deposit (Fig. 30) is located north of the town of Cañiza (Pontevedra province) and east of Porriño. The rock has been actively quarried at this site for about 19 years. Of the material moved, a block yield of about $70 \%$ is recorded, while another $20 \%$ is processed into small blocks. The average block sizes have a volume of about $7 \mathrm{~m}^{3}$. The dimensions vary between 2.5-3 m (length) $\times 1.5-2 \mathrm{~m}$ (width) $\times 1.3-2 \mathrm{~m}$ (height). But in general, the block sizes always depend on the mechanical equipment and the desired end product. Dismantling is done by blasting and by using the wire saw.

\section{Lithological characterisation of the GRIS ALBA and its technical properties}

The natural stone GRIS ALBA represents a grey to white, medium-grained massive granite with a homogeneous grain size and a slight foliation by intercalated biotite (Fig. 31a). The predominantly white to light grey colouration is due to a high percentage of quartz and plagioclase. The mineral grains 
occasionally reach sizes of $0.5-1 \mathrm{~cm}$. In contrast to the ROSA PORRIÑO granite, potassium feldspar plays only a minor role. Compared to the other minerals, the biotites have smaller grain sizes.

The rock shows only occasional limonitic discolouration. A typical feature of the GRIS ALBA granite is the frequent occurrence of aplitic and pegmatitic dykes and mafic enclaves (Fig. 31b). The veins reach thicknesses of a few to a maximum of $25 \mathrm{~cm}$, while the mafic enclaves can often be up to half a metre in size. Both elements are controlling the quality and décor of the rock.

\section{Geological characterisation of the GRIS ALBA deposit}

The GRIS ALBA granite deposit is accessible via seven excavation levels and probably represents the roof of a pluton (Fig. 30). The excavation walls of the 2nd to 7th levels are arranged perpendicularly and partly at right angles to each other. Area 1, an approximately vertical deposit wall with a maximum height of about $20 \mathrm{~m}$ is given (Fig. 32a). The orientation of the fractures shows three preferred directions, striking about $045^{\circ}, 115^{\circ}$ and $175^{\circ}$ (Fig. $32 \mathrm{~b}$ ). The strike of the excavation wall is parallel to the orientation of the dominant fracture set $\left(\sim 115^{\circ}\right)$, which is positive with regard to a building stone. Both horizontal and vertical partings are formed, which are only conditionally rectilinear. Pointed-angled outcrops are the result of the variable orientation of the interfaces.

Over short distances, there are clear differences in the distance distribution, with gap distances between $0.5 \mathrm{~m}$ and $2.5 \mathrm{~m}$. On average, blocks with a volume of about $4 \mathrm{~m}^{3}$ are to be expected according to the calculated characteristic values. Considering the medians, which are in part significantly below the arithmetic mean, a general promotion of smaller block volumes must be expected here. Thus, the determined average volume of $4 \mathrm{~m}^{3}$ can hardly meet the currently applicable requirements for raw blocks (average $7 \mathrm{~m}^{3}$ ).

The calculation of the raw block potential based on the currently applicable requirements for raw blocks (average $7 \mathrm{~m}^{3}$ ) with edge dimensions of $2.9 \mathrm{~m} \times 1.6 \mathrm{~m} \times 1.5 \mathrm{~m}$ results in a value of $59 \%$ (Fig. 33). However, this must be considered far too high, as the heterogeneity in the interface system often causes acute-angled in-situ blocks, which lead to material losses.

The core area of the deposit is hardly dissected by fracture planes. The fissure traces are only partly continuous and mostly show an irregular strike. They are often bent and strongly branched, show opening widths in the $\mathrm{mm}$ to $\mathrm{cm}$ range and partly show clear rock outcrops. Such irregular courses of fissure surfaces pose a problem in mining planning, as their course is difficult to predict.

The excavation walls are preferentially oriented in a N-S direction, while individual walls, mostly representing fissure surfaces, are oriented perpendicular to them (Fig. 34). These fissures show a high degree of continuity in their course, in contrast to the previously considered parting surfaces. They are mostly fissure zones that show a distinct regularity and occur approximately every 10-15 $\mathrm{m}$. The main mining wall (N-S) was thus laid out perpendicular to the strike direction of the dominant fracture set, which is positive with regard to the extraction of material capable of working stone. 
The schematic representation (Fig. 34) clearly shows that the fissures are irregular in their course, especially in the left area. By extrapolation of the fracture surfaces, the resulting models can only represent reality to a limited extent. In addition to the fracture surfaces, two $15 \mathrm{~cm}$ thick aplite veins were modelled as interfaces in subarea $\mathrm{B}$, because these act as a zone of weakness on the one hand and are not desirable in the stone production on the other.

The modelled areas show a stronger dissection in subarea A, which is caused by a thick fissure zone within the right side (Fig. 35). As a result, the extraction of ashlars within this area is only possible to a limited extent. In the left half, on the other hand, there are large in-situ blocks with a maximum volume of $300 \mathrm{~m}^{3}$. Thus, on the basis of the model, selective mining that concentrates on extraction in the left-hand area of the rock body makes sense. However, even here there are limitations in the use of the material because the orientation of the interfaces causes an irregular shape of the in-situ blocks.

Area $B$ is strongly dissected, especially in the central part, by the occurrence of a fissure zone and two aplite veins (Fig. 35). To the side of these, on the other hand, lie extremely large in-situ blocks with high ashlar potential. From the orientation of the fissure clusters to each other and the orientation of the excavation wall, approximately rectangular cuboids can be derived from the model for area B. The fissure zone and the aplite dikes are highly dissected. Thus, on the one hand, the extraction of blocks of very large volumes is possible, but on the other hand, the extraction of the material is made considerably more difficult, as no natural separation surfaces can be used in the extraction. This in turn leads to an increased demand for machinery and labour.

Projections of the number of resulting average blocks $\left(7 \mathrm{~m}^{3}\right.$ with $\left.2.9 \times 1.6 \times 1.5 \mathrm{~m}\right)$ from the investigated rock complexes based on the consideration of successive excavation slices yield the following results: For subarea A, 85 blocks can be predicted, which means a block yield of about $39 \%$ in relation to the total rock volume. In subarea $B$, on the other hand, this is about $64 \%$ with a forecast of 289 blocks. The clear differences in the percentages are primarily due to the formation of the in-situ block shapes. The irregular in-situ blocks from sub-area A limit the use of the available material, so that an increased roughness is unavoidable.

As is clear from the foregoing, the models only reflect reality to a limited extent, which must be considered in Part A in particular. Nevertheless, on their basis it is possible to gain a first insight into the size of the resulting block sizes and thus into the potential of the respective mining beds. In areas of low fracture density or in those where the fractures are straight and can be followed on at least two surfaces, the implementation of a previously prepared mining plan can be carried out without further planning and production increased on the basis of this.

For an increase in production, the detection of highly disturbed areas within this deposit is of great importance, so that they can be identified in the mining process. It was observed that the extraction of raw blocks in the quarry area presented here is associated with an enormous amount of overburden, but the material is not used by $100 \%$. Bricks or building blocks are not produced and there is no processing into crushed grain mixtures. 
If these unfavourable conditions of the interface orientation are associated with narrowly formed fracture spacing, a stone placement in this area can be excluded from the outset. Under these conditions, ongoing analyses of the interface system are necessary to identify suitable areas. Such conditions are given in the core area of the deposit, which is only insignificantly dissected by interfaces. Here, however, the orientation of the interfaces plays an important role and determines to what extent the material can be used or not. Therefore, it is important to determine the course of the fracture surfaces as far as possible and to record the shapes of the in-situ blocks. In this way, production can be increased on the basis of modelling with 3D-BlockExpert via prognostic statements and the implementation of suitable mining planning.

\section{Discussion And Conclusion}

Investigations were carried out in quarry areas of different lithologies in Germany and Spain. While Spain is one of the leading producers in the global natural stone industry, Germany ranks relatively lower. In addition, a decline in the extraction of the raw material is to be expected.

In the "Theumaer slate" deposit, a metamorphic slate rock is mined. The deposit is formed selectively and is strongly limited both in depth by an increased quartz content and laterally by steeply oriented faults. The interface geometry is relatively homogeneous. However, the orientation of the interfaces poses a significant problem in the mining process. Three fracture sets are formed, two of which intersect at an angle of about $35^{\circ}$. This results in acute-angled blocks, the formatting of which consequently results in a high loss of material. However, this seems to be unavoidable and, accordingly, with a net production of only $3 \%$, has a significant impact on the economic viability of the deposit. A change in the mining method would not achieve any success. Selective mining, as is currently practised, is therefore already an ideal solution. In this way, all fissures can be used as natural discontinuities. Even if production cannot be increased due to the geological conditions, it is at least possible to keep costs as low as possible by reducing the use of machinery.

The Seeberg sandstone deposit is relatively small compared to the Burgpreppach deposit. While both deposits are limited by stratigraphic changes in depth, the mining area in Seebergen is additionally limited by a strongly developed fault zone in the southern area. The investigations of the two Rhaetian sandstones were able to illustrate particularly well the necessity of interface analyses, especially when two deposit complexes are characterised by the same lithology. Thus, two strongly diverging interface systems were recorded in the two quarry complexes.

The Seeberg sandstone is dominated by two fracture sets that are almost orthogonal to each other and thus provide ideal conditions for economic mining. The basic problem of this deposit, however, is the thick overburden layer of clay and silt, which has to be removed before exploration and thus represents a high cost factor. Furthermore, the main building stone layer, i.e. the sandstone with the highest building stone potential, is located at the base of the deposit, so that there are three more thick sandstone levels above it, which are, however, more fissured and thus yield less profit in mining. With the help of numerical 
modelling, the individual sandstone beds and the in-situ blocks lying within them can be realistically represented. The extraction can thus be adapted to the course of the interfaces, so that the extraction of the blocks is facilitated and the costs for mechanical use are as low as possible.

The Burgpreppach deposit is characterised by a significant heterogeneity in the interface formation. This is expressed both in the interface orientation, which is characterised by four dominant strike directions, and in the interface courses. These are predominantly irregular. They jump, bend, cross-link and terminate at other interfaces. In this way, in contrast to the Seeberg deposit, it is difficult to predict the fracture course for progressive mining.

Optimisation in the dismantling process by means of numerical modelling is not possible. This is essentially due to the software-related limitations of the current state of development. The course of the fissure surfaces must be extrapolated to such an extent that, although it is possible to differentiate between areas worthy of mining and areas not worthy of mining, the models as a whole can only reflect reality to a limited extent.

The structure of the limestone deposit (Treuchtlingen) differs fundamentally from the deposit complexes of the previously considered rocks due to its quarrying approach. The reason for this structure is the mining method adapted to the limestones. Thus, the fissure surfaces are pre-drawn on the surfaces and used as natural parting surfaces, so that the rocks are mined layer by layer in this way. The excavation guidance thus seems to be optimally adapted to the geological conditions, which are characterised by three dominant fracture sets.

The granites investigated in Galicia represent deposits that, in contrast to the previously considered deposits, are neither limited in depth nor laterally. Despite the different distribution of the three deposits, comparative basic patterns in the respective structure could be recorded. All deposits are characterised by predominantly intact and only slightly disturbed core areas. In these areas large in-situ blocks with a lot of ashlar potential can be found. The marginal areas, on the other hand, are mostly characterised by a high fracture density, controlling the economic background of the production. Both deposit complexes of the ROSA PORRIŇO granite offer optimal conditions for a realistic numerical modelling with the software 3D-BlockExpert.

In contrast to the homogeneous formation of the interfaces in the ROSA PORRIÑO deposit complex, the fractures in the GRIS ALBA are often not straight. They are displaced or bent, interconnected and terminated. In addition, large opening widths are recognisable and now and then rock outcrops occur on the excavation walls. These properties are unfavourable for forecasts regarding the interface course, so that the numerical modelling can be represented less realistically in this deposit than in the previously considered granite of the ROSA PORRIŇO due to the software-related limitations. Nevertheless, it makes sense to model here as well in order to capture highly disturbed areas and to omit them in the mining process. 
Finally, the investigations have shown that the total amount of discontinuities has a decisive influence on the economic viability of a deposit and that it can vary significantly due to the lithology and tectonic events. This manifests itself in the orientation and spacing distribution of the interfaces as well as in their formation, continuity and termination behaviour. Under these conditions, there is an explicit need to record and assess the fracture geometry of a deposit in detail, both in the exploration phase and during active mining. Computational approaches have shown that their results are not always reliable, especially when the fractures are highly heterogeneous. Most calculations are based on an orthogonal reference system, which, however, as the explorations have shown, is rarely formed in this way. In the best case, the approaches can provide ideas and approximate values regarding the expected block sizes and yields of the deposit, so that a rough estimate of the occurrence can be made. In most cases, however, the statistical approaches are insufficient, so that the focus of the present work was placed on numerical modelling. This is because these are often superior to the computational approaches and, in contrast to various calculations, can graphically represent separation areas of all spatial layers. And thus, the geometry of the in-situ blocks and, with the help of targeted planning bases, contribute to an optimisation in mining and consequently to an increase in production. Geoscientific exploration of a deposit thus opens up opportunities to positively influence the extraction of natural stone through specialist knowledge and targeted planning, and thus makes a decisive contribution to the economic success of a quarrying project.

\section{Final Remarks}

In the construction industry, natural stones account for only a very small proportion of the raw materials and materials like concrete, mortar etc. While the annual production of numerous deposits for raw materials like clay, lime and dolomite and aggregates (sand, gravel, solid rock) as bulk rock deposits is often well over $100,000 \mathrm{~m}^{3}$, it is usually around $10,000 \mathrm{~m}^{3}$ or even significantly less in those for the extraction of building stone. The decisive criteria for the raw materials of the mass rock deposits are their mineralogical composition and material properties in relation to the intended use, in addition to economic aspects such as transport distances for processing. The determining criterion for the extraction of a rock as a building stone lies in its optical appearance and the rock fabric, i.e. the decoration. This is determined by the mineral composition and the microstructure. The actual usability of a rock with selected decoration is controlled by geological parameters, the rock properties and the fracture systems. Hoffmann (2007) presented the connection between exploration strategies, the rock technical properties and the output on raw blocks after quarrying and processing. By Strohmeyer (2003) and Mosch (2008) a detailed analysis of the rock-physical parameters for the individual rock types as well as their relations to each other took place. With the method developed by Mosch et al. (2011) for the analysis of nonorthogonal fracture systems, a differentiated recording of these structures can be combined with a product-oriented mining. Natural stones are extracted from rock types and deposit types due to the modern decoration requirements of the national markets and the international market. The type of bedding and fractrues are just as varied. Under the aspect of sustainability, the deposits have been utilized more extensively for some years, such as the processing to a crushed portion and unformatted stones, but the output of formatted raw blocks is in the foreground as the main product. The cubic shape 
and dimensions are oriented to further processing in semi- and fully-automated industrial systems from raw block processing to the flat or three-dimensional end product with different surface finishes. The raw block output worldwide is still predominantly well below $50 \%$ of the total volume of a quarry. At the same time, costs for energy expenditures, wages, machine acquisition and maintenance, and ultimately increasing environmental regulations are rising.

Selling prices for ingots remained unchanged or were only selectively increased for individual designs. One reason for this is the partly wide range of competing building stones available worldwide. This requires an effective use of resources with high block yields. The basis for this is knowledge of the interface structure. Modern techniques are available for recording the interfaces. For spot surveys, these are core drillings and video recordings of the borehole. Geoelectrics, georadar and ultrasound are used for further exploration approaches. In addition to the provision of the technology, all methods require a high cost and personnel expenditure on the one hand. At the same time, the methods result in a rather high uncertainty factor with simultaneous uncertainty of the detection of fractures at a distance from the measuring surface. An application in the ongoing process of mining is therefore ruled out. Therefore, the detection of the interface structure with the traditional, simple and cost-effective methods by means of compass and distance measurement still seems to make sense. However, the evaluation of the individual fractures with respect to their fracture width, fracture orientation and fracture coating is a decisive part of this. In combination with simple orthogonal based evaluation systems as well as in the extension to the non-orthogonal system according to Mosch et al. (2011) results can be achieved with relative certainty for a mining prediction. Thus, the block potential can be estimated in a specific mining progress. For the supply of the market, possible peak demands by large projects in mining directions can thus be controlled. At the same time, in addition to optimizing the block yield by selective cutting and milling, it is possible to produce ingots with specific dimensions in advance. An example of this is the use of blocks that reach a considerable length but only a small height in multiples of 30 or $40 \mathrm{~cm}$. Such blocks are preferred, for example, by producers for the manufacture of front panels for kitchen countertops in order to avoid cutting losses. The same applies to the supply of raw blocks for large projects of facades with known dimensions of panels. Particularly in such construction projects with often considerable cost pressure on the building products, the provision of optimally formatted raw blocks represents a decisive competitive advantage.

The analyses of the deposits showed that the use of traditional geoscientific methods in combination with modern exploration approaches is not only suitable for large deposits of magmatic rocks with an orthogonal fracture system. Also deposits of sedimentary rocks, both biogenic and clastic, with a distinct layered structure can use the presented methods for mining control and its progression. Especially these types of deposits of ornamental stones are often relatively small and have rates of output below $10,000 \mathrm{~m}^{3}$ per year. The determination of the fracture systems is a bit more complex, because the orientation to the sedimentary layers has to be done. At the same time, however, there are often favorable measuring conditions, since the horizontal mining areas facilitate a survey of the fractures and increase the certainty of the statement on the block occurrence. Thus, even these deposits with a high demand on the price structure for their raw blocks can make a mining plan cost-effective in the production process. 
Limitations of the methodology occur in deposits with a high occurrence of diagonally running and simultaneously branching fractures to the orthogonal basic joint system. Likewise, an application for the sector of slate deposits is not reasonable. The optimization of cutted blocks into merchantable rough blocks must also be reconsidered for rocks with a pronounced directional orientation in the decor. As an example, the orthogneiss ANDEER from Switzerland may be mentioned. The gneiss has a parting plane structure that is close to that of rocks in large magmatic deposits. However, this does not run in orientation to the foliation, after which an orientation of the gating takes place.

An aspect for a cost-efficient analysis of the stock situation and the possible block yield represents in numerous projects of the building industry also the demand of building owners to provide a delivery proof from the deposit with the offer of a building product of natural stone. Large processing companies and trading companies require the same level of planning security to secure their raw block base or finished products. The presented method allows here a cost-efficient and only with low time expenditure on-site analysis with geoscientists on site as well as own personnel.

Overall, the procedure can be used for mining optimization or the development of a targeted mining progress in short-term and medium-term planning.

\section{References}

1. Bogdanowitsch, M, Sousa, L, Siegesmund, S. (2021).Building stones quarries - improve the resources evaluation by block modelling and unmanned aerial photogrammetric survey.EnvironEarth Sci. (in review).

2. Dallmeyer, R. D. \& Martinez Garcia, E. (Hrsg.) (1990): Pre-MesozoicGeologyof Iberia. - 416 S.; Berlin, Heidelberg (Springer Verlag).

3. Davis, G. \& Reynolds, S. J. (1996): Structural Geology of Rocks and Regions. - 776 S.; New York (Wiley \& Sons).

4. DIN EN 12670 (1997): Terminologie von Naturstein. Normenausschuss Materialprüfung (NMP) im DIN Deutsches Institut für Normung e.V. Normenausschuss Bauwesen (NaBau) im DIN: 1-85.

5. Eisbacher, G. H. (1996): Einführung in die Tektonik. - 374 S.; Stuttgart (Enke Verlag).

6. Founti, M. (Hrsg.) (2004): Stone for construction and architecture - from extraction to the final product.Osneteditions, Vol. 14; Athen.

7. Fricke, S. \& Schön, J. (1999): Praktische Bohrlochgeophysik. - 254 S.; Stuttgart (Enke Verlag).

8. Gehlen K. v. (1956): Sekundär-hydrothermale Mineralisation im Burgsandstein des Wendelsteiner Höhenzuges bei Nürnberg. - Geol. BI. NO-Bayern 6: 12-21.

9. Geyer, G. \& Schmidt-Kaler, H. (2006): Wanderungen in die Erdgeschichte (20) - Die Haßberge und ihr Vorland. - 128 S.; München (Pfeil).

10. Gibbons, W. \& Moreno, T. (2002): The Geology of Spain. - 649 S.; London (Geological Society). 
11. Hafner, W. (1989): Juramarmorindustrie - eine traditionsreiche Werksteinindustrie. - Steinmetz und Bildhauer 1989, 5: 37-43.

12. Häfner, F. (2008): Die wirtschaftliche Lage der Naturwerksteinindustrie in Deutschland. - Mainzer Geowissenschaftliche Mitteilungen, 36: 189-212; Main.

13. Henningsen, D. \&Katzung, G. (2006): Einführung in die Geologie Deutschlands. - 234 S.; München (Spektrum Akademischer Verlag, Elsevier $\mathrm{GmbH}$ ).

14. Hoffmann, A., \&Siegesmund, S. (2007). Investigation of dimension stones in Thailand: an approach to a methodology for the assessment of stone deposits. Zeitschrift der Deutschen Gesellschaft für Geowissenschaften, 375-416.

15. Hoffmann, A. (2007): Naturwerksteine Thailands: Lagerstättenerkundung und Bewertung. - Diss.

16. Univ. Göttingen, $242 \mathrm{~S}$.

17. ICEX (InstitutoEspañol de ComercioExterior) (2005): Spanien: Der Natursteinsektor. Branchenreport. - 22 S. - [Unveröff.].

18. ISRM (1978): Suggested methods for the quantitative description in rock masses. - International Society for Rock Mechanics Commission on Standards of Laboratory and Field Tests. - International Journal of Rock Mechanics and Mining Sciences \& Geodynamics Abstracts, 15 (6): 319-368.

19. Koch, R., Baier, A., Lorenz, H. \& Fritsch, A. (2003): Sandsteine des Keupers als Naturwerksteine im und um Nürnberg. - Jber. Mitt. oberrhein. geol. Ver., N.F. 85: 45-64.

20. Lotze, F. (1945): Zur Gliederung der Varisziden in der Iberischen Meseta. GeotektonischeForschungen 6: 78-92.

21. Lu, P. \& Latham J.P. (1999): Developments in the assessment of in-situ block size distributions of rockmasses. - Rock Mechanics and Rock Engineering, 32 (1): 29-49.

22. Meier, D. \& Kronberg, P. (1989): Klüftung in Sedimentgestein: Erscheinungsformen, Datenaufnahme, Datenbearbeitung, Interpretation. - 116 S.; Stuttgart (Enke Verlag).

23. Montani, C. (2003): Stone 2002 - World marketing handbook. - Faenza, Gruppo Editoriale Faenza Editice.

24. Montani, C. (2008): Stone 2008 - World marketing handbook. - Faenza, Gruppo Editoriale Faenza Editice.

25. Demarco, M. M., Oyhantçabal, P., Stein, K. J., \& Siegesmund, S. (2011). Black dimensional stones: geology, technical properties and deposit characterization of the dolerites from Uruguay. Environmental Earth Sciences, 63(7), 1879-1909.

26. Demarco, M. M., Oyhantçabal, P., Stein, K. J., \&Siegesmund, S. (2013). Granitic dimensional stones in Uruguay: evaluation and assessment of potential resources. Environmental earth sciences, 69(4), 1397-1438.

27. Demarco, M. M., Oyhantçabal, P., Stein, K. J., \&Siegesmund, S. (2013). Dolomitic slates from Uruguay: petrophysical and petromechanical characterization and deposit evaluation. Environmental earthsciences, 69(4), 1361-1395. 
28. Mosch, S. (2008): Optimierung der Exploration, Gewinnung und Materialcharakterisierung von Naturwerksteinen. - Diss. Univ. Göttingen, 275 S.

29. Mosch, S., López de Luchi, M. G., \& Siegesmund, S. (2007). Dimensional stones in Argentina. Zeitschrift der Deutschen Gesellschaft für Geowissenschaften, 447-469.

30. Mosch, S., Nikolayev, D., Ewiak, O. \& Siegesmund, S. (2009): Optimierung der Werksteingewinnung. Steinbruch und Sandgrube, 5/09: 8-11.

31. Mosch, S., Nikolayew, D., Ewiak, O., \& Siegesmund, S. (2011). Optimized extraction of dimension stone blocks. Environmental Earth Sciences, 63(7), 1911-1924.

32. Nelles, P. L. (1996): Die Granit-Natursteingewinnung weltweit. - Erzmetall, 49(5): 286-299.

33. Nikolayev, D., Siegesmund, S., Mosch, S. \& Hoffmann, A. (2007): Modelbasedpredictionofunfracturedrockmasses. - Zeitschrift der Deutschen Gesellschaft für Geowissenschaften, 158(3): 483-490.

34. Palmström, A. (1982): The volumetric joint count - a useful and simple measure of the degree of rock jointing. - Kurzfassung, Proc. 4th Int. Cong. Int. Assoc. Eng. Geol., 5: 221-228; Balkema, Niederlande.

35. Palmsgröm, A. (1986): The volumetric joint count as a measure of rock mass jointing. - Conference on Fragmentation, Form and Flow in Fractured Media, Jerusalem, Israel, 06.01.-09.01.1986: 19 pp.

36. Palmsgtröm A. (1995): RMi- a rock mass characterization system for rock engineering purposes. Diss. Univ. of Oslo, Norwegen. - [Unveröff.].

37. Peschl, A. (1983): Natursteine. - VEB Deutscher Verlag für Grundstoffindustrie, Leipzig.

38. Peschel, A. \& Franz, E. (1968): Der Fruchtschiefer von Theuma (Vogtl.). Beziehung zwischen Genese und Verwertbarkeit. - Zeitschrift für angewandte Geologie, Bd. 14 (1968), 9: 483-488.

39. Priest S. D. (1993): Discontinuity analysis for rock engineering. - 473 S.; London (Chapman and Hall).

40. Primavori, P. (1999): Planet stone. - 326 S.; Verona (Giorgio Zusi Editore S. A.S.).

41. Ritter-Höll, A. (2005). Werksteinqualitäten im Jura Kalkstein (Malm Delta 1 bis 4?) in Abhängigkeit von Primärfazies und Diagenese am beispiel ausgewählter Schicjten des Steinbruchs der Fa. Balz (Pappenheim-Südliche Frankenalb). PhDthesis 155pp, unpublished

42. Schroeder, J. H. \& Asch, K. (2006): Natursteine in Deutschland: Vorkommen und Geologie. - Karte, Ulm (Ebner).

43. Schwate, W. (1994): Seeberger Sandstein aus dem Thüringer Becken - Abbau und Verarbeitung. Stein 1994, 4: 27-30.

44. Selonen O. \&Suominen, V. (Hrsg.) (2003): Nordic stone. - 64 S.; Paris (UNESCO:IAEG).

45. Smith, M. R. (Hrsg.) (1999): Stone: Building stone, rock fill and armour stone in construction. Geological Society of London, Engineering Geology Special Publications, Vol. 16.

46. Schneider, C., 2009. Optimierung im Abbau von Naturwerkstein auf der Basis von Kluftanalysen. Diplomarbeit. Goettingen. 
47. Siegesmund, S., Dürrast, H., 2014. Physical and Mechanical Properties of Rocks. In: Siegesmund, S., Snethlage, R. Stone in Architecture: Properties, Durability, 97-224. Berlin, Heidelberg, s.l.: Springer Berlin Heidelberg.

48. Siegesmund, S., Török, A., 2014. Building Stones. In: Siegesmund, S., Snethlage, R. Stone in Architecture: Properties, Durability, 11-96. Berlin, Heidelberg, s.l.: Springer Berlin Heidelberg.

49. Singewald, C., 1992. Naturstein-Exploration und Gewinnung. 260 S. Köln, Bad Bentheim (Rudolf Müller).

50. Sousa, L. M. O., 2007. Granite fracture index to check suitability of granite outcrops for quarrying. Engineering Geology 92 (3-4): 146-159. 10.1016/j.enggeo.2007.04.001.

51. Sousa, L. M. O., 2010. Evaluation of joints in granitic outcrops for dimension stone exploitation. Quarterly Journal of Engineering Geology and Hydrogeology 43 (1): 85-94. 10.1144/1470-9236/08076.

52. Sousa, L. M. O., Barabasch, J., Stein, K.-J., Siegesmund, S., 2017. Characterization and quality assessment of granitic building stone deposits: A case study of two different Portuguese granites. Engineering Geology 221: 29-40. 10.1016/j.enggeo.2017.01.030.

53. Sousa, L. M. O., Oliveira, A. S., Alves, I. M. C., 2015b. Influence of fracture system on the exploitation of building stones: the case of the Mondim de Basto granite (north Portugal). Environmental Earth Sciences 75 (1): 39. 10.1007/s12665-015-4824-6.

54. Stein, K.-J. (2009): GutachtenzumBurgpreppacherSandstein. - [Unveröff.].

55. VanderPluijM, B. A. \&Marshak, S. (2004): Earth Structure. - 656 S.; New York (W.W. Norton \& Company).

56. VereinteNationen (1976): The development potenzial of dimension stone. - Department of Economic and Social Affairs, ST/ESA/34: 95 S.; New York.

57. Yarahmadi, R., Bagherpour, R., Taherian, S.-G., Sousa, L. M.O., 2018. Discontinuity modelling and rock block geometry identification to optimize production in dimension stone quarries. Engineering Geology 232: 22-33. 10.1016/j.enggeo.2017.11.006.

\section{Figures}



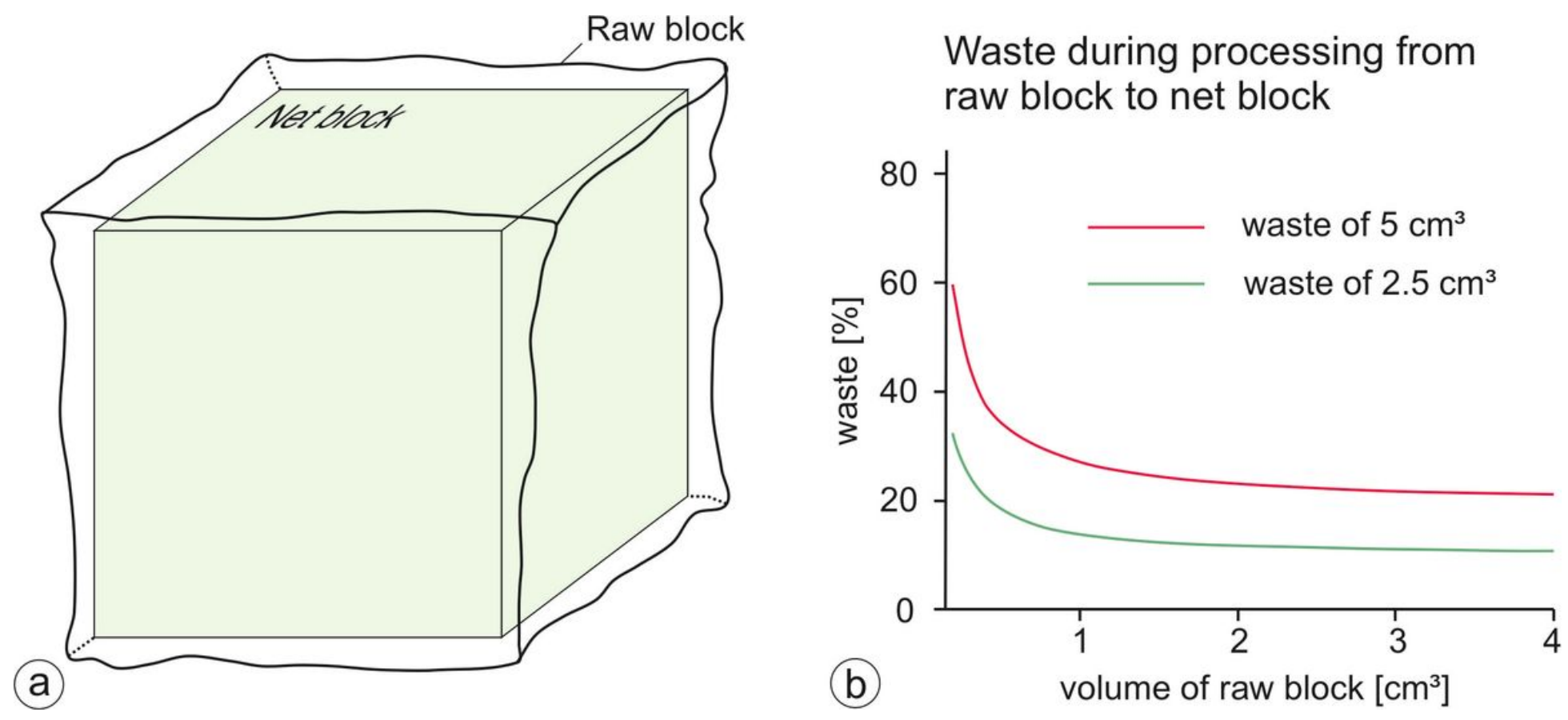

Figure 1

Net block with "enveloping" raw block. b) Waste (in \%) produced during processing from raw to net block. The proportion of waste develops potentially, thus increases extremely with smaller volumes (modified after Singewald. 1992).

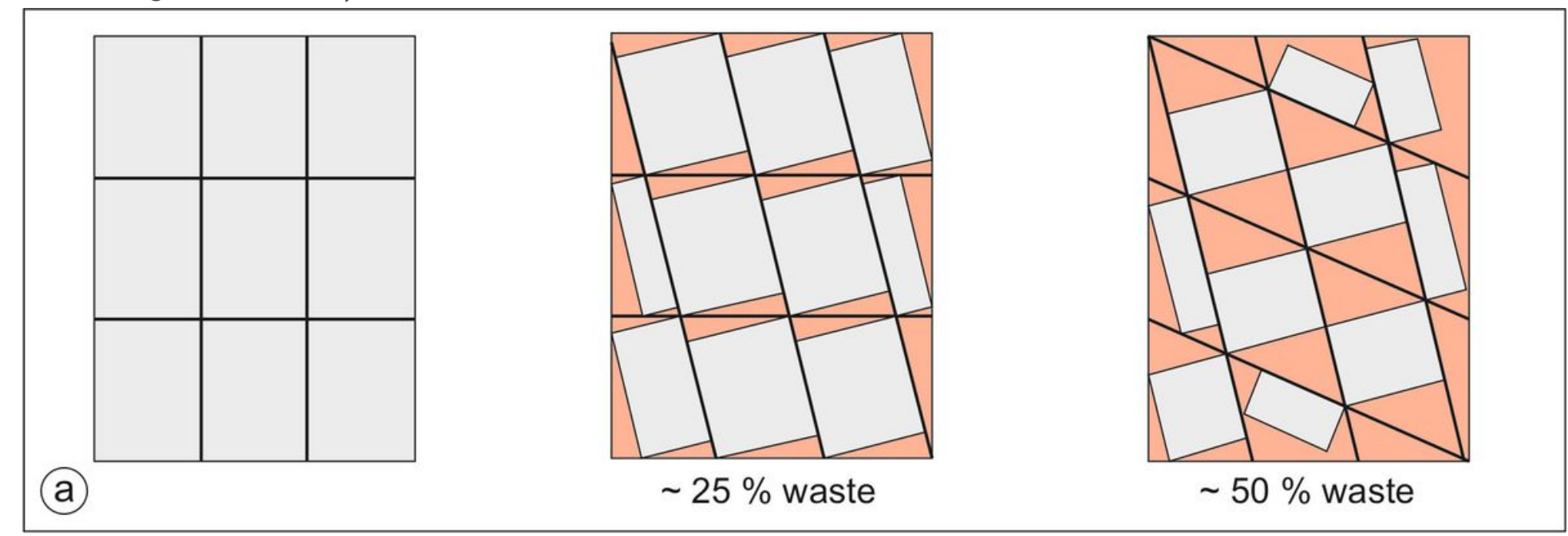

(b)
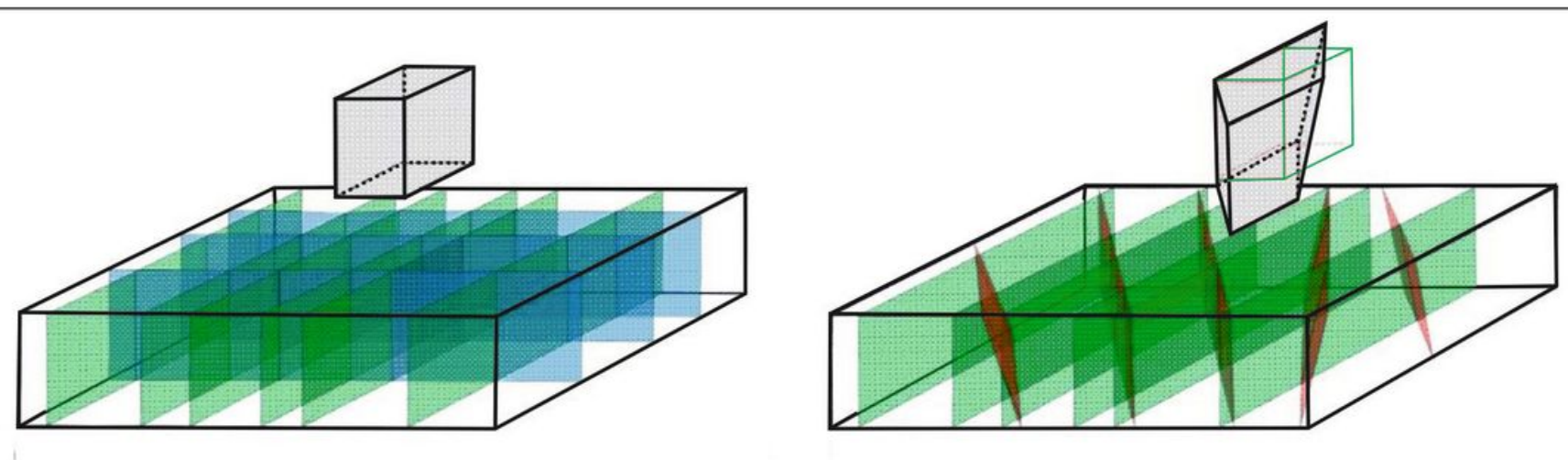
Figure 2

Schematic representation of the resulting in-situ blocks from different fracture geometries. a) Increase in the amount of overburden with a simultaneous decrease in the average block size due to deviation from the orthogonality of the fracture system while the distance distribution remains the same. b) Increase of acute-angel of in-situ blocks due to deviation from orthogonality in strike and dip (after Mosch, 2008).

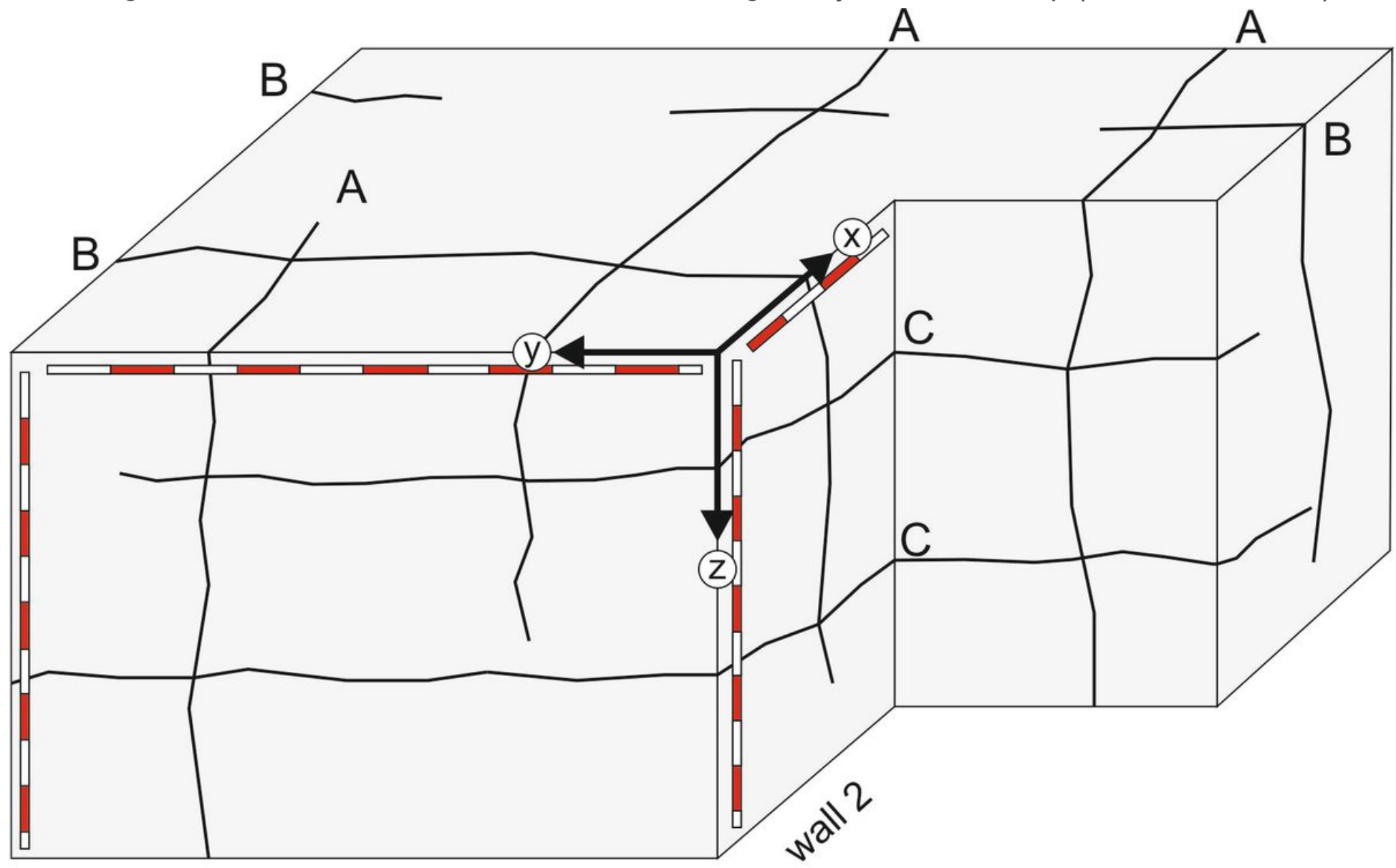

wall 1

Figure 3

Schematic sketch of investigation compartments to determine the fracture distribution in a mining area (fracture layers A, B, C; modified after Smith, 1999).
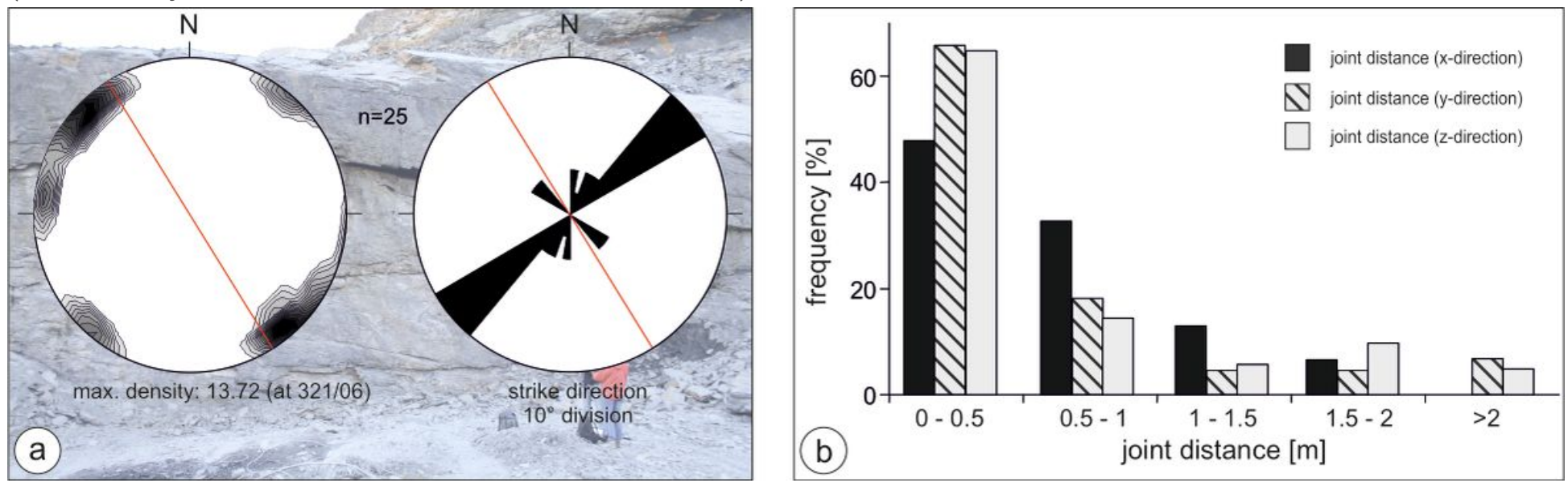
Figure 4

Example of the presentation of fracture data obtained in the shist quarry O'Barco (Galicia, Spain). a) Joint orientation presented by a stereonet projection: distribution density diagram (left) and joint frequency diagram (right); the red line indicates the strike of the mining bench. b) Presentation of fracture distances using a histogram.

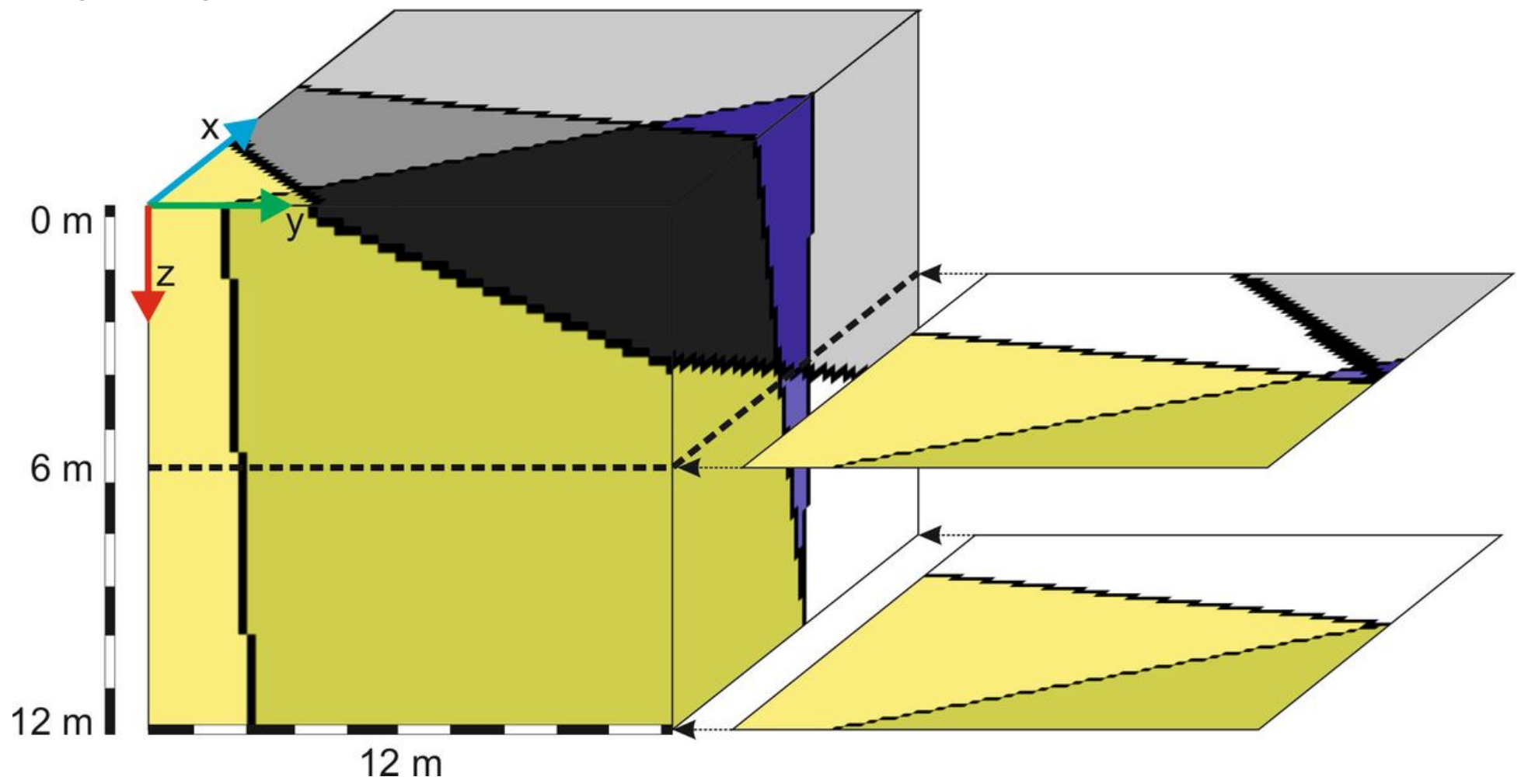

Figure 5

Interface course in a modelled rock complex. With the help of the software it is possible to view freely selectable cut surfaces perpendicular to the outer walls. Here, the course of the interfaces is shown on the $x y$-surface, whereby areas of the same colour belong to an in-situ block.

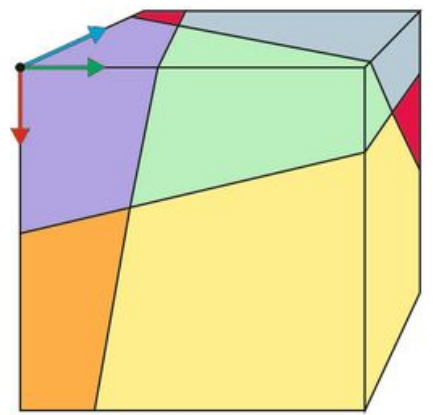

(a)

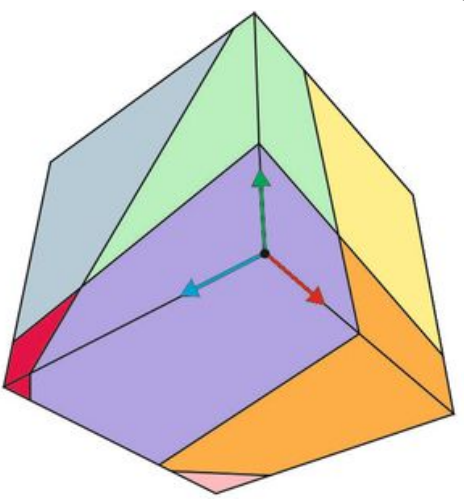

(b)

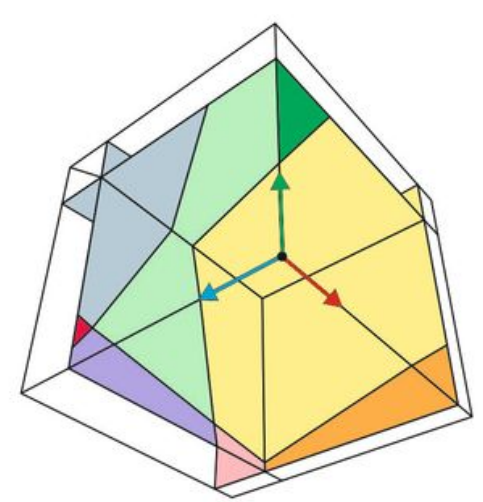

(c)

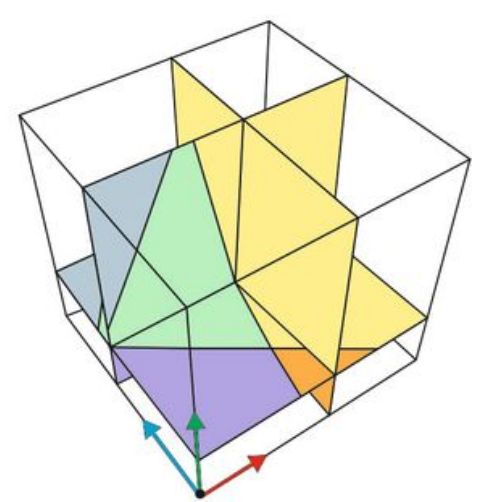

(d)

Figure 6 
Display options of a data set calculated by the 3D-BlockExpert software. a) The Intel $\circledast$ Array Viewer programme creates a three-dimensional model of a segmented body. b - d) Free rotation of the body as well as arbitrary displacement of the cut surfaces parallel to the outer walls provides insight into the course of the cut surfaces and the nature of the in-situ blocks.

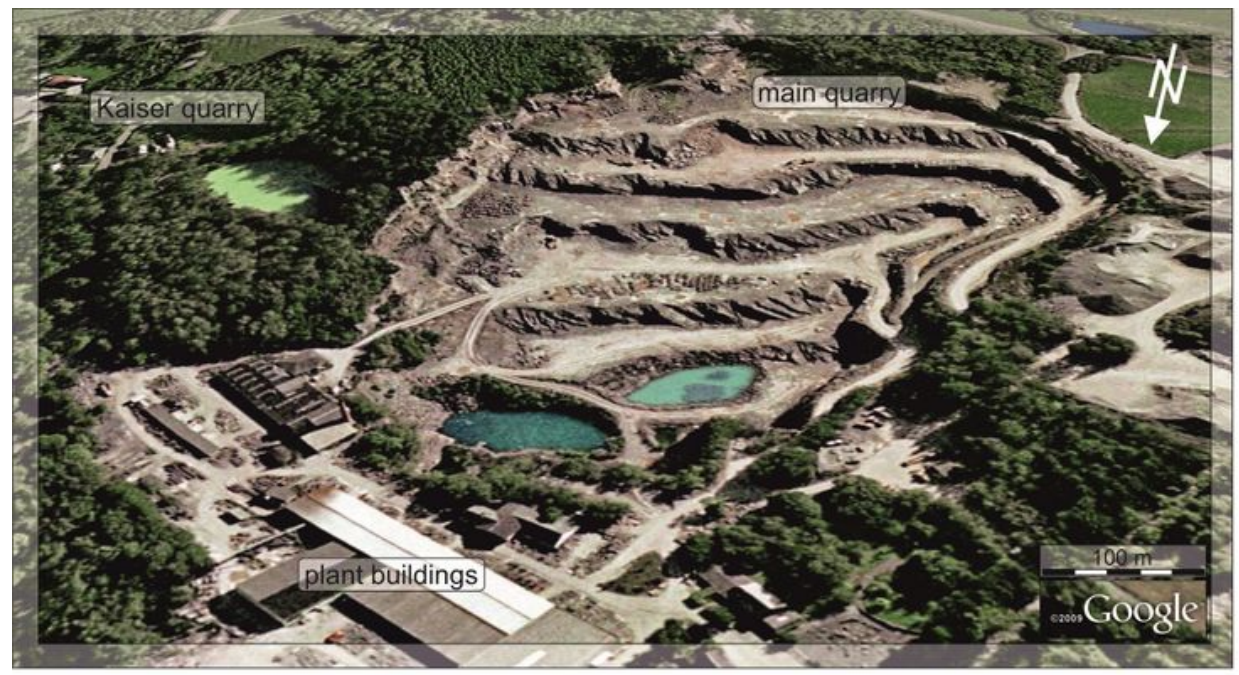

(a)

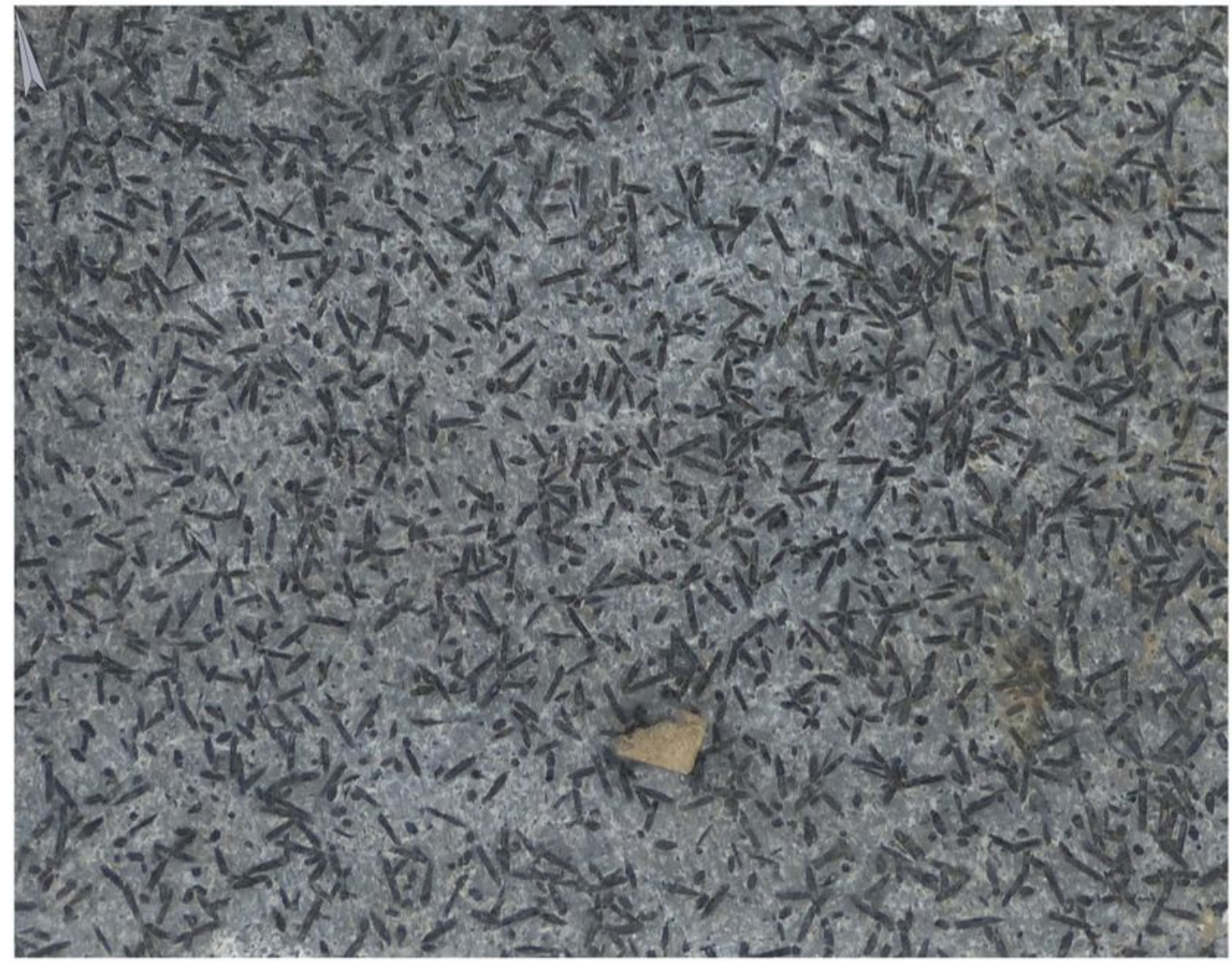

(b)

Figure 7 
a Extent of the Theuma opencast mine (image based on Google Earth Pro, 12.10.2009). The main quarry with the terraced mining floors can be seen in the background. In the $E$ is the disused Kaiser quarry. In the foreground, the factory buildings for the final production of the raw blocks can be seen. $b$ The Theuma Slate is an unique ornamental stone regarding his colour and decor Note: The designations employed and the presentation of the material on this map do not imply the expression of any opinion whatsoever on the part of Research Square concerning the legal status of any country, territory, city or area or of its authorities, or concerning the delimitation of its frontiers or boundaries. This map has been provided by the authors.
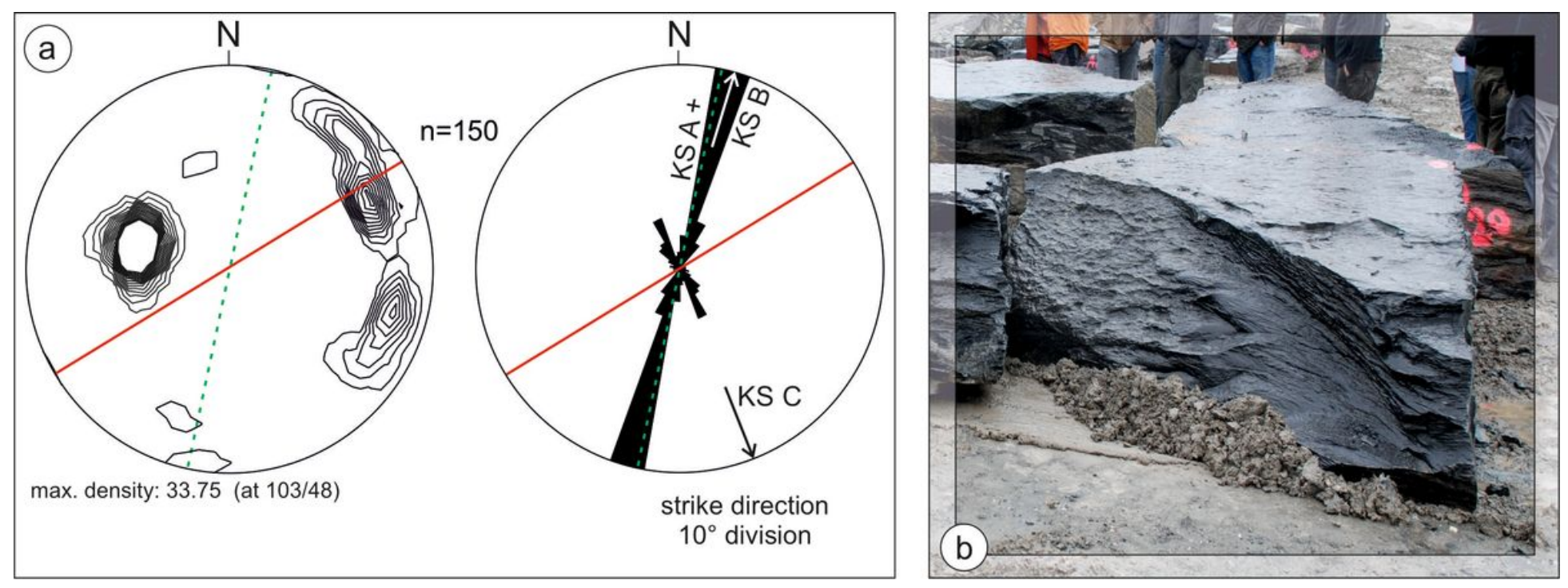

Figure 8

a) Representation of the spatial position of the interfaces in Schmidt's network by means of distribution density diagram (left) and fracture rose diagram (right) in the fruit slate quarry of Theuma; red = strike of the excavation wall, green = strike of the older faults. Three fracture groups are visible (KS A, KS B, KS C), some of which form an acute angle to each other, resulting in irregularly formed blocks here (b). 


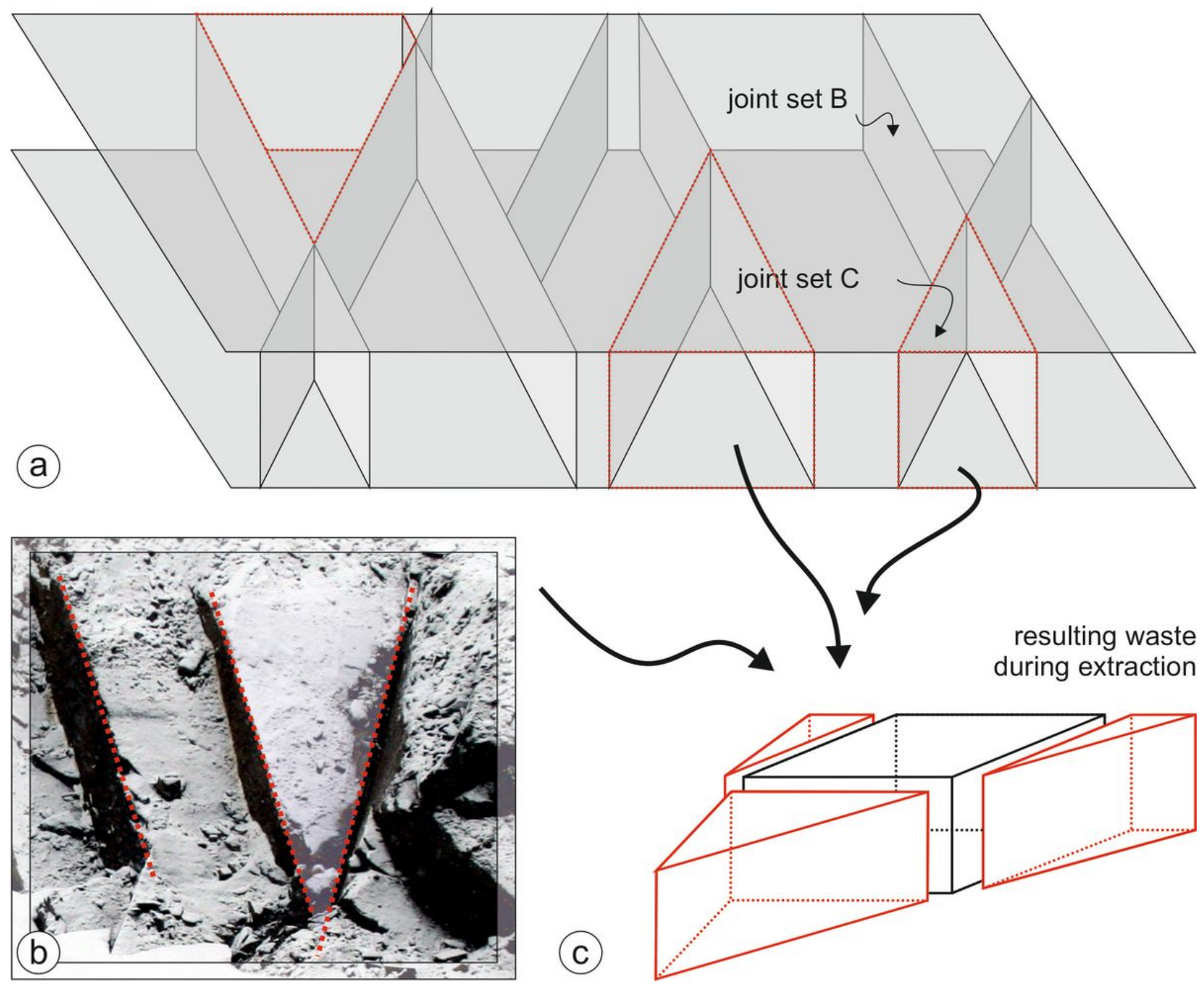

Figure 9

Characterisation the fracture spacing in the Theume slate quarry a) Fissure distance distribution in the excavation of the fruit shale with directional reference. b) Overview of the fissure distances of the individual fissure layers with a representation of the respective mean values, medians and standard deviations. The mean values result in an average block (grey) shown in (c). For comparison, the maximum (blue) and minimum (red) block dimensions determined by the natural stone plant Theuma are also shown. 


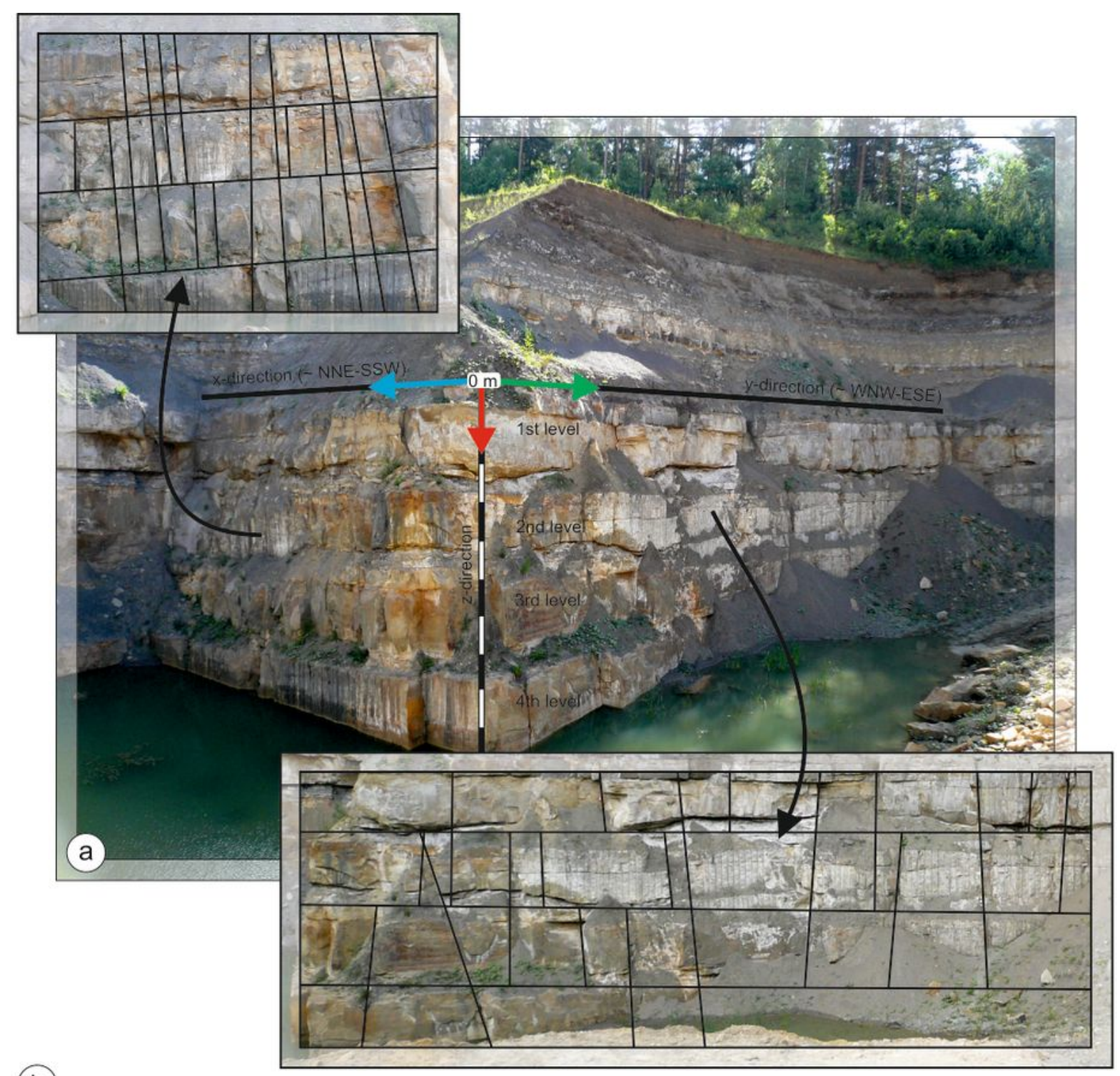

(b)

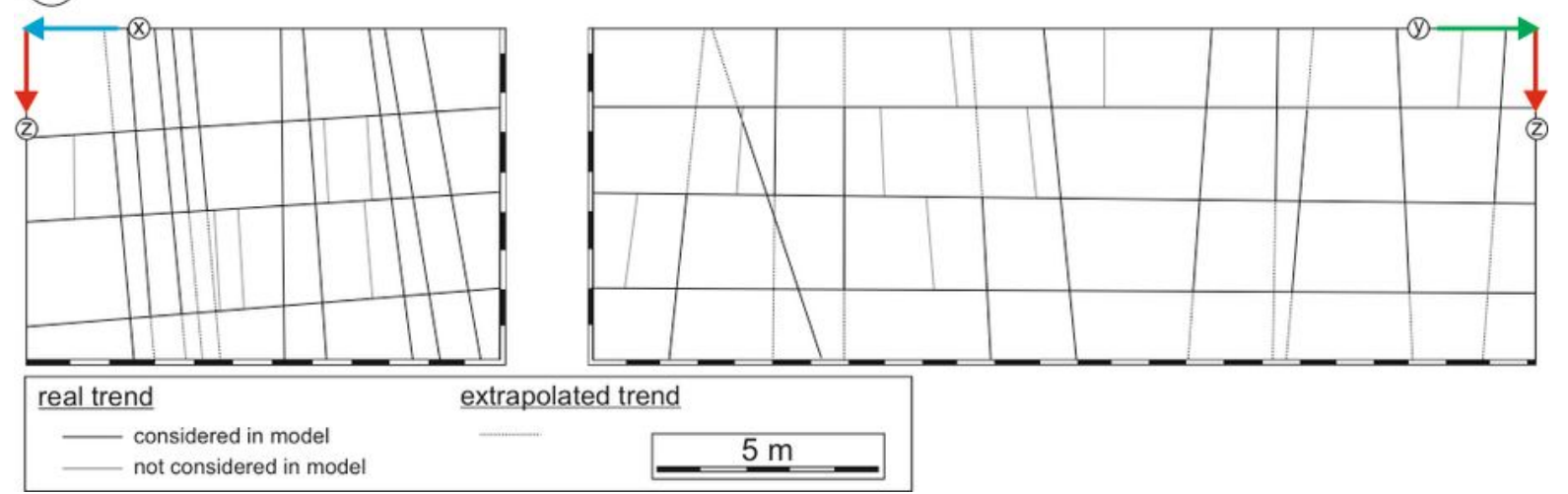

Figure 10

Representation of the deposit area modelled with 3D-BlockExpert in the Seeberg sandstone quarry (Thuringia). a) Orientation of the fractures on the investigated mining walls. b) Simplified or extrapolated representation of the fracture surfaces. Only those joints cross-cutting at least two sandstone beds were included in the modelling. 

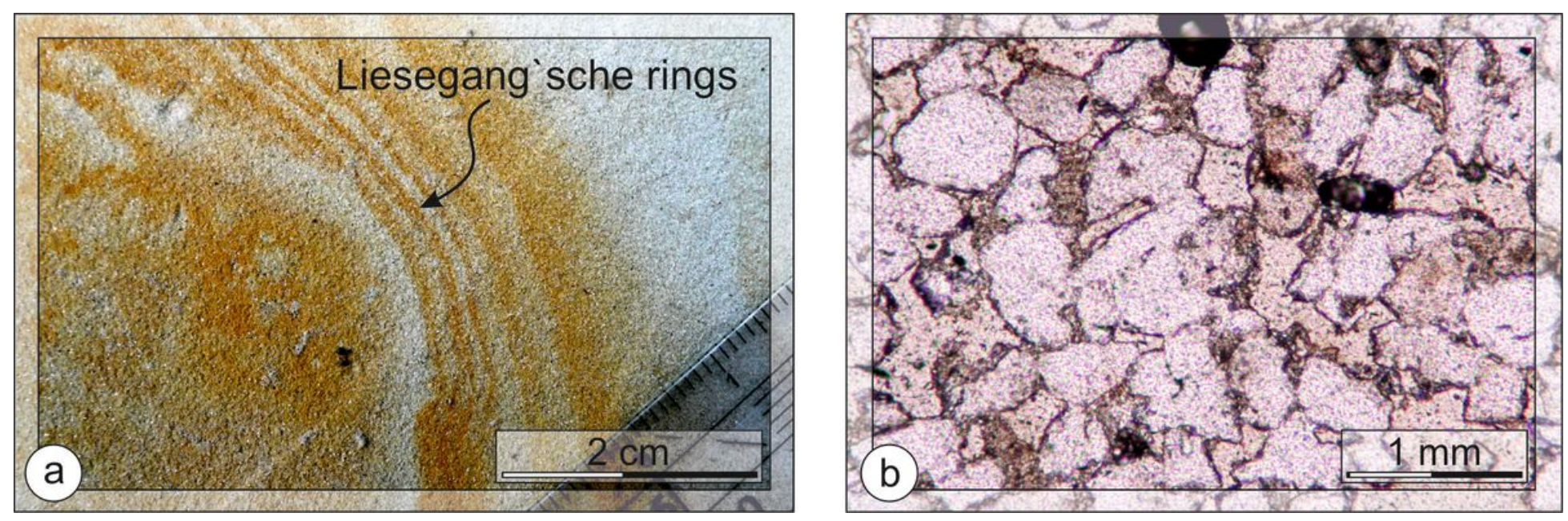

Figure 11

a) Macroscopic representation of the Seeberg sandstone with Liesegang rings. b) Microscopic representation of the Seeberg sandstone.

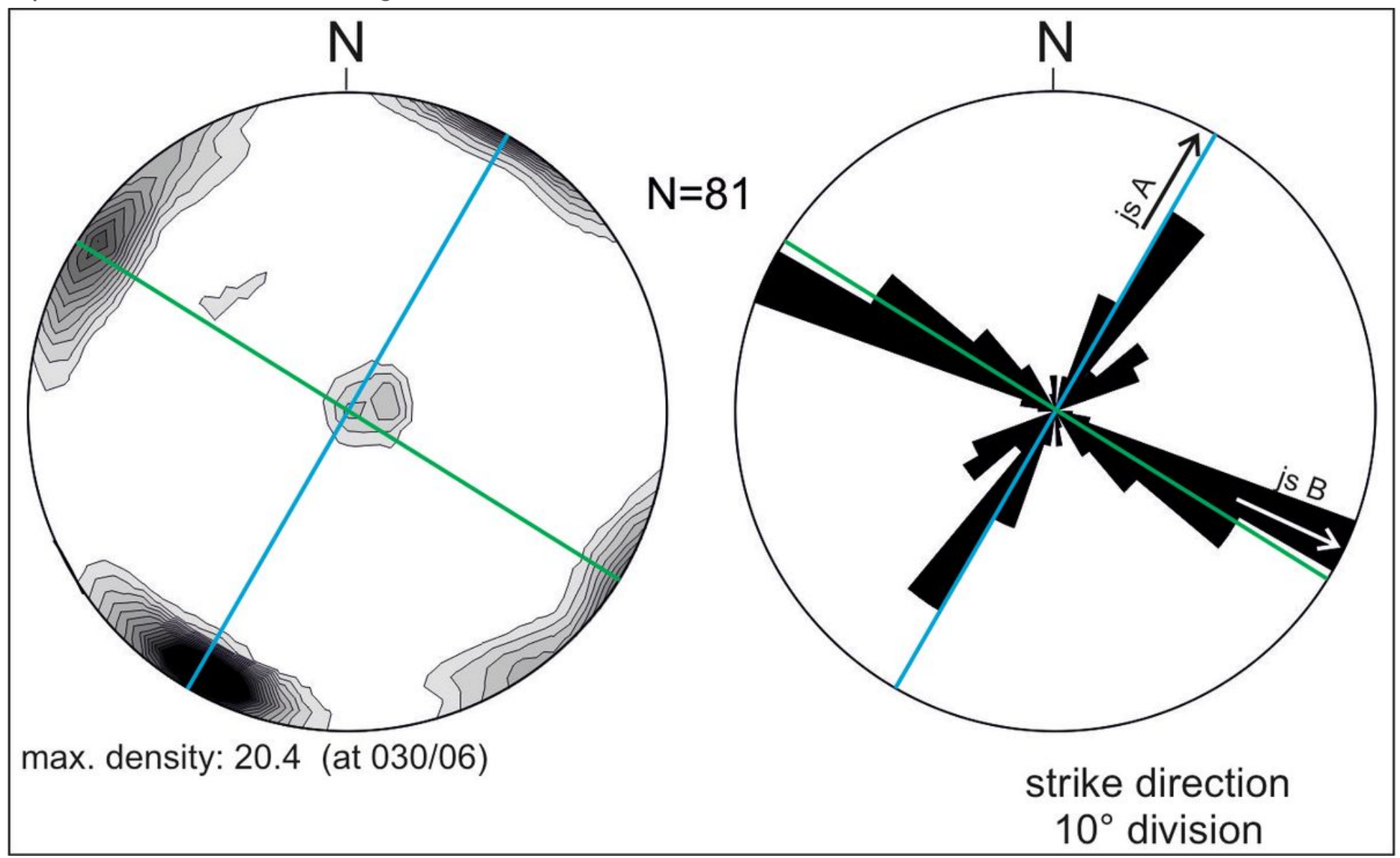

Figure 12

Characterisation of the fracture system in the Seeberg sandstone. The representation of the spatial position of the interfaces in Schmidt's network by means of a distribution density diagram (left) and 
fracture rose diagram (right) shows an orthogonal fracture system. The green and blue lines indicate the strike of the excavation walls (blue = x-direction, green = y-direction, Fig. 39).

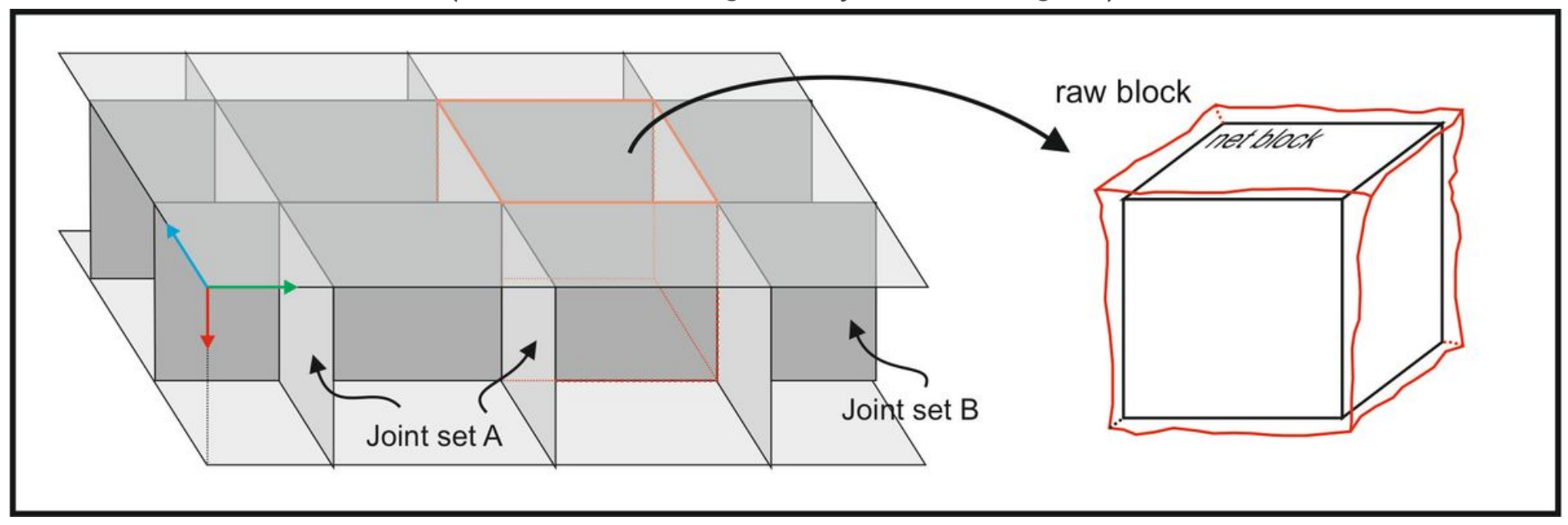

\section{Figure 13}

Schematic representation of the fracture geometry occurring in the Seeberg sandstone quarry (Thuringia) and the resulting raw block shapes.
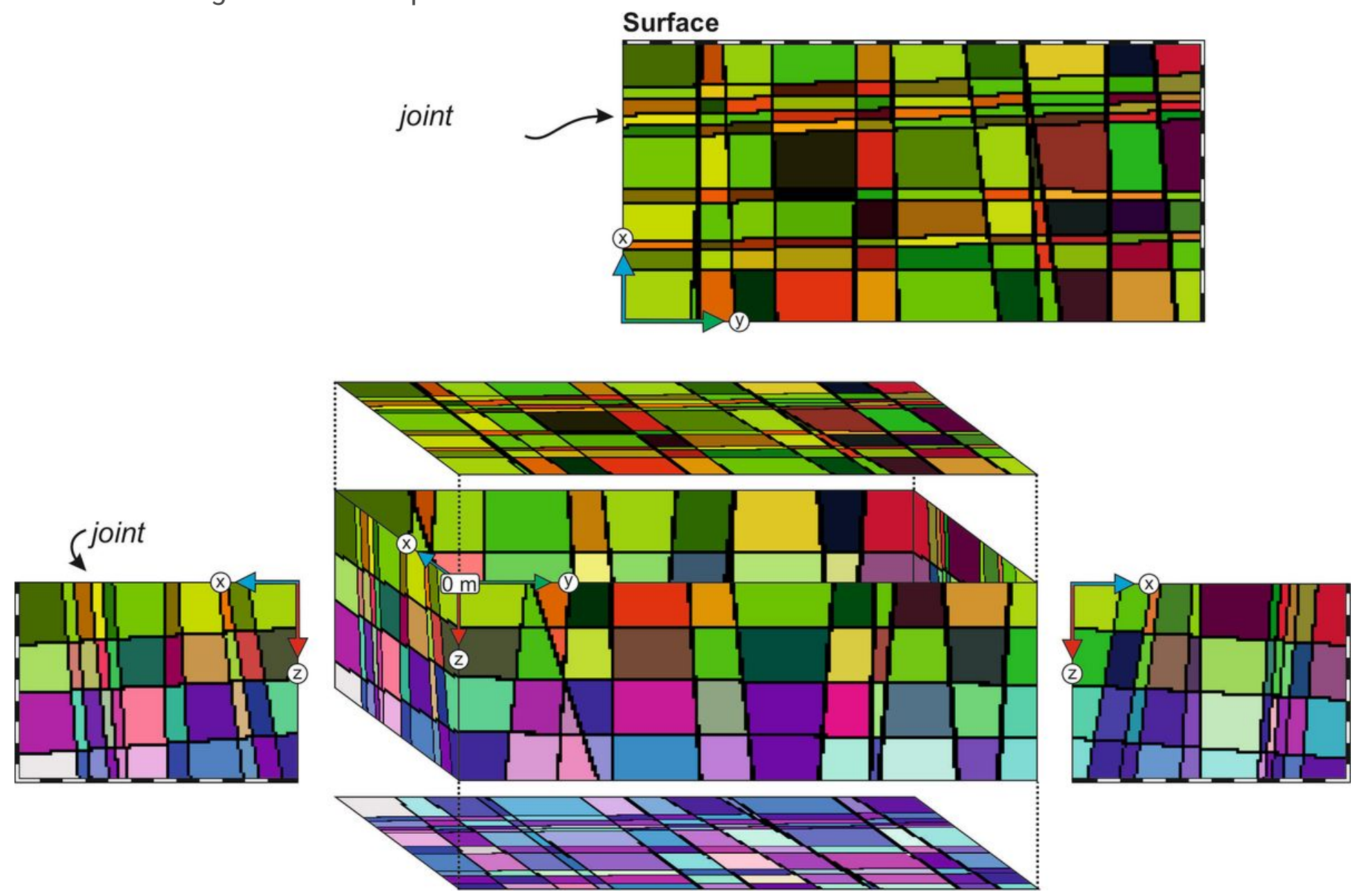

Figure 14 
Graphical representation of the model generated with 3D-BlockExpert for the Seeberg sandstone quarry in Thuringia (number of fissures 24, edge length of voxels $12.5 \mathrm{~cm}$; scale in metre divisions). The modelled area of the deposit shows approximately cuboidal in-situ blocks.
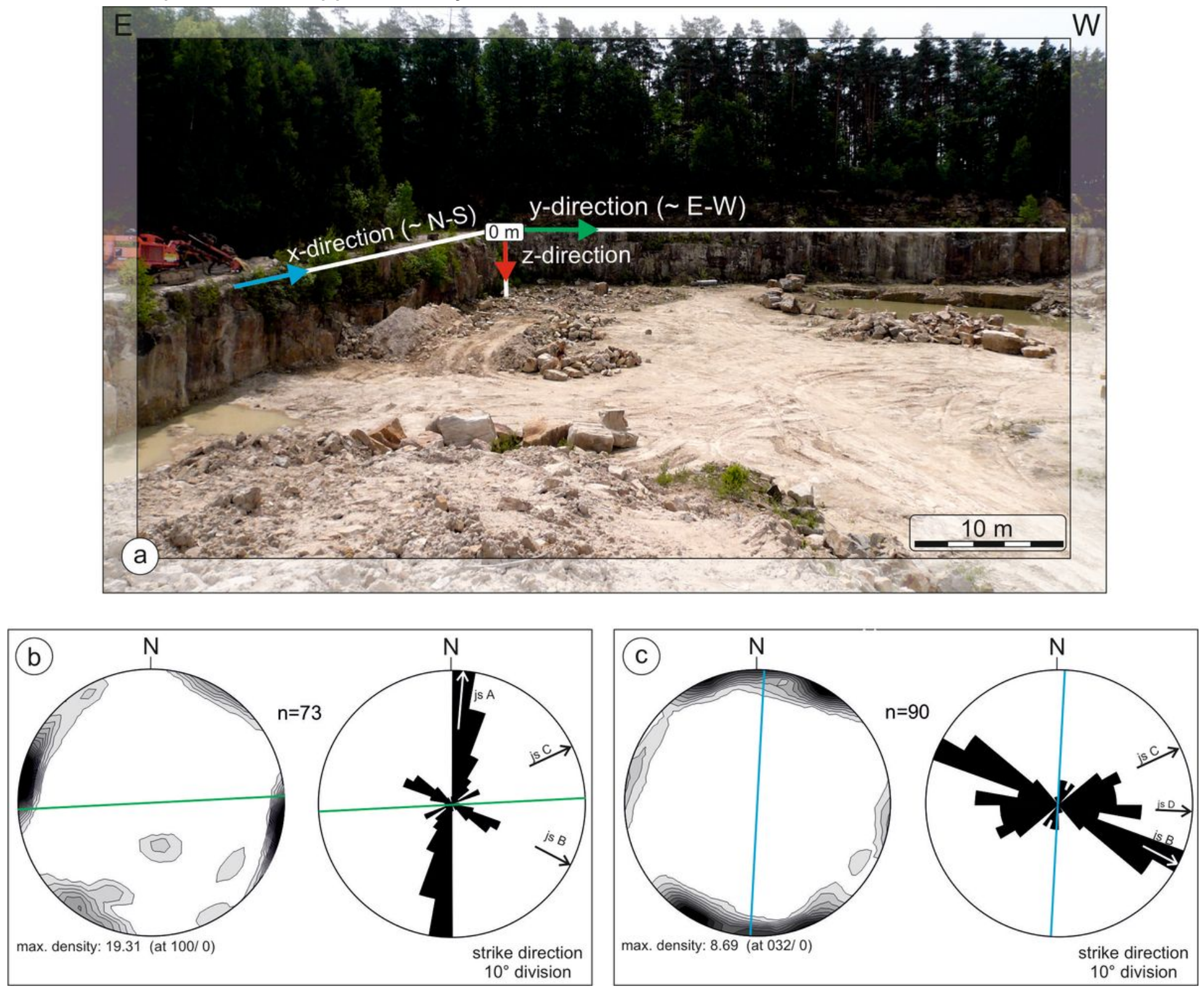

Figure 15

Representation of the spatial position of the interface structure in the Burgpreppach Rhaetian Sandstone (a). b) Projection of the interfaces in y-direction ( E-W) by means of distribution density diagram (left) and fissure rose diagram (right). c) Projection of the interfaces in x-direction ( N-S) by means of distribution density diagram (left) and fissure rose diagram (right). The blue and green lines indicate the strike direction of the respective degradation wall. 


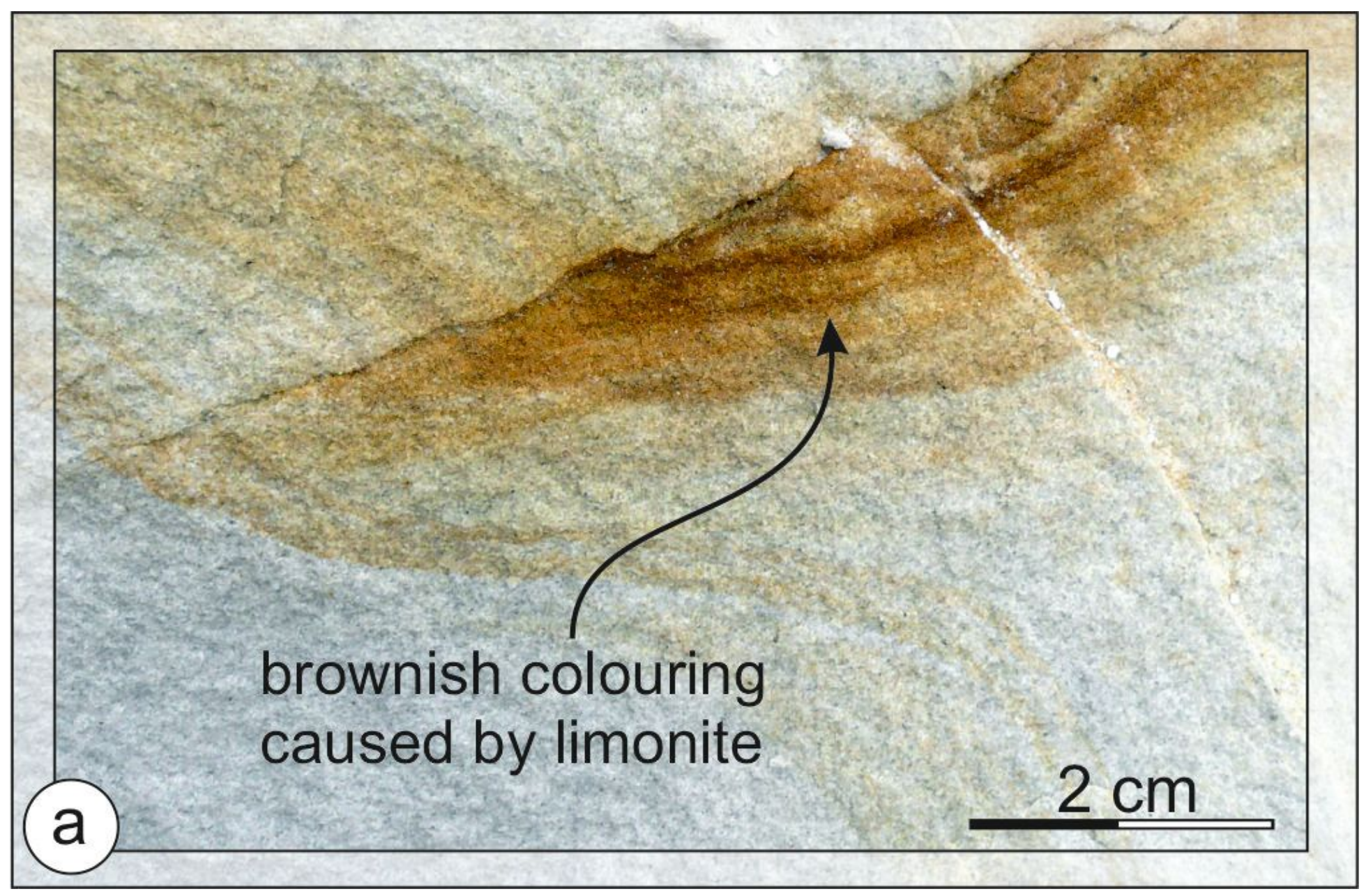

Figure 16

a) Macroscopic view of the Burgpreppach sandstone with limonitic brown colouration. b) Microscopic view of the Burgpreppach sandstone. A quartz grain with typical quartz accretion fringe can be seen (photo: K.-J. Stein). 


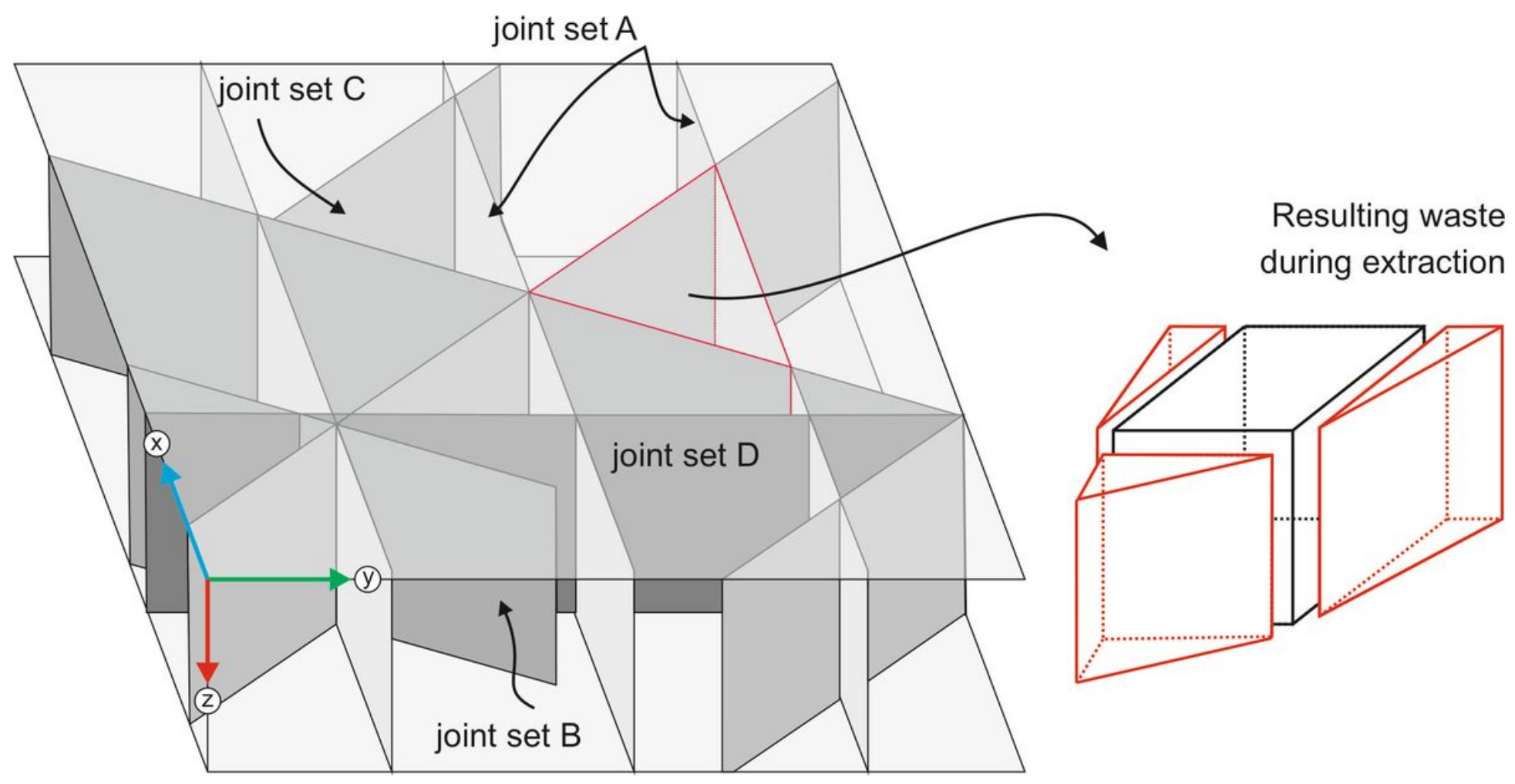

Figure 17

Schematic representation of the fracture geometry occurring in the Burgpreppach deposit complex. The lack of an orthogonal interface system often leads to the formation of acute-angled in-situ blocks, which cause a high material loss when formatting to a net block. 


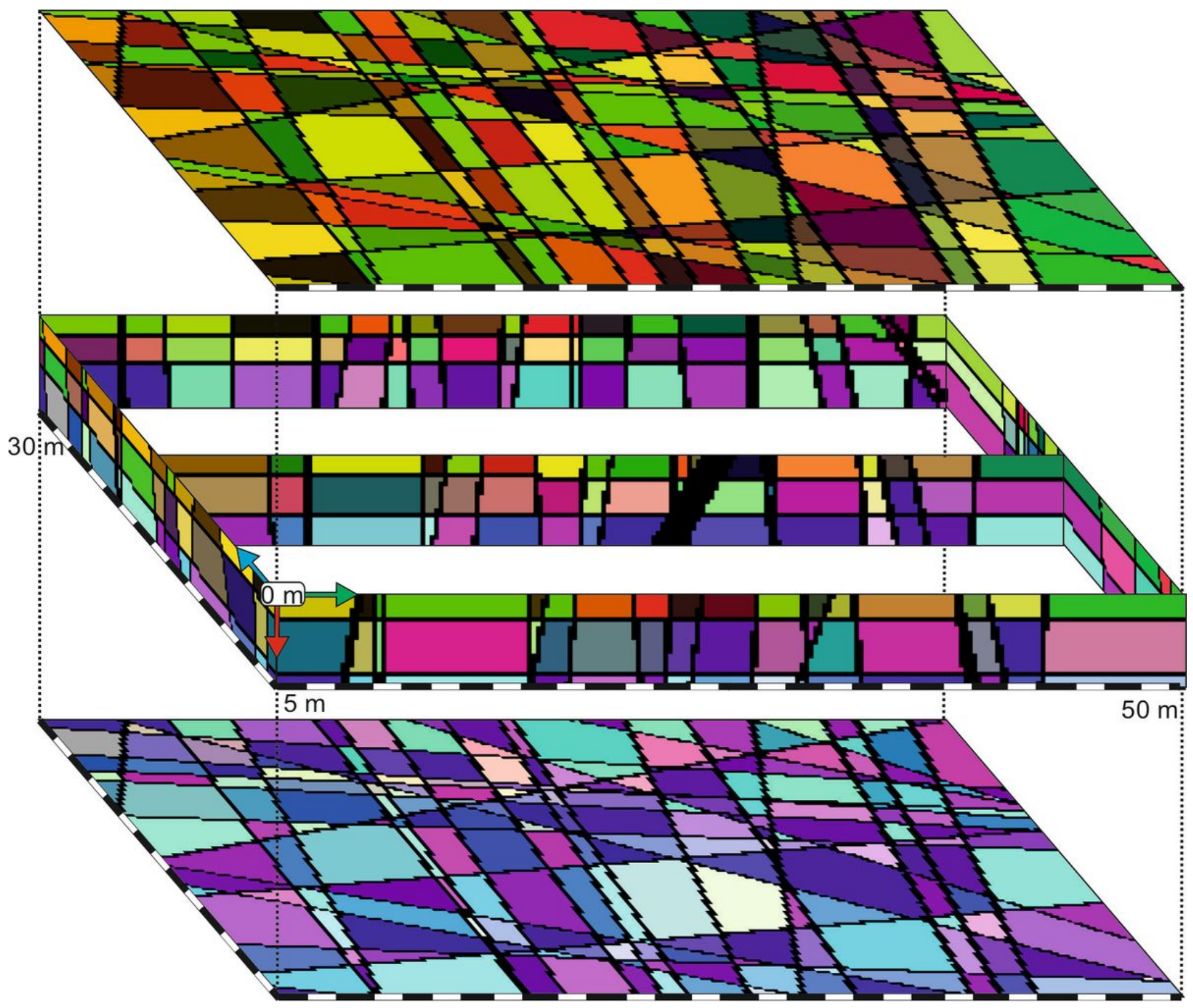

Figure 18

Graphical representation of the model generated with 3D-BlockExpert in the Burgpreppach sandstone quarry in northern Bavaria (number of fissures 33, edge length of voxels $25 \mathrm{~cm}$ ). The deposit complex is overall strongly and irregularly dissected. 


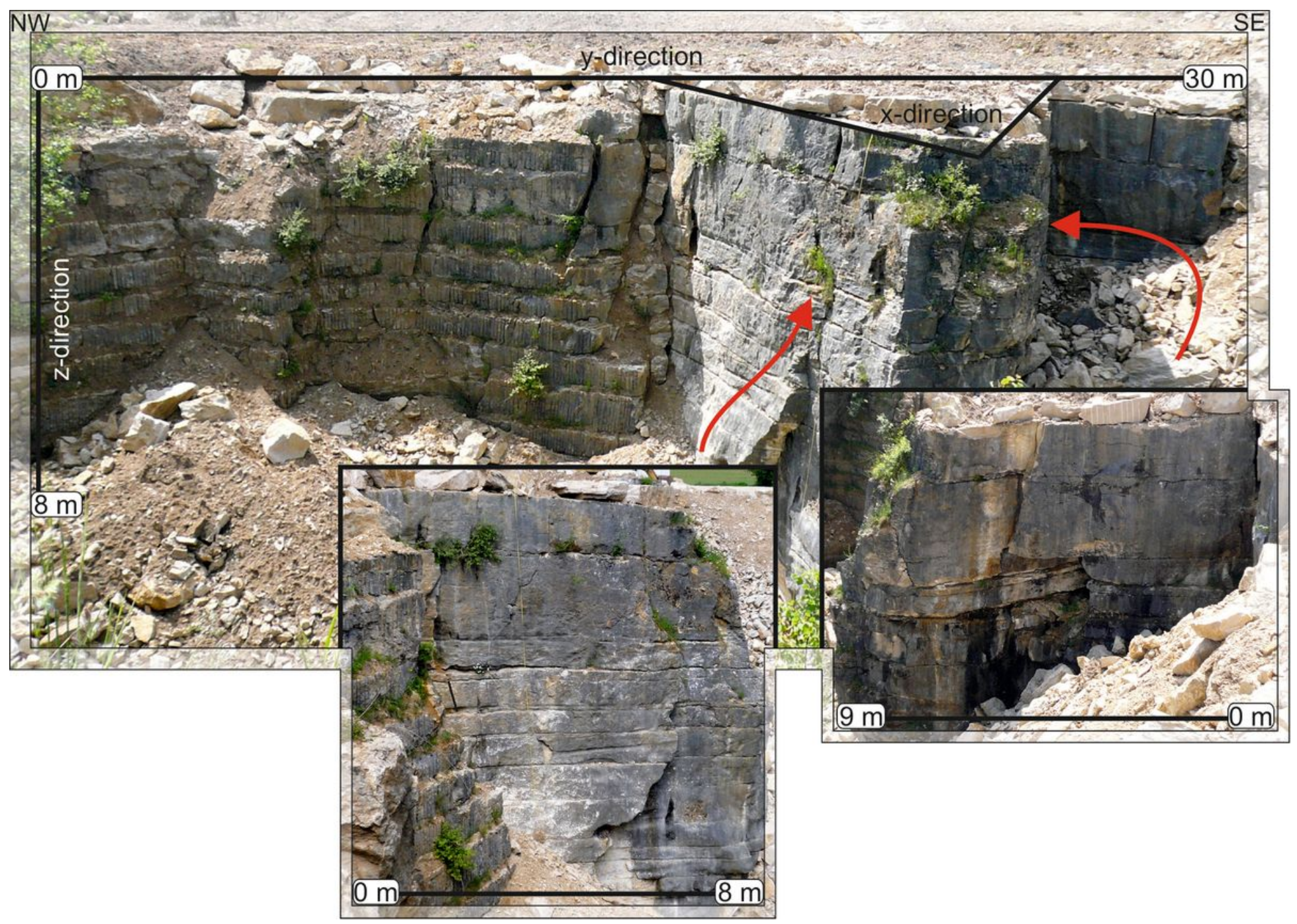

\section{Figure 19}

The NE' deposit area of the limestone quarry near Treuchtlingen. There are approximately three spatial directions $-x, y$ and $z$. The two deposit walls running at an acute angle to each other in the $x$-direction indicate fissure surfaces.
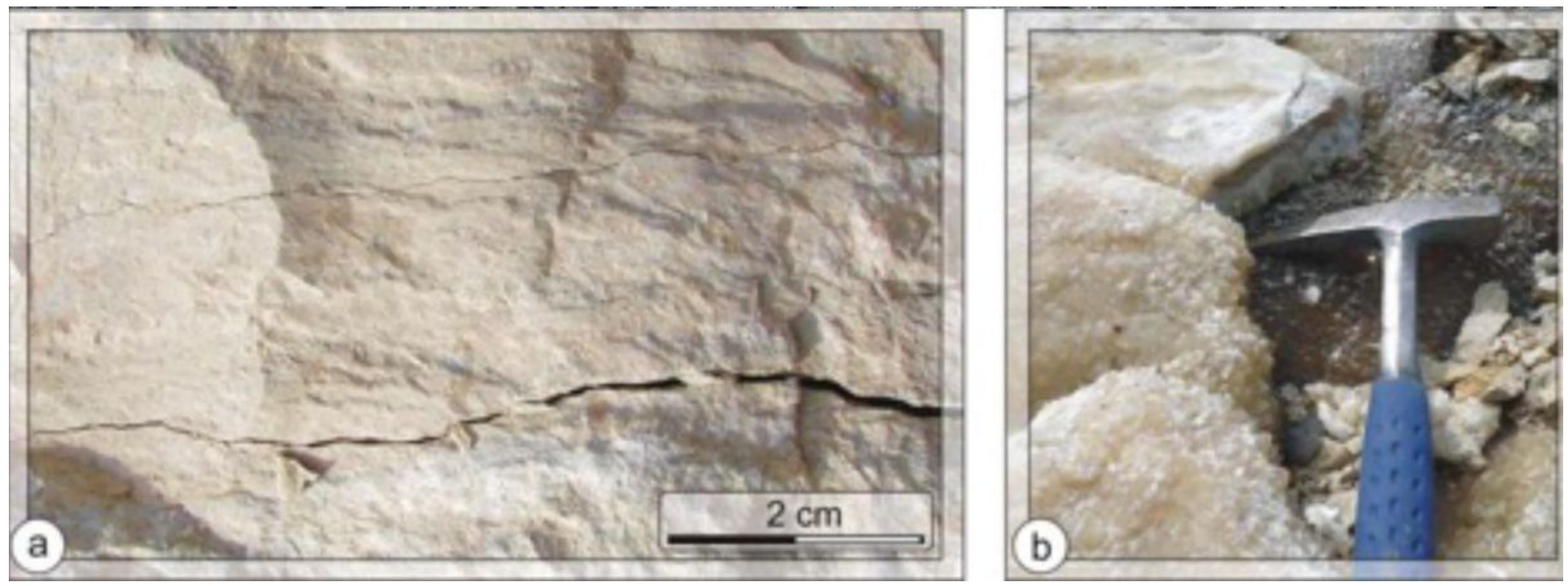
Figure 20

a) The JURAMARMOR iis very fingrained and light grey. Microcarst phenomena and sintering are common features
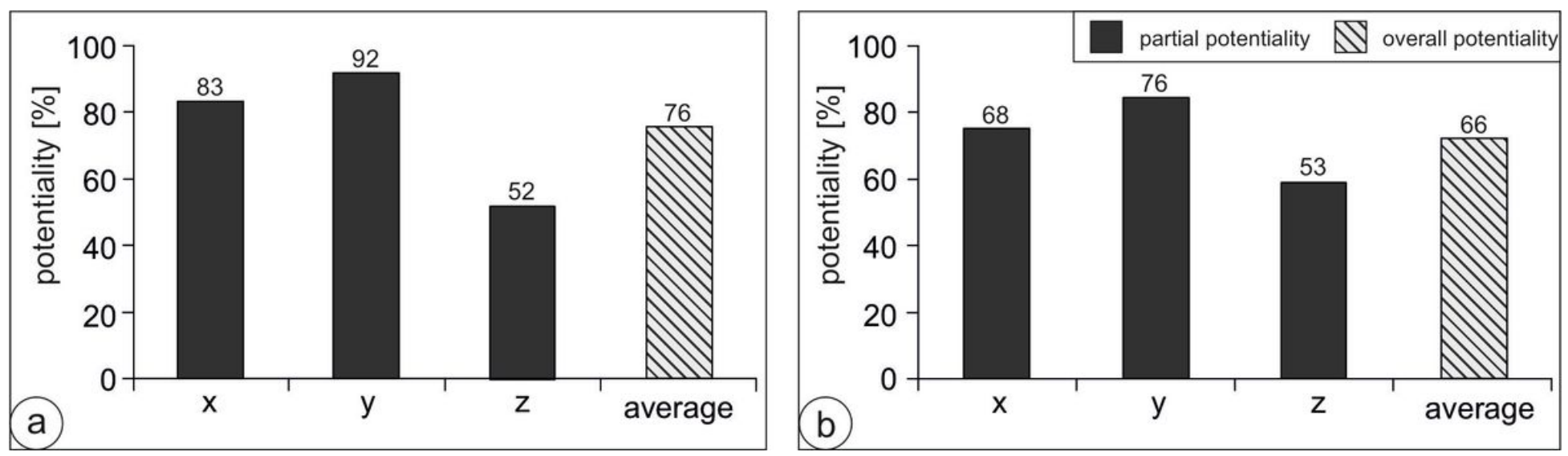

\section{Figure 21}

Determined raw block openings in the limestone quarry in Treuchtlingen for a) the minimum block defined by Singewald (1992) and b) for the average block calculated on the basis of the gap distance distribution.

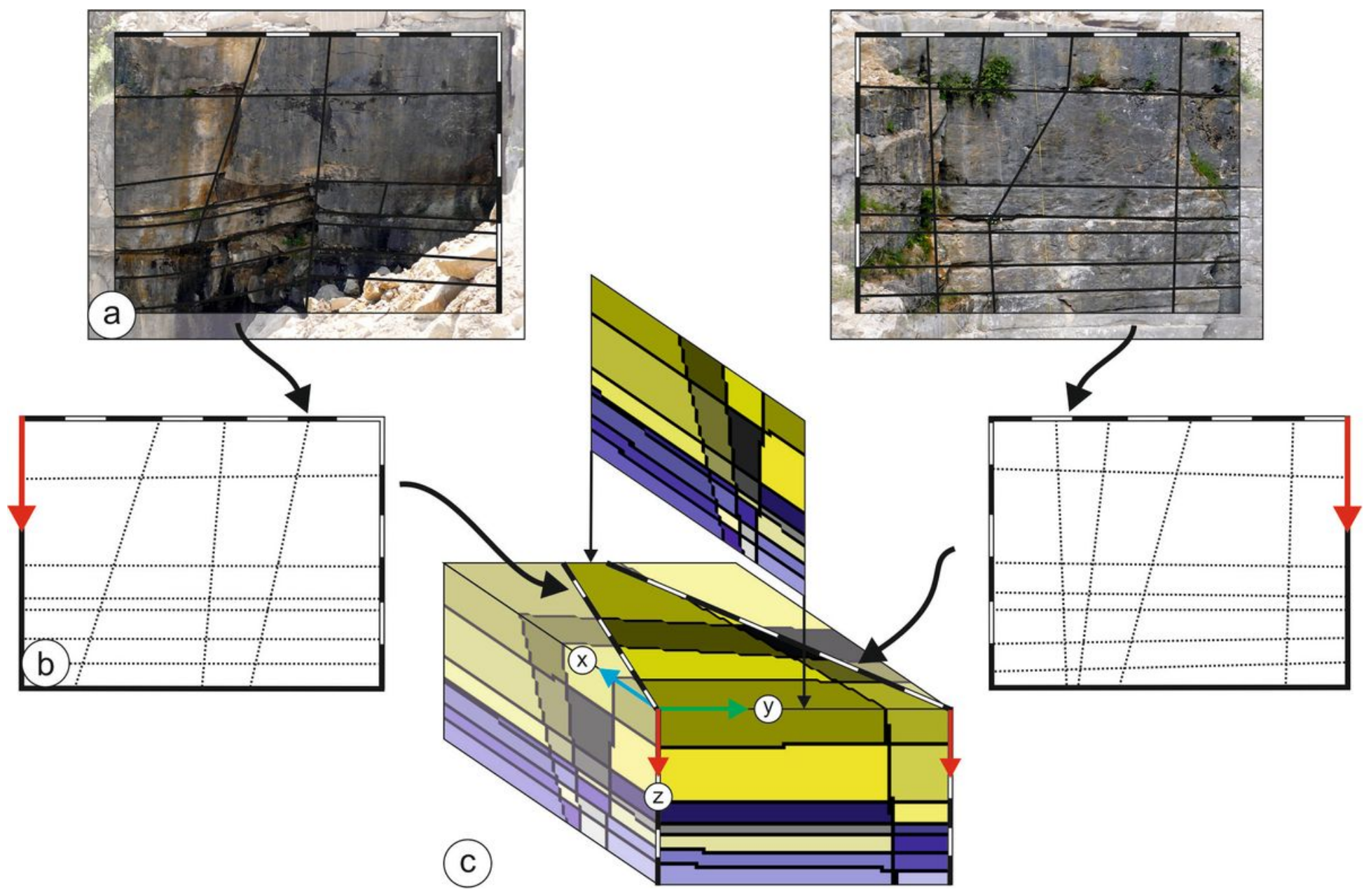


Modelling 1 of the deposit complex near Treuchtlingen (scale in metre divisions). a) Course of the interfaces on the investigated excavation walls. b) Simplified or extrapolated representation of the interfaces and c) the model generated with 3D-BlockExpert. The transparent areas represent blocks that have already been mined.
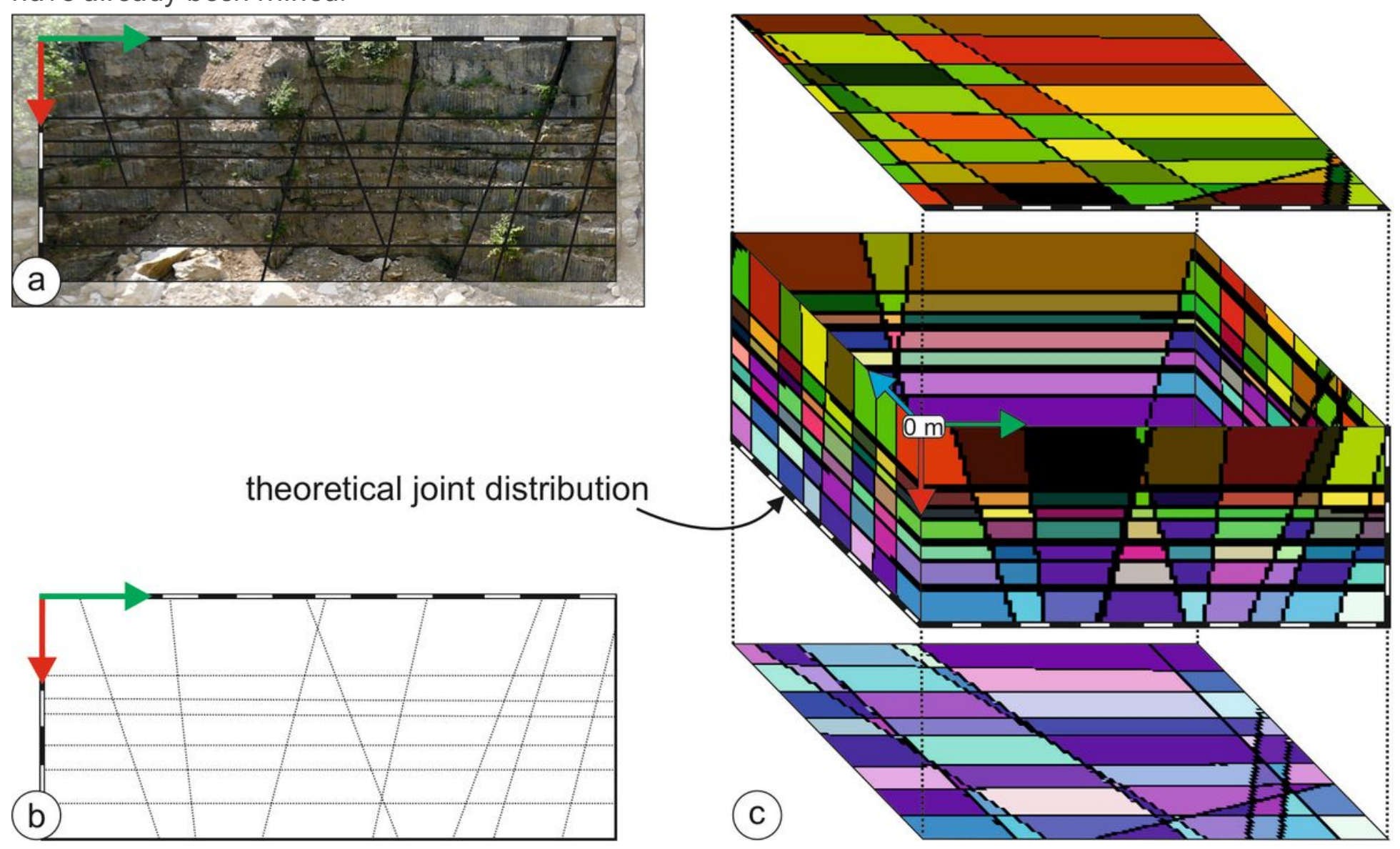

(c)

theoretical joint distribution

\section{Figure 23}

Model 2 in the limestone quarry in Treuchtlingen (scale in metre scale) a) interface course on the excavation front and b) its simplified or extrapolated course. c) The model generated with 3DBlockExpert. 


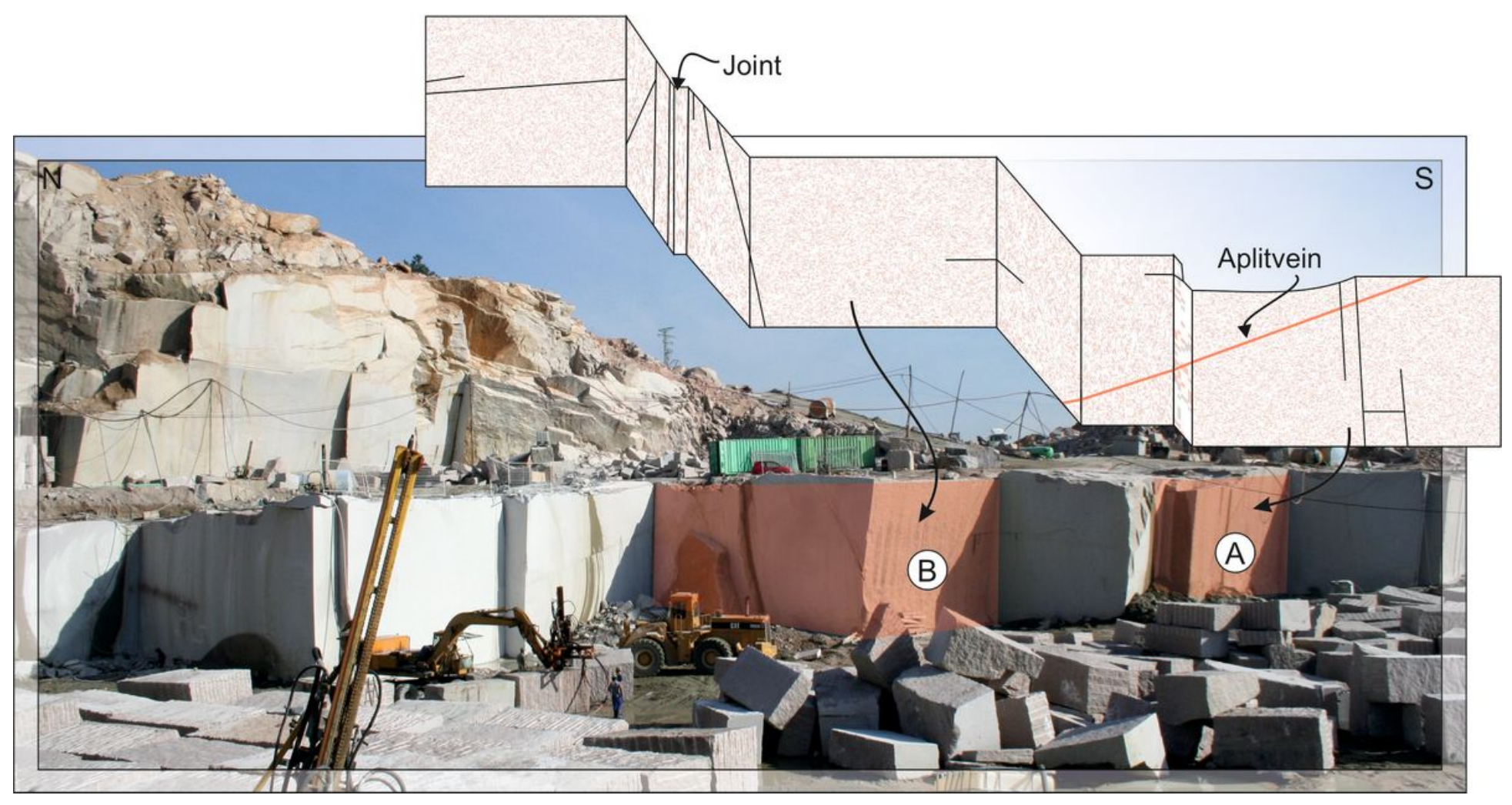

Figure 24

Part of a core area in the ROSA PORRIŇO 1 deposit complex (granite, Spain) with a schematic representation of the excavation walls. Only a small number of fissures were measured over a profile section of approx. $80 \mathrm{~m}$, so that this area is only weakly dissected overall. The coloured areas $(A+B)$ represent the rock complexes modelled with 3D-BlockExpert.
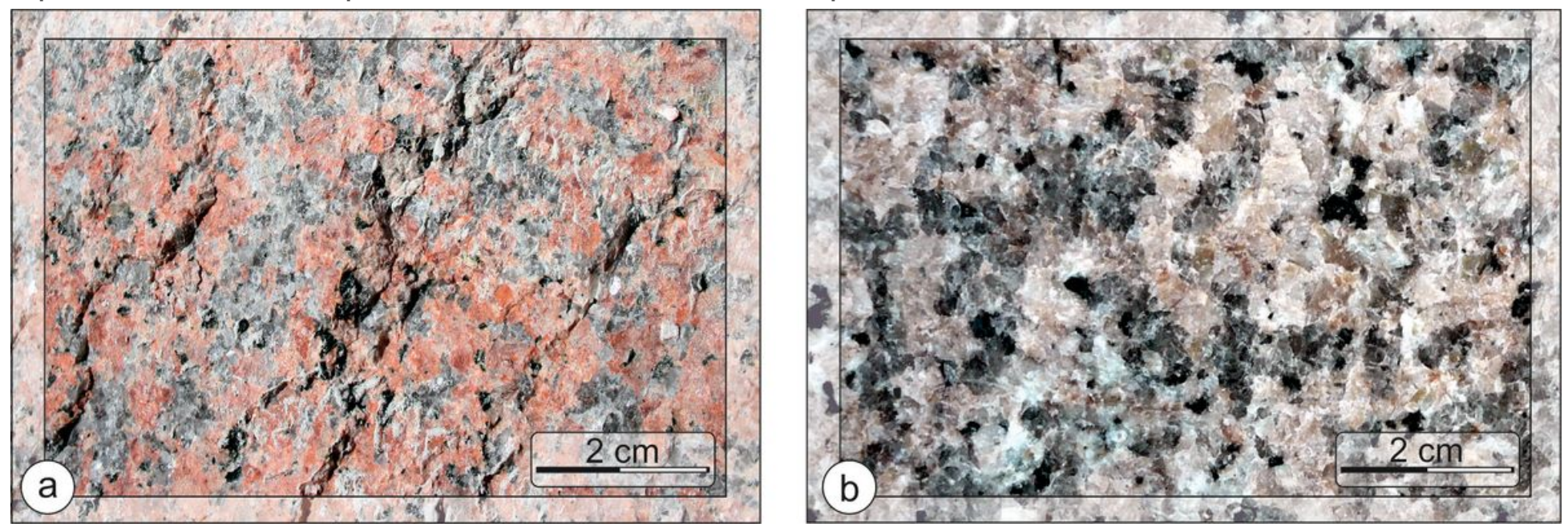

Figure 25

Macroscopic representation of ROSA PORRIŇO granite (Galicia, Spain). a) ROSA PORRIŇO 1 and b) ROSA PORRIŇO 2. 

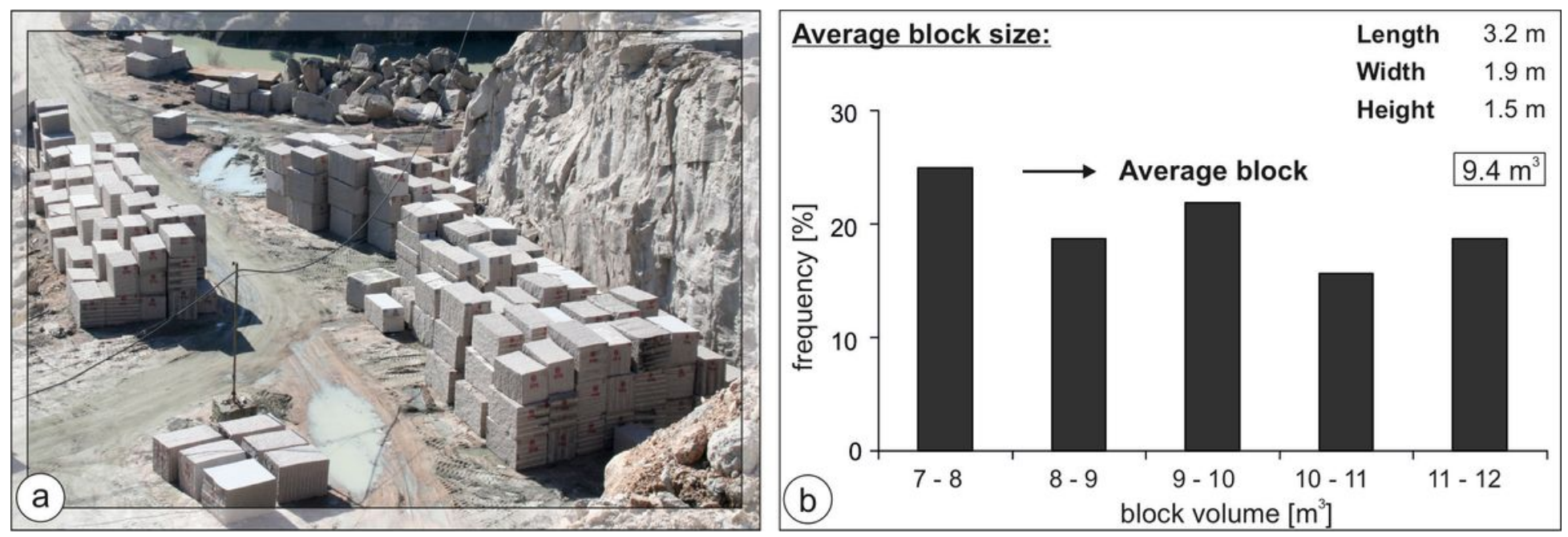

Figure 26

The raw blocks in the trestle deposit reach volumes between $7 \mathrm{~m} 3$ and $12 \mathrm{~m} 3$. The average value can be considered as a typical block size for the investigated deposit area (ROSA PORRIŇO granite quarry, Spain).
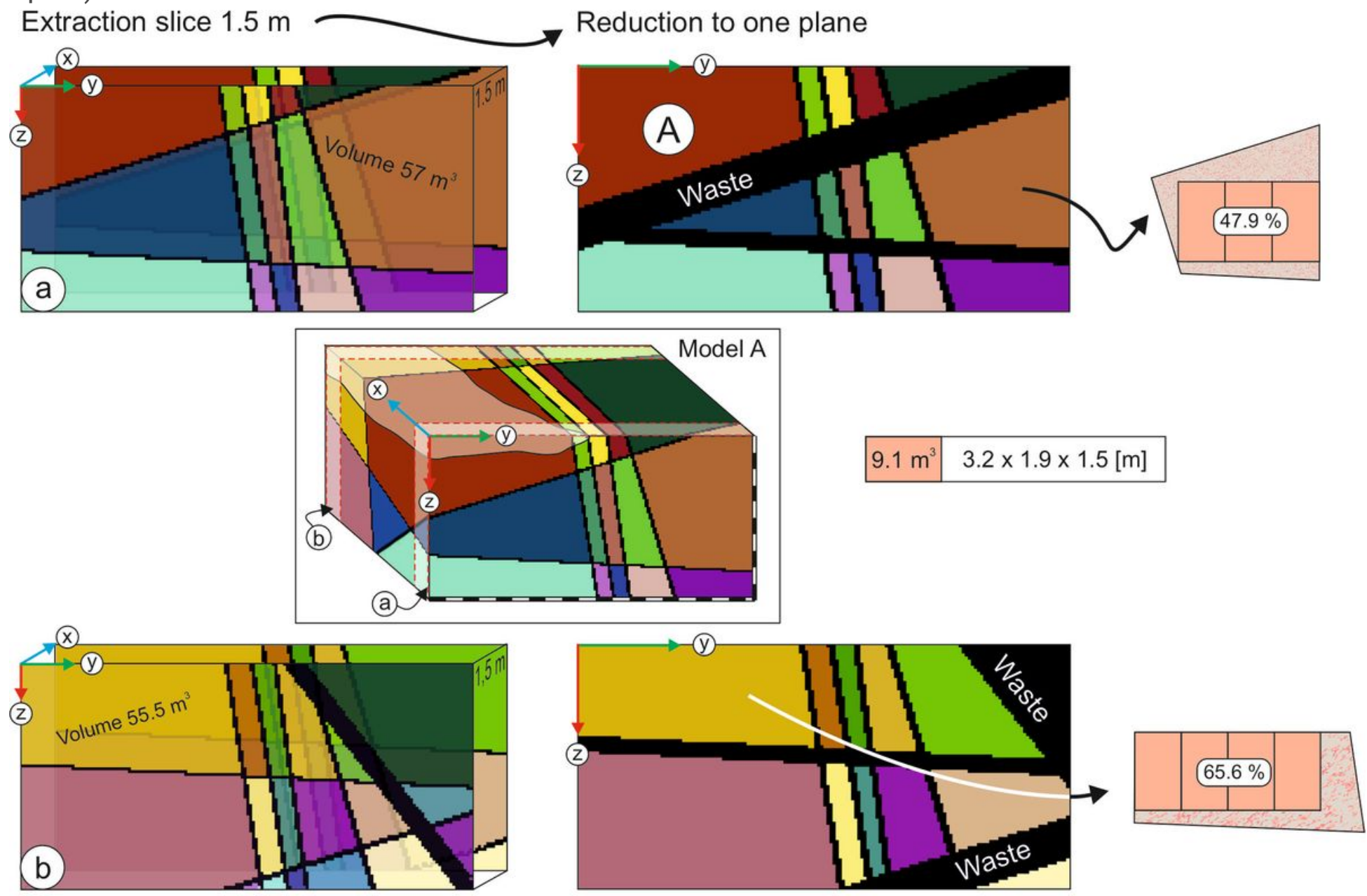

Extraction slice $1.5 \mathrm{~m}$

Reduction to one plane

Figure 27 
Comparison of two in-situ block shapes and their effects in mining. A quarry slab with a thickness of 1.5 $m$ is shown in each case, which is reduced to a plane with the help of the difference consideration function. Since the in-situ block shown in (a) deviates from the cuboid shape, fewer blocks can be extracted from it with a comparable volume than from the block illustrated in (b) (granite quarry ROSA PORRIŇO 1, Spain).

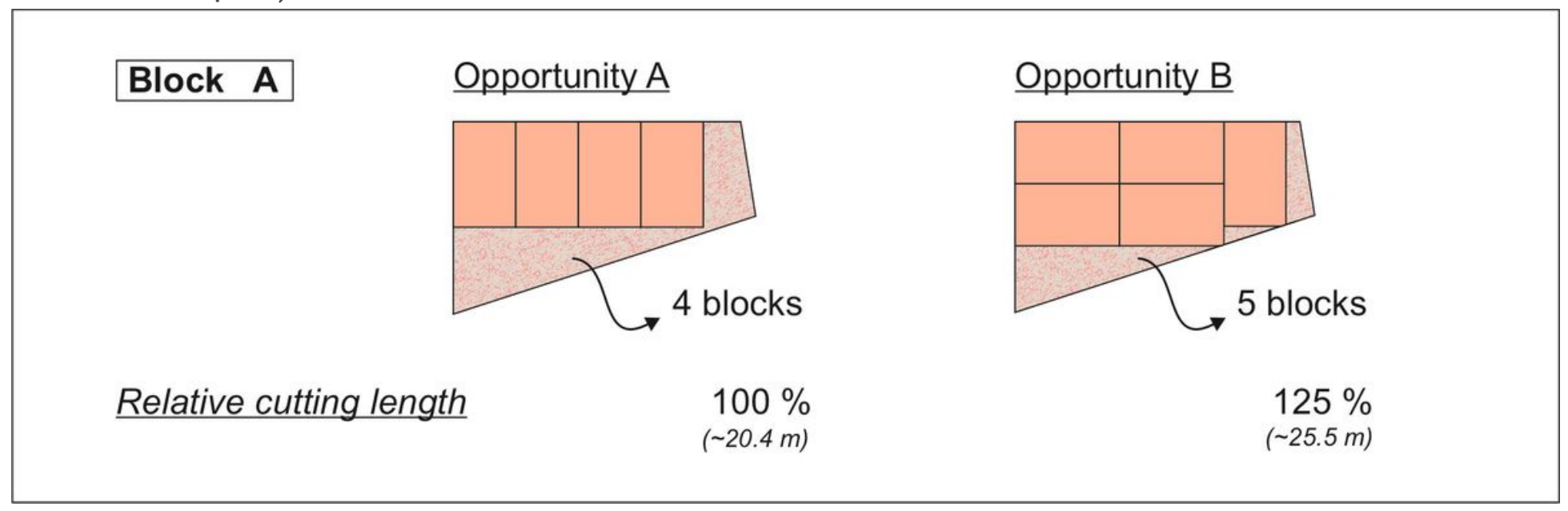

\section{Figure 28}

For optimised land use of block A (see Fig. 94a), two possibilities are shown as examples (block size: 3.2 x 1.9 x 1.5 m; granite quarry ROSA PORRIŇO, Spain).

\section{Model A}

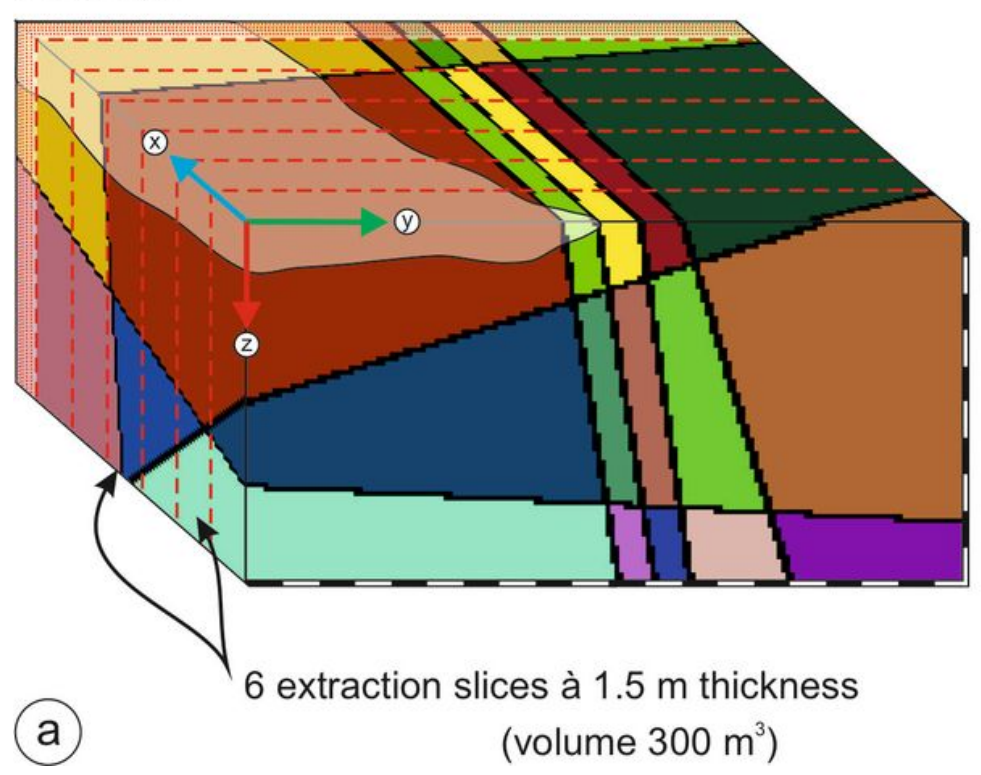

\section{Model B}

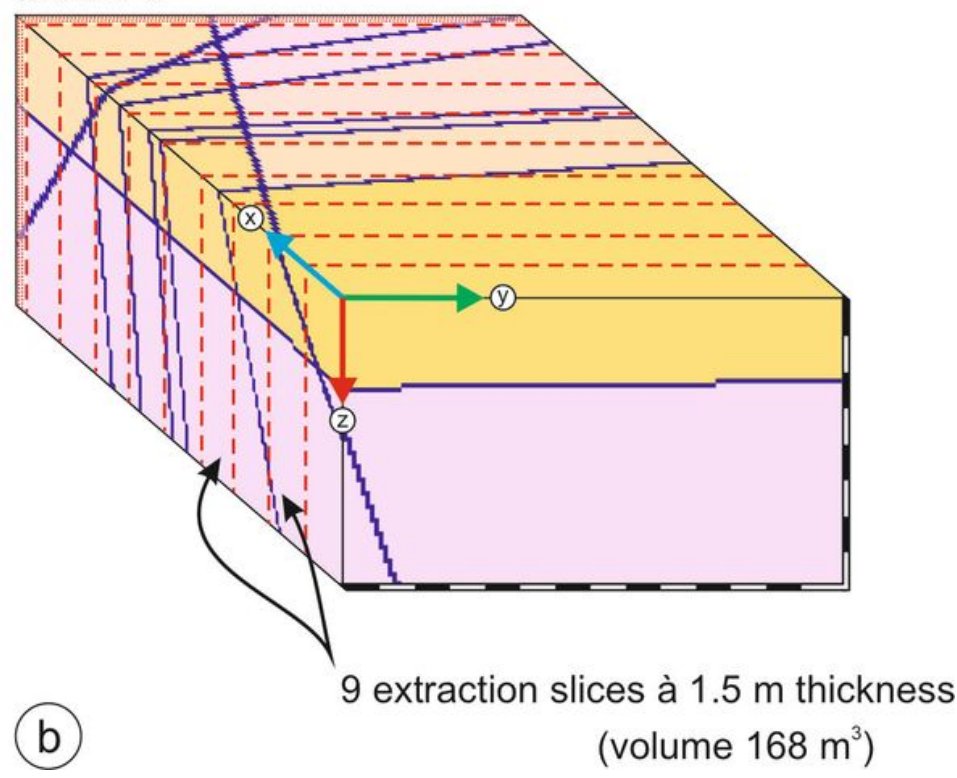

Figure 29

Assessment of the block potential (scale in meter). a) Model A results in 6 blocks of $300 \mathrm{~m} 3$ volume and b) Model B results in 9 blocks of $168 \mathrm{~m} 3$ volume (ROSA PORRIŇO). 


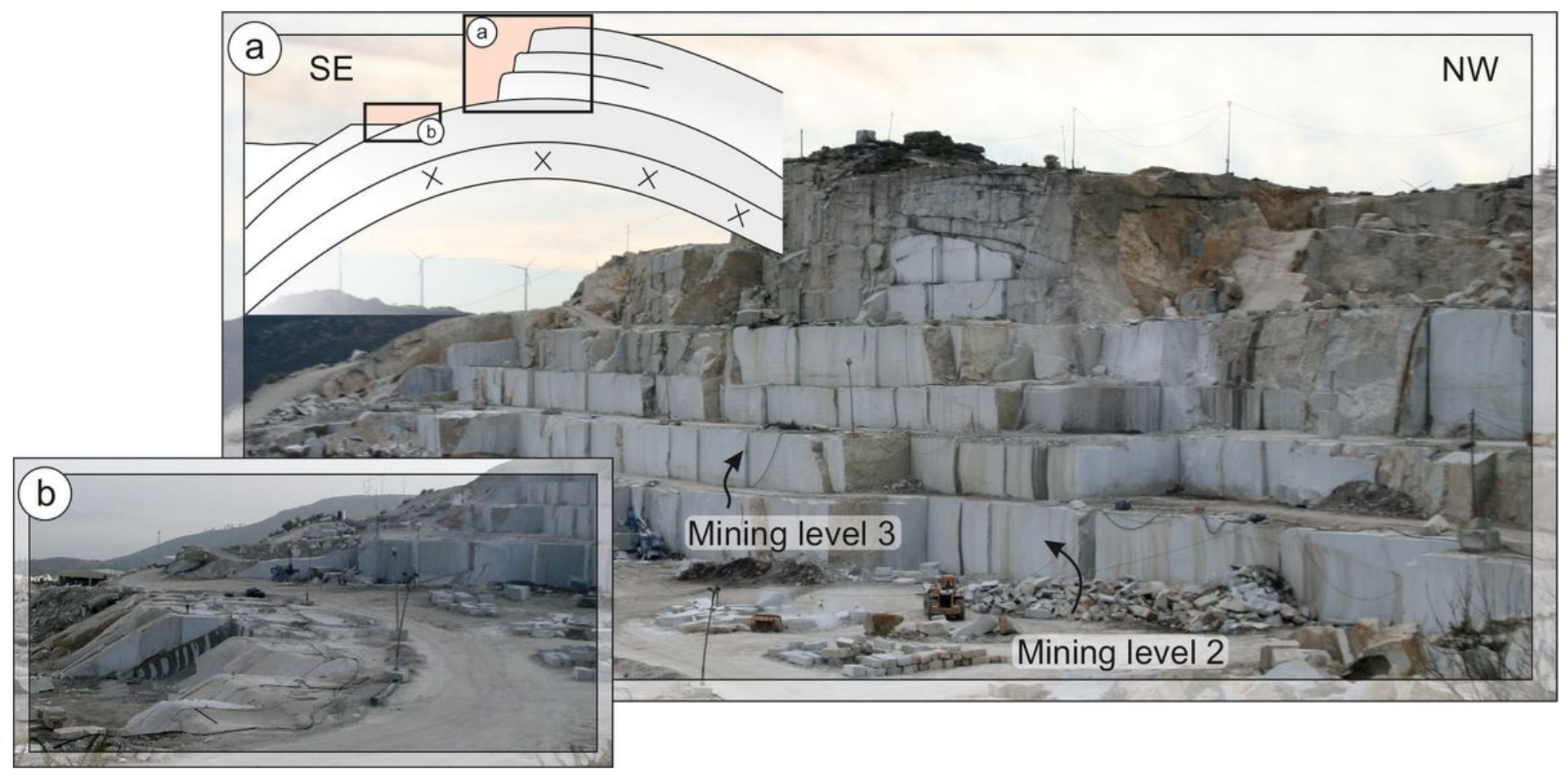

Figure 30

The GRIS ALBA deposit complex (granite quarry Spain). a) The mining walls of the uppermost levels are mainly vertically cut. b) The walls of the lowermost level are inclined due to the slope.
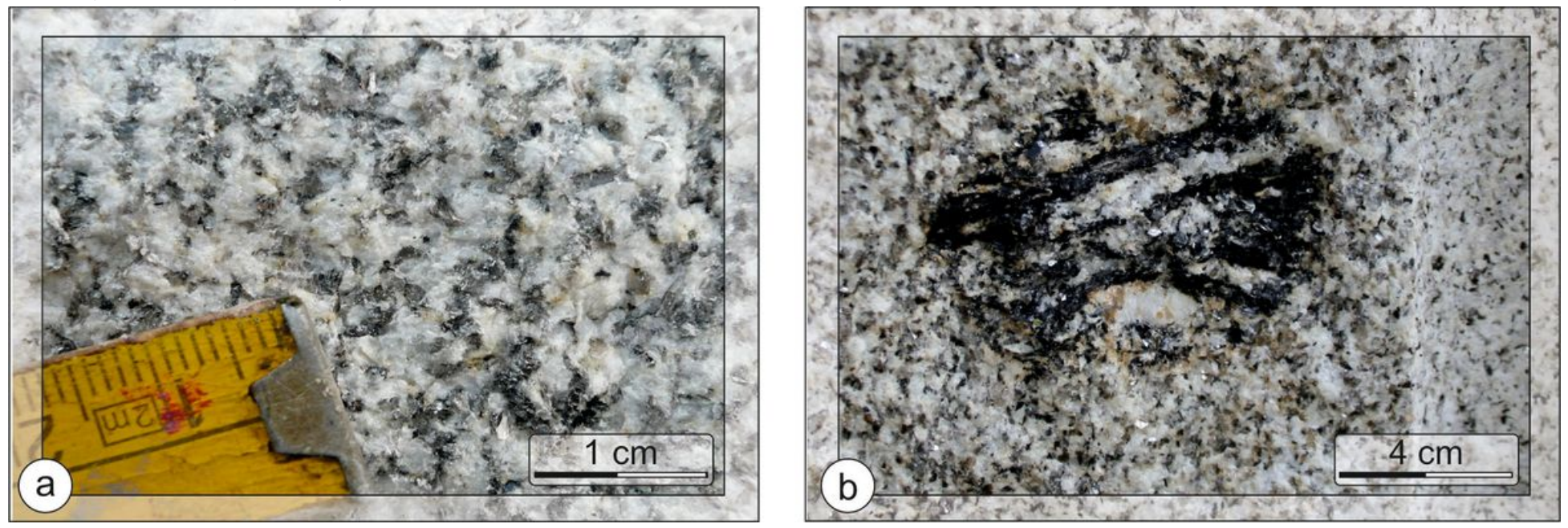

\section{Figure 31}

(a) Macroscopic representation of GRIS ALBA granite (granite quarry Spain). b) Frequentmafic enclaves were observed. 

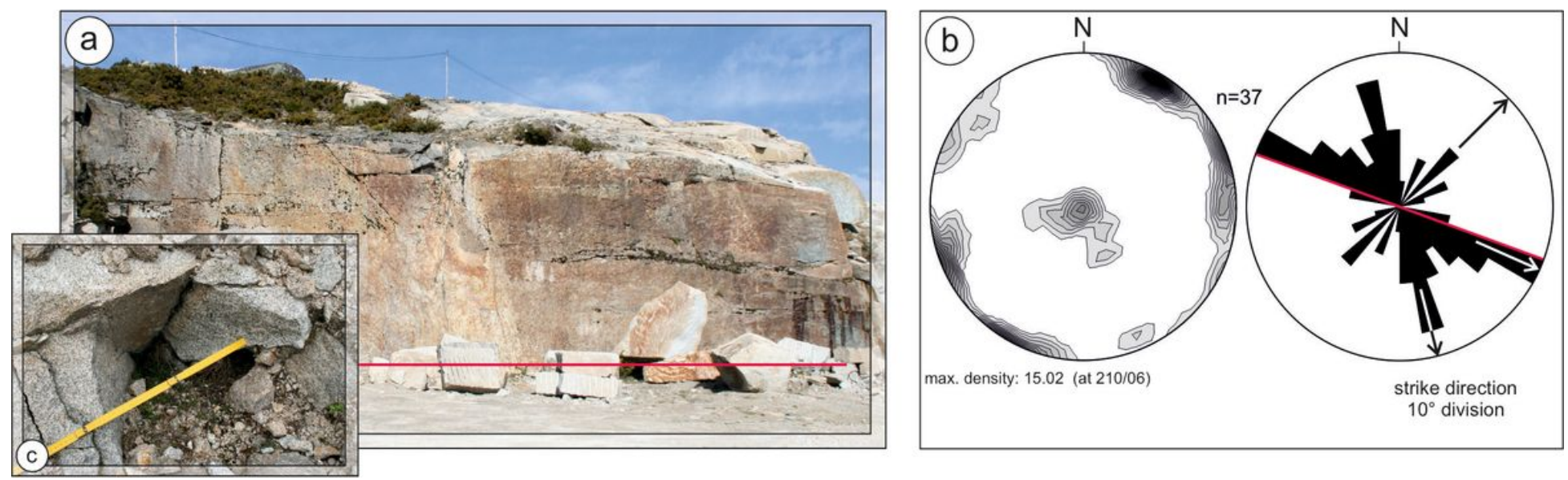

Figure 32

a) The investigated deposit area at the edge of an old quarry (GRIS ALBA granite quarry, Spain). b) Stereographic projection of the fracture surfaces by means of density diagram (left) and fracture rose diagram (right). The red line indicates the strike direction of the wall. c) The natural cleavage surface system often results in acute-angled blocks that break out of the rock mass.

\section{Potentiality for average blocks}

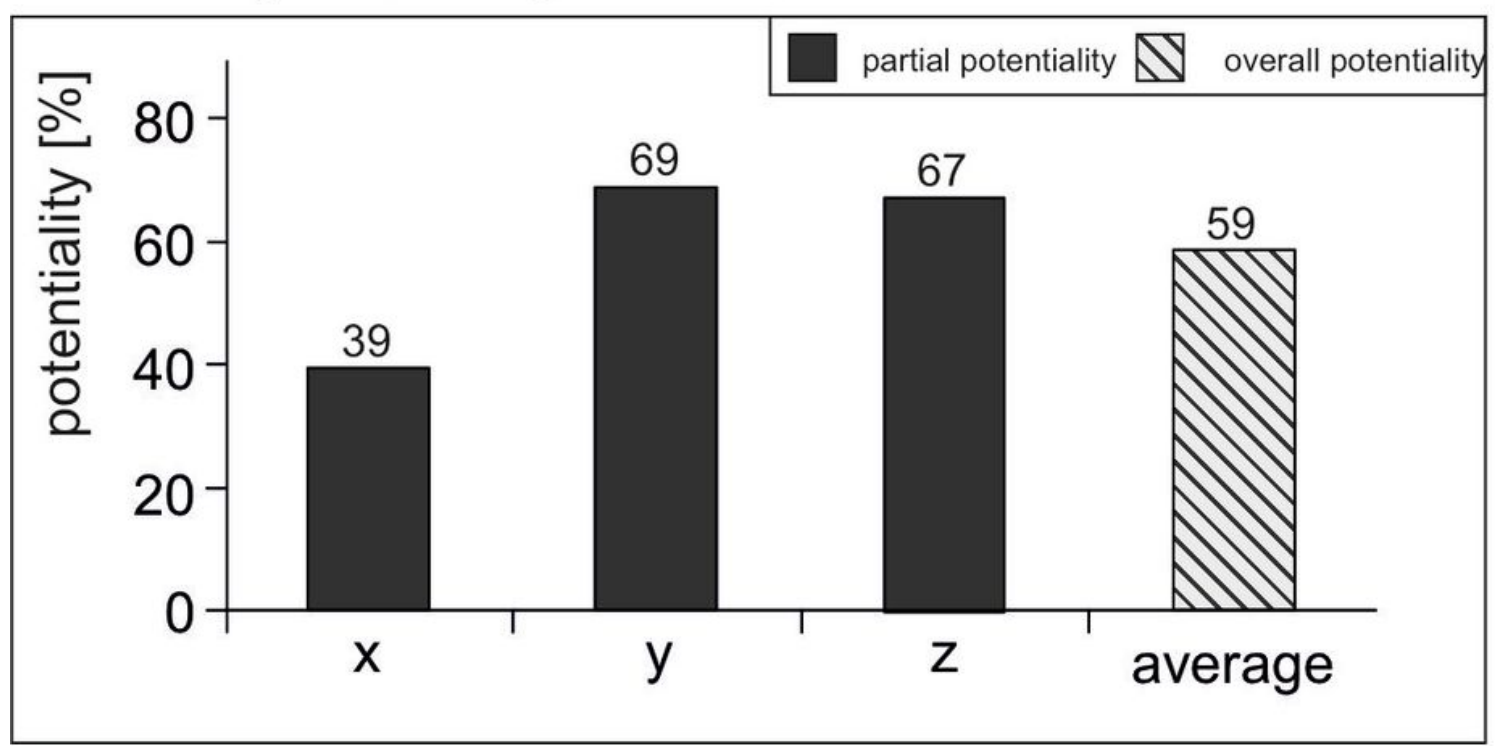

$7 \mathrm{~m}^{3}$

length $2.9 \mathrm{~m}$ width $\quad 1.6 \mathrm{~m}$ height $1.5 \mathrm{~m}$

Figure 33

Determined raw block openness for an area of rock at the edge of an old quarry (GRIS ALBA granite quarry, Spain). The calculation was made on the basis of a raw block that meets the requirements for ashlars in this quarry. 


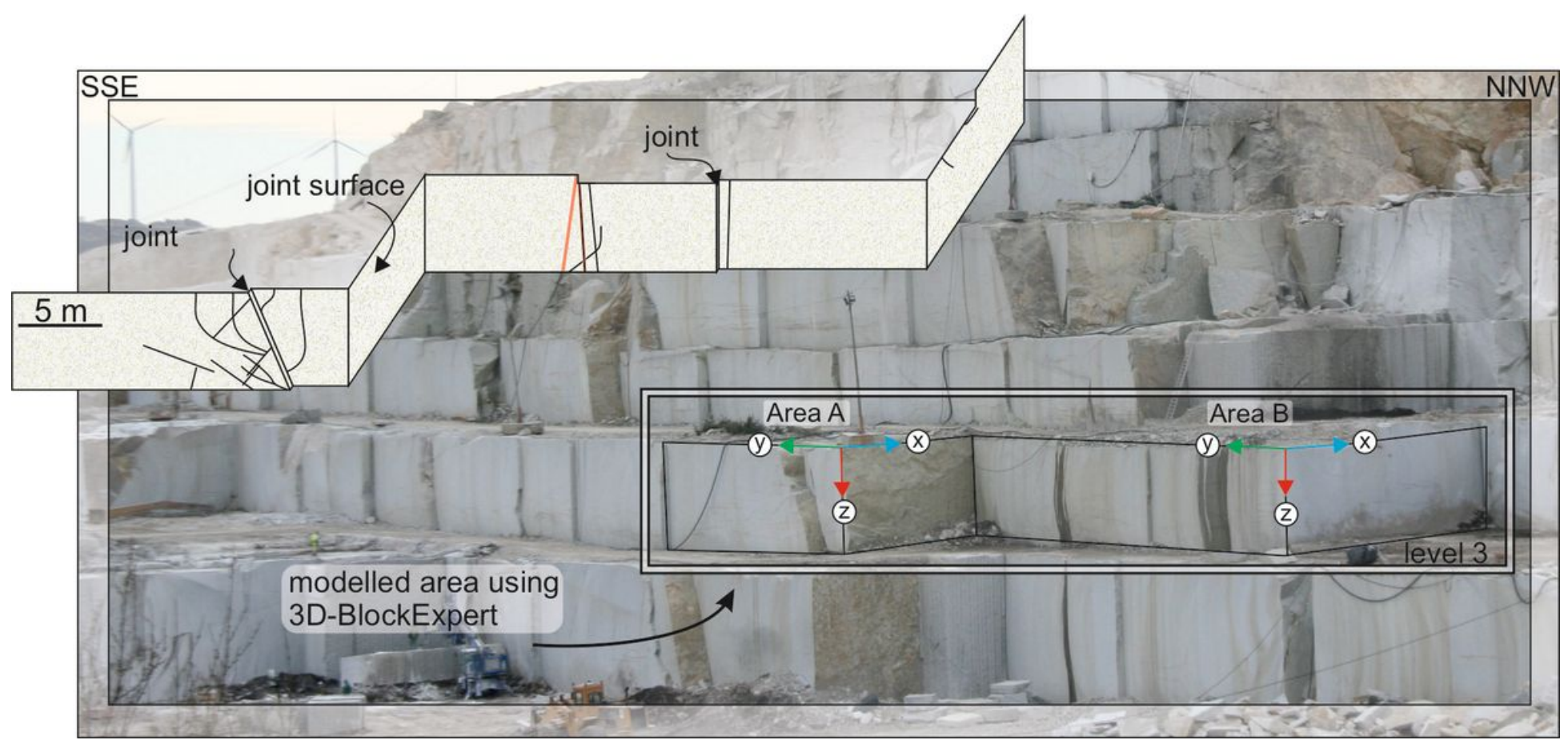

\section{Figure 34}

Illustration of the active excavation floor (GRIS ALBA granite quarry, Spain). The framed area indicates the rock complex modelled with 3D-BlockExpert. For an overview, the front area of the excavation floor is also shown schematically.

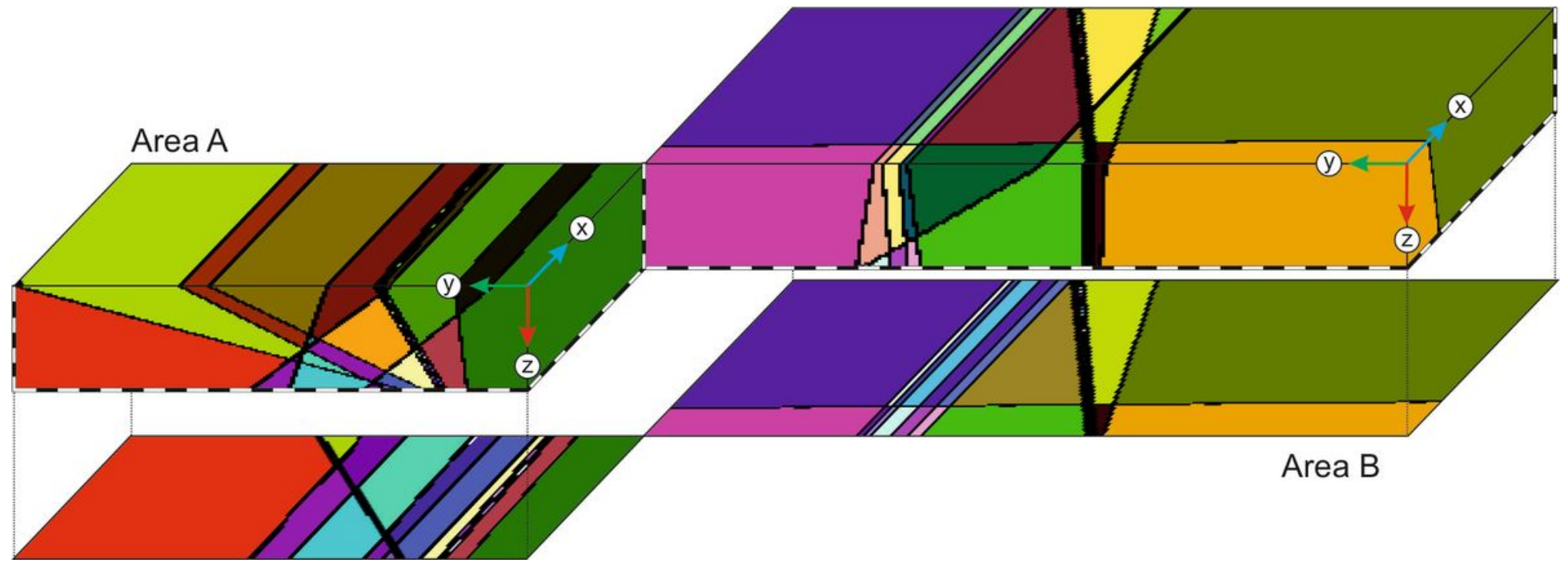

\section{Figure 35}

The models generated with 3D-BlockExpert (GRIS ALBA granite quarry, Spain). Subarea A: 10 joints, edge length of the voxels $12.5 \mathrm{~cm}$. Subarea B: 10 joints, edge length of voxels $16 \mathrm{~cm}$. Scale in meter 